\title{
Í́ARo BoszczowsKı
}

\author{
Análise espacial da ocorrência de \\ infecções bacterianas da corrente sanguínea \\ causadas por agentes multirresistentes em \\ unidades de terapia intensiva do estado de São Paulo
}

Tese apresentada à Faculdade de Medicina da Universidade de São Paulo para obtenção do título de Doutor em Ciências

Programa de Doenças Infecciosas e Parasitárias

Orientadora: Profa. Dra. Anna Sara Shafferman Levin

Coorientador: Prof. Dr. Francisco Chiaravalloti Neto

São Paulo

2016 
Dados Internacionais de Catalogação na Publicação (CIP)

Preparada pela Biblioteca da

Faculdade de Medicina da Universidade de São Paulo

Creprodução autorizada pelo autor

\section{Boszczowski, Ícaro}

Análise espacial da ocorrência de infecções bacterianas da corrente sanguínea causadas por agentes multirresistentes em unidades de terapia intensiva do Estado de São Paulo / Ícaro Boszczowski. -- São Paulo, 2016.

Tese(doutorado)--Faculdade de Medicina da Universidade de São Paulo. Programa de Doenças Infecciosas e Parasitárias.

Orientadora: Anna Sara Shafferman Levin.

Coorientador: Francisco Chiaravalloti Neto.

Descritores: 1.Resistência microbiana a medicamentos 2.Bacteremia 3.Indicadores econômicos 4.Indicadores de serviços 5.Indicadores básicos de saúde 6.Análise espacial

USP/FM/DBD-277/16 


\section{Dedicatória}

Aos meus saudosos pais.

A todos que me acompanharam na construção deste trabalho. 


\section{Agradecimentos}

À professora Anna Sara Shafferman Levin, mestra de enorme generosidade, que teve papel fundamental nas escolhas feitas por mim ao longo da carreira, minha gratidão e carinho. Seu espírito crítico e empreendedor, sua perspicácia e erudição foram fundamentais para apontar os rumos desta investigação desde a sua concepção até a análise dos dados.

Às queridas amigas e colegas Denise Brandão de Assis e Geraldine Madalosso que apoiaram este trabalho e dedicaram tanto tempo a trabalhar nos bancos de dados da Divisão de Infecção Hospitalar do Centro de Vigilância Epidemiológica da Secretaria Estadual de Saúde de São Paulo para tornar possíveis as análises.

À Thais Olitta, por sua enorme disponibilidade ao longo dos últimos sete anos trabalhando na organização e junção dos diferentes bancos de dados e planilhas gigantes, além da elaboração dos mapas. Deste trabalho intenso, nasceu uma amizade sólida.

Ao professor Francisco Chiaravalloti Neto, meu coorientador, que com muita paciência e dedicação, na operação em muitos momentos, nos ajudou a aplicar os métodos fundamentais para dar resposta às nossas questões.

Um agradecimento especial aos colegas do Hospital das Clínicas de São Paulo, que apoiaram de muitas maneiras este trabalho, debatendo ideias ou dividindo o trabalho em momentos de ausência para o cumprimento de todas as etapas necessárias.

Ao professor Oswaldo Santos Baquero, pelo seu empenho na análise estatística e na sua dedicação à busca de soluções. 
Ao querido amigo Joacyr Barbosa, o Job, pelo carinho de sempre e pela enorme disponibilidade. Obrigado pelo grande apoio que me deu em todas as etapas da minha formação desde a graduação.

Às amigas queridas de todas as horas, Lourdes Miranda e Chris Nicoletti, pelo apoio incondicional. Além de amigas, são colegas de trabalho por quem tenho profundo respeito e em quem muito me inspirei pelos exemplos de integridade e competência com que atuam.

Ao amigo André Luiz Vieira que foi um grande apoiador e incentivador deste trabalho.

Aos meus pais queridos, pelo carinho e dedicação que tiveram conosco. Minha eterna gratidão e saudade.

Ao Paulo Gavião, pelo companheirismo, carinho e presença em todos os momentos. 


\section{Apoio}

Este projeto foi financiado pela Fundação de Amparo à Pesquisa do Estado de São Paulo (FAPESP) sob o registro 2011/19128-1 na categoria de pesquisa básica. 


\section{NORMATIZAÇÃO}

Esta tese está de acordo com as seguintes normas, em vigor no momento desta publicação:

Referências: adaptado de International Committee of Medical Journals Editors (Vancouver).

Universidade de São Paulo. Faculdade de Medicina. Serviço de Biblioteca e Documentação. Guia de apresentação de dissertação, teses e monografias. Elaborado por Anneliese Carneiro da Cunha, Maria Júlia de A. L. Freddi, Maria F. Crestana, Marinalva de Souza Aragão, Suely Campos Cardoso, Valéria Vilhena. $3^{a}$ ed. São Paulo: Divisão de Biblioteca e Documentação; 2011.

Abreviaturas dos títulos dos periódicos, de acordo com List of Journals Indexed in Index Medicus. 


\section{Sumário}

Lista de tabelas

Lista de quadros

Lista de anexos

Lista de figuras

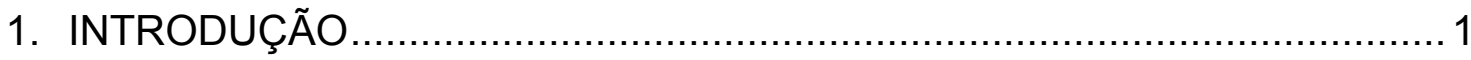

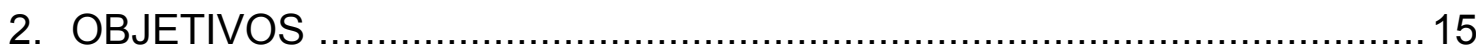

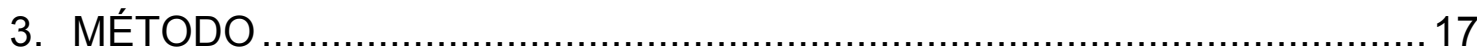

3.1 Tipo de estudo, área e população envolvidas ............................... 18

3.2 Variável dependente .............................................................. 21

3.3 Variáveis independentes ........................................................ 24

3.3.1 Variáveis socioeconômicas e indicadores de saúde ................24

3.3.2 Variáveis relacionadas à natureza do hospital ........................ 28

3.3.3 Consumo de antimicrobianos ........................................... 29

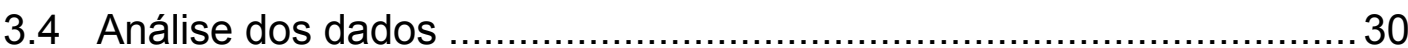

3.4.1 Análise espacial ..................................................... 31

3.4.1.1 Organização dos dados espaciais ......................... 31

3.4.1.2 Análise exploratória de dados espaciais................... 31

3.4 .2 Análise estatística ....................................................... 33

3.4.2.1 Modelo hierárquico ............................................. 33

3.4.2.2 Análise bayseana ......................................... 35

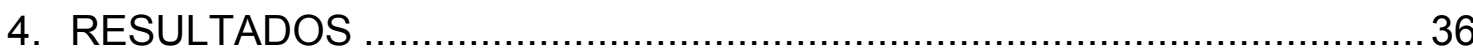

4.1 Descrição dos hospitais incluídos .............................................. 37

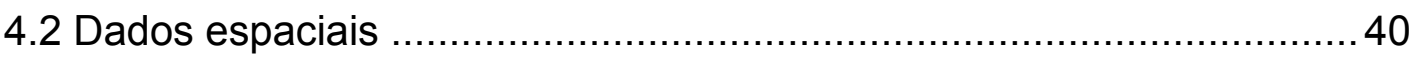

4.3 Análise estatística .................................................................... 48

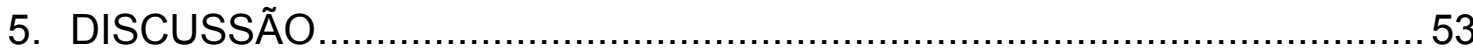

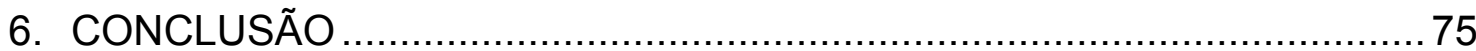

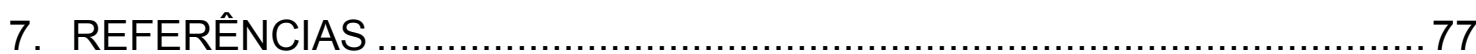

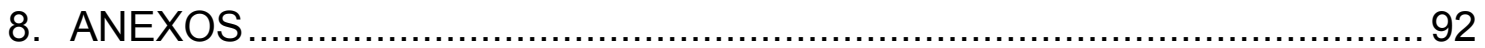




\section{Listas}

TABELAS

Tabela 1 - Distribuição dos hospitais, segundo sua natureza administrativa, notificantes ao sistema de vigilância de infecções relacionadas à assistência à saúde do Estado de São Paulo entre 2009 e 2011

Tabela 2 - Coordenadas geográficas e planas definidoras da área analisada neste estudo.

Tabela 3 - Número de hospitais notificantes segundo município. Sistema de vigilância de infecções relacionadas à assistência à saúde do Estado de São Paulo entre 2009 e 2011

Tabela 4 - Distribuição dos hospitais, segundo número de leitos de unidade de terapia intensiva (UTI), notificantes ao sistema de vigilância de infecções relacionadas à assistência à saúde do estado de São Paulo entre 2008 e 2011

Tabela 5 - Incidência de infecção da corrente sanguínea (percentil 90) segundo patógeno multirresistente em unidades de terapia intensiva ( $n=$ número de UTIs reportadas) do estado de São Paulo, 2008-2011

Tabela 6 - Análise de dependência espacial das incidências de ICS por bactérias multirresistentes em UTIs do estado de São Paulo nos anos de 2008 a 2011. A estimativa foi feita pelo cálculo do índice global de Moran utilizando-se matriz de vizinhança pelo método do vizinho mais próximo (oito vizinhos). A probabilidade foi calculada numa base de 999 permutações .

Tabela 7 - Resultado da análise de fatores associados à corrente sanguínea por Acinetobacter sp resistente aos carbapenêmicos em unidades de terapia intensiva do Estado de São Paulo nos anos de 2008 a 2011 
Tabela 8 - Resultado da análise de fatores associados à infecção da corrente sanguínea por Pseudomonas aeruginosa resistente aos carbapenêmicos em unidades de terapia intensiva do Estado de São Paulo nos anos de 2008 a 2011

Tabela 9 - Resultado da análise de fatores associados à corrente sanguínea por Escherichia coli resistente às cefalosporinas de terceira geração em unidades de terapia intensiva do Estado de São Paulo nos anos de 2008 a 2011

Tabela 10 - Resultado da análise de fatores associados à infecção da corrente sanguínea por Klebsiella pneumoniae resistente às cefalosporinas de terceira geração em unidades de terapia intensiva do Estado de São Paulo nos anos de 2008 a 2011

Tabela 11 - Resultado da análise de fatores associados à infecção da corrente sanguínea por Staphylococcus aureus resistente à meticilina em unidades de terapia intensiva do Estado de São Paulo nos anos de 2008 a 2011

Tabela 12 - Resultado da análise de fatores associados à infecção da corrente sanguínea por Enterococcus sp resistente à vancomicina em unidades de terapia intensiva do Estado de São Paulo nos anos de 2008 a 2011

Tabela 13 - Indicadores socioeconômicos, de qualidade e acesso aos serviços de saúde dos 105 municípios incluídos na análise. $\mathrm{O}$ ano base do cálculo do indicador está descrito entre parênteses. 
QUADROS

Quadro 1 - Bactérias multirresistentes causadoras de infecção da corrente sanguínea primária ou secundária ocorridas em Unidades de Terapia Intensiva do Estado de São Paulo entre os anos de 2008 a 2011 e reportadas ao sistema de vigilância de infecções relacionadas à saúde da Divisão de Infecção Hospitalar do Centro de Vigilância Epidemiológica da Secretaria de Saúde do estado de São Paulo

Quadro 2 - Classificação hierárquica das variáveis independentes investigadas na análise de regressão de Poisson como fatores associados à infecção da corrente sanguínea laboratorialmente confirmada em unidades de terapia intensiva do estado de São Paulo 


\section{ANEXOS}

Anexo 1 - Relação de hospitais participantes, município de localização, natureza administrativa, e número total de leitos e leitos de unidade de terapia intensiva

Anexo 2 - Variáveis socioeconômicas, de qualidade e acesso aos serviços de saúde inicialmente selecionadas pelos investigadores. Dados do censo de 2010 do Instituto Brasileiro de Geografia e Estatística (IBGE), DATASUS e Sistema Estadual de Análise de Dados (SEADE). As variáveis das linhas em cinza permaneceram na análise após teste de colinearidade (coeficiente de Pearson $\geq$ $0,5)$

Anexo 3 - Descrição dos antimicrobianos selecionados inicialmente pelos investigadores. Os antimicrobianos marcados em cinza permaneceram na análise após teste de colinearidade (coeficiente de Pearson $\geq 0,5$ ) 
FIGURAS

Figura 1 - Distribuição dos municípios participantes do estudo $(n=105)$. O sistema de coordenadas geográficas utilizadas foi com o Datum World Geodetic System (WGS 1984)

Figura 2 - Distribuição espacial dos hospitais participantes do estudo $(n=309)$. O sistema de coordenadas geográficas utilizadas foi com o Datum World Geodetic System (WGS 1984)

Figura 3 - Distribuição espacial das incidências de ICS por Acinetobacter sp resistente a carbapenêmico nas UTI do estado de São Paulo nos anos 2008 a 2011

Figura 4 - Distribuição espacial das incidências de ICS por Pseudomonas aeruginosa resistente a carbapenêmicos em UTIs do estado de São Paulo nos anos 2008 a 2011.

Figura 5 - Distribuição espacial das incidências de ICS por Escherichia coli resistente a cefalosporinas de terceira geração em UTIs do estado de São Paulo nos anos 2008 a 2011

Figura 6 - Distribuição espacial das incidências de ICS por Klebsiella pneumoniae resistente a cefalosporinas de terceira geração em UTIs do estado de São Paulo nos anos 2008 a 2011

Figura 7 - Distribuição espacial das incidências de ICS por Staphylococcus aureus resistente à oxacilina em UTIs do estado de São Paulo nos anos 2008 a 2011

Figura 8 - Distribuição espacial das incidências de ICS por Enterococcus sp resistente à vancomicina em UTIs do estado de São Paulo nos anos de 2008 a 2011

Figura 9 - Dados dos onze antimicrobianos mais consumidos no estado de São Paulo no período de 2008 a 2011 em milhões de DDD. DDD (dose diária definida) 


\section{Resumo}

Boszczowski I. Análise espacial da ocorrência de infecções bacterianas da corrente sanguínea causadas por agentes multirresistentes em unidades de terapia intensiva do Estado de São Paulo [Tese]. São Paulo: Faculdade de Medicina, Universidade de São Paulo; 2016.

Introdução - A resistência bacteriana aos antimicrobianos é resultado de mecanismos adaptativos destes microrganismos e se constitui em importante problema de saúde pública em razão da limitação terapêutica que este fenômeno impõe, sobretudo no tratamento de infecções invasivas de pacientes críticos. O surgimento de patógenos resistentes no ambiente hospitalar assim como seu comportamento epidemiológico é um evento complexo de múltiplas causas. A pressão seletiva decorrente do uso destas drogas é evidente desde o início do uso clínico da penicilina. No entanto, a inter-relação entre pressão seletiva e determinantes de outra natureza como sociais, econômicos e geográficos precisam ser mais bem compreendidos. Objetivos - 1. Investigar a existência de dependência espacial na ocorrência de infecção da corrente sanguínea em UTI no estado de São Paulo causadas por bactérias multirresistentes (BMR). 2. Investigar a associação entre a ocorrência de infecção da corrente sanguínea por BMR e consumo global de antimicrobianos no estado de São Paulo, indicadores socioeconômicos e de saúde. Método - Planejamos um estudo descritivo, ecológico e de multinível envolvendo unidades de terapia intensiva do estado de São Paulo. Definimos infecção da corrente sanguínea causada por seis patógenos multirresistentes e notificada à Secretaria de Saúde do Estado de São Paulo entre os anos de 2008 a 2011 como variável dependente. As variáveis independentes foram o consumo global (comunitário e hospitalar) de antimicrobianos neste período e variáveis socioeconômicas e de qualidade e acesso aos serviços de saúde. $O$ consumo de antimicrobianos foi obtido a partir de um banco de dados de uma empresa de prospecção de vendas destas drogas, IMS Health Brazil. As variáveis socioeconômicas e de qualidade e acesso aos serviços de saúde foram obtidas do Instituto Brasileiro de Geografia e Estatística (IBGE) e do Sistema Estadual de Análise de Dados (SEADE). Utilizamos um modelo 
hierárquico (multinível) incluindo as variáveis socioeconômicas distalmente, variáveis de acesso e qualidade de serviços de saúde medialmente e uso de antimicrobianos proximalmente. Dado o grande número de zeros em nossa variável de desfecho ( $34 \%$ a $85 \%$ a depender do patógeno avaliado), a verosimilhança foi modelada com base em uma distribuição de Poisson inflada por zeros. Os modelos foram ajustados seguindo a abordagem INLA, especificando prioris não informativas para as variáveis "município" e "hospital". As análises foram feitas no software R 3.2.1, usando os pacotes INLA 0.0-1432754561 e INLAOutputs 0.0.2. Resultados - Identificamos associação direta entre consumo global de penicilina e inversa com índice de Gini no estado de São Paulo e infecção da corrente sanguínea causada por Staphylococcus aureus resistente à oxacilina (MRSA). Para os demais agentes etiológicos estudados, não observamos o consumo global (comunitário e hospitalar) de antimicrobianos ou de variáveis socioeconômicas, de acesso e qualidade da assistência à saúde como determinantes da infecção da corrente sanguínea em unidades de terapia intensiva do estado de São Paulo. Observamos maior incidência de Enterococcus resistente à vancomicina (VRE), Pseudomonas aeruginosa resistente a carbapenens, Acinetobacter sp resistente a carbapenens e Escherichia coli resistente a cefalosporinas de terceira geração em hospitais públicos comparados a hospitais filantrópicos e menor incidência de VRE, Klebsiella pneumoniae resistente a cefalosporinas de terceira geração, Pseudomonas aeruginosa resistente a carbapenens, Acinetobacter $\mathrm{sp}$ resistente a carbapenens e Escherichia coli resistente a cefalosporinas de terceira geração em Santas Casas comparadas a hospitais filantrópicos. Por fim, observamos maior incidência de Klebsiella pneumoniae resistente a cefalosporinas de terceira geração em hospital privado comparado a hospital filantrópico. Conclusões -1 . Observamos que, embora não de maneira uniforme, a maioria dos patógenos estudados, nos diferentes anos, forma agrupamentos geográficos, ou seja, não estão distribuídos aleatoriamente no espaço estudado. 2. Não observamos, neste estudo, relação entre consumo de antimicrobianos na comunidade e infecção por patógenos multirresistentes em pacientes críticos tratados em unidades de terapia intensiva, exceto entre uso de penicilina e infecção por MRSA. 3. Observamos relação entre maior concentração de renda e menor incidência de infecção por MRSA. 4. Observamos associação entre baixas incidências de infecção por patógenos multirresistentes e Santas Casas, o que pode ser um marcador de desigualdade social confirmando o achado descrito acima da relação entre alto índice de Gini (maior concentração de renda) e menor 
incidência de MRSA ou, alternativamente, se constituir em fragilidade do diagnóstico laboratorial. 5. Há necessidade de estudos que explorem esta relação observada entre maior concentração de renda e categoria do hospital (Santa Casa) com menores incidências de infeç̧ão por patógenos multirresistentes em UTI.

Descritores: 1.Resistência microbiana a medicamentos 2.Bacteremia 3. Indicadores econômicos 4. Indicadores de serviços 5. Indicadores básicos de saúde 6.Análise espacial 


\section{Abstract}

Boszczowski I. Spatial analysis of bacterial bloodstream infections caused by multidrug resistant organisms in intensive care units of the State of São Paulo [Thesis]. São Paulo: "Faculdade de Medicina, Universidade de São Paulo"; 2016.

Introduction - Bacterial resistance to antimicrobial drugs is a result of microrganisms adaptive mechanisms and poses a great problem for public health because this phenomenon limits therapeutic options, especially for critical patients. The emergence of resistant pathogens in the hospital setting and their epidemiological behavior is a complex event with multiple causes. Selective pressure due to the use of these drugs has been evident since we started using penicillin for clinical purposes. However, interactions between selective pressure and other determinants like social, economic and geographic need to be better understood. Objetives - 1.To investigate the occurrence of spatial dependency among intensive care units (ICU) in the state of São Paulo related to the incidence of bloodstream infection caused by multidrug resistant organisms (MDRO). 2. To investigate the association of the incidence of bloodstream infection caused by MDROs, socioeconomic and health indicators. Method - We planned a descriptive, ecologic and multilevel study involving ICUs of the state of São Paulo. The incidences of bloodstream infection caused by a priori defined six MDROs reported to the State Health Department between 2008 and 2011 were defined as dependent variables. Independent variables were the global consumption (community and hospital) of antimicrobial drugs during the period of the study which was obtained from sales database of IMS Health Brazil, a sales prospecting company. Socioeconomic, quality and access to healthcare services indicators were obtained from Instituto Brasileiro de Geografia e Estatística (IBGE) and Sistema Estadual de Análises de Dados (SEADE). We used a hierarchical model (multilevel) including socioeconomic variables distally, quality and access to healthcare services medially and antimicrobial use proximally. Because of the great number of zeros observed within the dependent variable (34\% to $85 \%$ depending on the pathogen), the likelihood was modeled based on a Poisson distribution inflated with zeros. The models 
were adjusted following an INLA approach, determining non-informative prioris for the variables "municipality" and "hospital". Analysis were performed using R 3.2.1 software, INLA packages 0.0-1432754561 and INLAOutputs 0.0.2. Results - We identified significant positive association between global consumption of penicillin and negative association with higher Gini index both with methicillin resistant Staphylococcus aureus (MRSA). We did not identified other significant associations between global antimicrobial use, socioeconomic and healthcare indicators and multiresistant organisms causing bloodstream infections. There were greater incidences of vancomycin resistant Enterococci (VRE), carbapenem resistant Pseudomonas aeruginosa and Acinetobacter sp, third generation cephalosporin resistant Escherichia coli and Klebsiella pneumoniae in public hospitals compared to philanthropic hospitals and there were lower incidences of VRE, carbapenem resistant Pseudomonas aeruginosa and Acinetobacter $\mathrm{sp}$, third generation cephalosporin resistant Escherichia coli and Klebsiella pneumoniae in Santas Casas compared to philanthropic hospitals. Finally, we observed greater incidence of third generation cephalosporin resistant Klebsiella pneumoniae in private hospitals compared to philanthropic hospitals. Conclusions -1 . We observed that, although not consistently, for most of analized pathogens, in different years, form geographic clusters, i.e they are not randomly spatially distributed. 2. Based on our findings, the incidence of bloodstream infections caused by MDROs in ICUs are not related to global antimicrobial use, except for the relation between penicillin use and MRSA infection. 3. We observed that greater income concentration is related to lower incidence of MRSA. 4. The lower incidences of bloodstream infections caused by MDROs in Santas Casas might be a surrogate for social inequality confirming the finding of higher Gini index related to lowest MRSA infection or, alternatively being related to poor laboratory diagnostic performance. 5. Further studies exploring the observed relationship between greater income concentration and low incidence of MDRO infections in ICU are needed.

Descriptors: drug resistance, microbial; bacteremia; economic indexes; indicators of health services; health status indicators; spatial analysis. 


\section{Introdução}




\section{INTRODUÇÃO}

A resistência bacteriana aos antimicrobianos é resultado de seus mecanismos de adaptação determinados por seu patrimônio genético ${ }^{1}$. A capacidade adaptativa por sua vez é essencial para o processo evolutivo das espécies bacterianas. Os mecanismos genéticos que levam à resistência aos antimicrobianos são principalmente três ${ }^{2}$. O primeiro é constituído por mutações gênicas pontuais que podem determinar alteração estrutural do alvo da droga ou produção de enzimas que podem levar à sua degradação. O segundo é decorrente de rearranjos de seqüências de DNA determinados por elementos genéticos móveis denominados transposons ou seqüências de inserção que não são auto-replicáveis, mas podem se transportar independente do genoma bacteriano do qual se desprendeu. Estes elementos móveis podem carrear genes ou grupo de genes que determinam fenótipo de resistência. A terceira forma de armazenamento de genes de resistência ocorre em elementos genéticos extra-cromossômicos denominados plasmídeos com capacidade de auto-replicação. À exceção das mutações cromossômicas pontuais, os genes localizados em transposons, seqüências de inserção e plasmídeos podem ser transferidos entre diferentes indivíduos da mesma espécie ou até mesmo entre diferentes gêneros.

Os mecanismos de resistência mais conhecidos até o momento são
a) inativação enzimática;
b) alteração de permeabilidade;
c) bomba de 
efluxo; d) alteração do sítio de ação da droga; e) proteção do sítio de ação; f) superprodução de alvos.

O problema da resistência aos antimicrobianos surgiu com o uso clínico destas drogas. É consenso que a descoberta da penicilina por Alexander Fleming em 1928 e sua purificação por Florey e Chain foi um dos maiores avanços da medicina em toda a história da humanidade ${ }^{3,4}$. No entanto, logo após o início de seu uso clínico surgiram os primeiros relatos de resistência de Staphylococcus aureus a esta droga ${ }^{2}$.

Ficou bem demonstrado que cepas de Staphylococcus aureus produtoras de $\beta$-lactamase (penicilinase) hidrolisavam a penicilina tornando seu uso ineficaz no tratamento de infecções estafilocócicas. Ainda na década de 50 a meticilina, uma penicilina estável à ação das penicilinases, foi sintetizada em laboratório. A meticilina não chegou a ser utilizada na prática clínica, mas sua congênere, a oxacilina, foi amplamente difundida para uso clínico ${ }^{5}$.

Poucos anos após a introdução da oxacilina na prática clínica surgiram cepas de Staphylococcus aureus que apresentavam alteração da estrutura em sua parede bacteriana reduzindo a afinidade de ligação à oxacilina, denominados Staphylococcus aureus resistentes à meticilina ou MRSA (methicillin resistant Staphylococcus aureus), uma referência à penicilina sintética que deu origem às penicilinas penicilinase-resistentes. Para estes agentes a alternativa terapêutica inicial foi o desenvolvimento de glicopeptídeos, inicialmente a vancomicina e posteriormente a teicoplanina. 
A partir do surgimento dos primeiros isolados de Staphylococcus aureus com este perfil de resistência, sua incidência vem aumentando gradativamente em ritmos diferentes dependendo da área geográfica. Segundo relatos do NNISS (National Nosocomial Infection Surveillance System, atual National Healthcare Safety Network) a prevalência de MRSA aumentou de 2,1\% em 1975 para 35\% em 1991 e atualmente alguns centros com prevalência de mais de $70 \%^{6,7}$. A ocorrência de MRSA extrapola os limites do ambiente de assistência à saúde tendo sido descrito como agente etiológico de infecções comunitárias ${ }^{5}$.

Em 1997, foi relatado no Japão isolados de Staphylococcus aureus com sensibilidade reduzida aos glicopeptídeos ${ }^{8}$.

Em 2001 foram isolados, no Brasil, 4 espécimes de Staphylococcus aureus com sensibilidade reduzida à vancomicina ${ }^{9}$. Em 2003, foi publicado nos EUA caso de isolamento em material clínico de Staphylococcus aureus com resistência plena à vancomicina ${ }^{10}$. Novas classes de drogas surgiram como alternativa aos glicopeptídeos como linezolida, estreptograminas, daptomicina e glicilciclina. No entanto, algumas destas drogas já exibem algum grau de resistência.

Nas unidades de terapia intensiva do estado de São Paulo, entre os agentes causadores de infecção da corrente sanguínea, houve aumento significativo da proporção de multirresistentes entre os anos de 2005 e 2010. As proporções de Acinetobacer sp resistente a carbapenem, Escherichia coli e Klebsiella pneumoniae resistente a cefalosporinas de terceira geração 
aumentaram, respectivamente de $20 \%$ para $68 \%$, $20 \%$ para $30 \%$ e $43 \%$ para $61 \%{ }^{11}$

A premissa de que o uso de antibióticos está relacionada ao aumento do consumo de antibióticos por meio de seleção de bactérias resistentes a estas drogas encontra plausibilidade quando observamos a evolução da resistência em isolados clínicos de Enterococcus sp. ${ }^{12}$. No final dos anos de 1970 houve aumento substancial da comercialização de cefalosporinas, uma classe à qual Enterococcus sp. são intrinsecamente resistentes. O consumo cresceu tanto na comunidade como no ambiente hospitalar. No mesmo período em que um aumento de infecções urinárias causadas por Enterococcus sp. aumentou dez vezes, houve aumento do consumo de 64.000 para $114.000 \mathrm{~g} / \mathrm{ano}$ de cefalosporinas ${ }^{13}$.

Concomitantemente passou-se a observar maior frequência da participação deste gênero na etiologia das infecções hospitalares. Uma publicação do National Nosocomial Surveillance System (NNISS) dos Estados Unidos da América (EUA) de 1984 coloca este gênero como a terceira causa de infecção hospitalar daquele país ${ }^{14}$. Houve um aumento de três vezes no número de bacteremias hospitalares causadas por Enterococcus sp. comparando-se o período de 1970-73 a 1982-83 12 enquanto as taxas de infecções enterocócicas na comunidade permaneceram relativamente constantes. No entanto, outros fatores além do aumento do consumo de cefalosporinas podem ter concorrido para a maior participação dos Enterococci nas infecções hospitalares, como maior sobrevida de pacientes invadidos com cateteres urinários, cateteres venosos 
centrais, sondas e drenos, pacientes imunossuprimidos em razão dos avanços em transplantes. O quanto cada um destes fatores ou a combinação deles contribuiu para o aumento destes agentes é difícil dizer. Este período que vai da segunda metade da década de 70 à primeira metade dos anos 80 é marcada por aumento de Enterococcus sp. preservando sua sensibilidade à ampicilina e aminoglicosídeos. Em 1988, houve o primeiro relato de isolamento de Enterococcus faecalis e Enterococcus faecium resistentes à vancomicina ${ }^{15}$. Rapidamente novos relatos sucederam a este primeiro e em uma década havia publicações de diferentes partes do mundo ${ }^{16-21}$. O primeiro relato de infecção causada por Enterococcus resistente à vancomicina no Brasil é de $1996^{22}$. Além da seleção de resistentes, outro aspecto importante é a disseminação destes agentes no ambiente de assistência à saúde facilitada pela sua longa sobrevivência em superfícies inanimadas ${ }^{23,24}$.

Logo após a introdução da penicilina para uso clínico, ainda na década de 1940, houve demonstração laboratorial de que submeter cepas de Streptococcus pneumoniae a doses sub-letais de penicilina poderia selecionar cepas resistentes a essa droga $25,26,27$. O mecanismo de resistência desta bactéria às penicilinas é mediado por genes cromossômicos que codificam as proteínas ligadoras de penicilina (PLPs) 1a, 1b, 2 a, 2b, 2x e 3. Tais proteínas são enzimas catalisadoras da síntese da parede celular da bactéria. A redução de afinidade pelas PLPs ocorre de forma cumulativa de maneira que o aumento das concentrações inibitórias mínimas surge gradativamente. 
Trajetória semelhante de surgimento de resistência pode ser descrita para bactérias Gram-negativas ao longo da segunda metade do século XX, ou seja, tão logo o uso clínico de aminoglicosídeos e cefalosporinas foi iniciado surgiram os primeiros relatos de resistência a estas drogas ${ }^{28}$. Antes do uso clínico da penicilina, já havia sido descrita a primeira $\beta$-lactamase em Escherichia coli ${ }^{29}$. Muitos gêneros de bactérias Gram-negativas tem um gene cromossômico constitutivo de $\beta$-lactamase, provavelmente produto da evolução a partir de proteínas ligadoras de penicilina. Acredita-se que a ocorrência deste gene seja decorrente da pressão seletiva exercida por microorganismos produtores de $\beta$-lactâmicos ${ }^{30}$. A primeira $\beta$-lactamase mediada por plasmídio foi a TEM 1, descrita no início da década de $1960{ }^{31}$. A enzima TEM 1 foi descrita originalmente como isolada de hemocultura de uma paciente grega, chamada Temoniera, daí sua designação ${ }^{32}$. Poucos anos após sua identificação, essa enzima se disseminou amplamente entre diferentes gêneros e espécies bacterianas em larga escala geográfica. A enzima SHV 1 (variável sulfidrila), também comumente mediada por plasmídio, presente em Klebsiella pneumoniae e Escherichia coli também foi identificada no mesmo período que TEM 1.

Nas duas décadas que se seguiram, novos antibióticos $\beta$-lactâmicos (oximino-cefalosporinas) surgiram com a função de resistir à atividade hidrolítica dessas $\beta$-lactamases. O primeiro relato do isolamento de uma enzima capaz de hidrolisar estes novos $\beta$-lactâmicos ocorreu na Alemanha em 1985. Tratava-se da produção de uma enzima SHV-2 em Klebsiella ozanae originada da troca de um resíduo de aminoácido de SHV-1 ${ }^{33}$. Em 
razão do aumento do espectro de sua atividade, esta enzima foi denominada $\beta$-lactamase de espectro ampliado ou da sigla em inglês ESBL (extendedspectrum $\beta$-lactamase). Daqui por diante, neste texto, vamos nos referir a estas enzimas como ESBLs dado o uso corrente desta sigla entre infectologistas e microbiologistas. Atualmente, centenas de ESBLs já foram descritas ${ }^{34}$.

Diante deste cenário, muitos investigadores tentaram estabelecer a relação entre uso de antimicrobianos e surgimento de resistência ${ }^{35-46}$. Inúmeras publicações abordando prevalência de agentes resistentes em hospitais ou investigação de surtos de infecção relacionada à assistência à saúde encontraram o uso prévio de antimicrobianos como fator de risco para o desenvolvimento de infecção ou colonização por bactéria resistente ${ }^{47}$.

Entre os vários estudos originais que tentaram demonstrar a relação de uso de antimicrobiano e indução de resistência, muitas vezes o cenário descrito envolve um surto em ambiente hospitalar. Chow et al. ${ }^{48}$, publicou em 1991, estudo conduzido em seis hospitais norte-americanos, nos quais amostras de Enterobacter foram obtidas antes e após o uso de antimicrobianos. Em sete de onze casos, os isolados sensíveis eram relacionados aos resistentes. Outro estudo tentou demonstrar, também por meio de tipagem molecular, que cepas de Gram-negativos sensíveis e resistentes a cefalosporinas de terceira geração antes e após o uso de antimicrobianos, respectivamente, eram idênticas em metade dos casos ${ }^{49}$. Carmeli et al. ${ }^{50}$, relacionou o uso de antimicrobiano e o surgimento de resistência de Pseudomonas aeruginosa. Neste estudo, 271 pacientes com 
infecção foram observados, e isolados resistentes surgiram após terapia antimicrobiana em $10,2 \%$ dos casos. Houve maior associação com o uso de imipenem comparado ao uso de ceftazidima.

No entanto, esta relação não pode ser facilmente estabelecida em decorrência das inúmeras variáveis a que as populações que desenvolvem infecção/colonização por bactéria resistente estão submetidas.

Além disso, é relevante diferenciar a geração de bactérias multirresitentes no cenário hospitalar da disseminação por meio da transmissão cruzada destes agentes. Ferreira publicou estudo cujo objetivo era avaliar o surgimento de resistência de Pseudomonas aeruginosa e Acinetobacter spp. ao imipenem e à ciprofloxacina após o uso destas drogas. No entanto, as cepas sensíveis e as resistentes não eram relacionadas segundo estudo de tipagem molecular. Já entre as cepas resistentes havia predominância de um clone de $P$. aeruginosa e todos os isolados de Acinetobaceter spp. eram idênticos ${ }^{51}$. Outro estudo descreve o surgimento e rápida disseminação de $A$. baumannii multirresistente num hospital de Taiwan ${ }^{52}$. O surgimento de resistência coincidiu com o aumento do uso de ciprofloxacina, no entanto a tipagem molecular demonstrou um clone predominante. Neste caso, em teoria, tanto a seleção como a transmissão de um clone selecionado pode ter ocorrido de maneira sequencial. O uso de antimicrobianos pode alterar a flora bacteriana indígena propiciando um ambiente adequado ao estabelecimento de "novas populações" resistentes e estas por sua vez podem se disseminar no contato 
pessoa a pessoa, no ambiente e por meio das mãos de profissionais de saúde.

Nesta perspectiva é importante ressaltar que medidas de prevenção da disseminação de agentes como higiene das mãos, precauções de contato e higiene adequada do ambiente próximo ao paciente são medidas fundamentais para o controle da multirresistência ${ }^{53,54}$.

Apesar da complexidade e das múltiplas faces possíveis da resistência bacteriana, o uso indiscriminado de antimicrobianos parece contribuir em algum grau para o surgimento de resistência e a restrição do seu uso faz parte das recomendações para o seu controle ${ }^{55}$.

Estratégias como rodízio ou uso cíclico de antimicrobianos foram estudadas como forma de se reduzir a incidência de bactérias resistentes principalmente em unidades de terapia intensiva. No entanto seus resultados não são conclusivos e muitas dúvidas persistem quanto à efetividade desta medida $56,57,58$.

No Brasil, a Portaria 2616, publicada em 13 de maio de 1998, atribui como competência da Comissão de Controle de Infecção Hospitalar, em seu item 3.7 "definir, em cooperação com a Comissão de Farmácia e Terapêutica, política de utilização de antimicrobianos, germicidas e materiais médico-hospitalares para a instituição" com o objetivo de se manter algum controle sobre a utilização destas drogas ${ }^{59}$.

Já na comunidade, o uso de antimicrobianos, seja para tratamento clínico ou para outros fins como indústria alimentícia e pecuária tem sido tema de discussão em vários estudos que abordam a relação entre uso 
destas drogas e a emergência de resistência ${ }^{60}$. A disseminação de $S$. pneumoniae resistentes à penicilina em várias partes do mundo tem se mostrado um problema epidemiológico de grande impacto, sobretudo na população pediátrica ${ }^{61}$. No entanto, estudos que avaliaram uso de antimicrobiano e surgimento de resistência de $S$. pneumoniae à penicilina não conseguiram estabelecer esta relação ${ }^{61}$. Um estudo islandês avaliou o impacto, por meio de uma intervenção educacional, da redução da densidade de utilização de antimicrobianos em quatro comunidades distintas da Islândia e a redução do número de crianças entre um e sete anos de idade portadoras de $S$ pneumoniae resistentes à penicilina. Embora o programa tenha sido efetivo na redução da densidade de utilização de antimicrobianos, não o foi para reduzir a taxa de indivíduos colonizados ${ }^{62}$.

O uso de antimicrobianos como promotores de crescimento na alimentação animal surgiu na década de 1940. Em 1946 foi publicado o primeiro trabalho utilizando aureomicina com este objetivo ${ }^{63}$. Além disso, o uso profilático e terapêutico das criações de ave e gado de corte se faz necessário para garantir a produção de alimentos ${ }^{64,65}$. Embora tenha sido demonstrada colonização por bactérias resistentes em animais alimentados com ração contendo antimicrobiano como promotor de crescimento, não se conhece até o momento qual é o impacto desta prática na cadeia alimentar e na saúde humana ${ }^{66}$. Alguns estudos da década de 1990 demonstraram relação entre o uso de avoparcina, um glicopeptídeo, em ração animal e a colonização do trato gastrintestinal destes animais por Enterococcus faecium com resistência a glicopeptídeos ${ }^{67,68}$. Em razão destes achados, a 
comunidade européia proíbe o uso de avoparcina na criação de gado de corte e em 1998 proibiu a utilização de bacitracina, virginiamicina, espiramicina e tilosina com o mesmo fim.

Nos EUA, a comunidade tem se posicionado a favor da manutenção do uso de antimicrobianos como promotores do crescimento defendendo que, caso este seja abandonado, haveria um aumento expressivo do custo de produção do gado, com redução da segurança alimentar. Alguns autores argumentam também que não há evidência definitiva de que o uso de antimicrobianos em doses sub-terapêuticas induza a resistência bacteriana em animais e ainda que não há evidência do impacto negativo na saúde humana.

No Brasil, em 1992, a Portaria $n^{\circ} 159$, do Ministério da Agricultura veda o uso de antimicrobianos para ação como aditivos sistêmicos, promotores de crescimento ou conservantes como tetracilinas, penicilinas, cloranfenicol e sulfonamidas. O Ofício Circular 19/98 de 16/11/98 do Ministério da Agricultura, suspende o uso de Avoparcina e a Portaria 448 de 10/09/98 proíbe o uso de Cloranfenicol, Furazolidona e Nitrofurazona ${ }^{69}$. Além disso, a resolução européia de não mais consumir carne em que tenha sido utilizado antimicrobiano como promotor de crescimento no seu processo de produção pode significar barreira comercial importante para produtores brasileiros, com prejuízo anual de milhões de dólares. Novas tecnologias estão sendo estudadas como alternativa para promotores do crescimento baseado apenas em antimicrobianos. Estudos com probióticos, ácidos orgânicos e manejo alimentar estão em andamento ${ }^{63}$. 
O desenvolvimento de resistência é bastante complexo e a capacidade da maioria dos estudos em estabelecer as diferentes causas e a contribuição individual de cada uma é limitada em função das pequenas populações abordadas em cada estudo, na maioria das vezes relacionada a surtos de infecção hospitalar ou a estudos de prevalência em "unidades fechadas" como unidades de terapia intensiva.

Há poucos estudos populacionais desenhados para avaliar a relaçãoentre uso de antimicrobiano e surgimento de resistência bacteriana $^{70,71}$.

Propomos a avaliação da relação entre uso de antimicrobianos e perfil de resistência bacteriana em uma grande área geográfica por meio de estudo ecológico utilizando sistema de informação geográfica para a análise da distribuição de bactérias multirresistentes numa dada área geográfica e o padrão de consumo de antimicrobianos nesta mesma região.

A análise da distribuição geográfica de um evento para se compreender o comportamento epidemiológico de uma doença foi utilizado pela primeira vez por John Snow quando ele reconstituiu a ocorrência de cólera em Londres estudando por meio de mapas a distribuição de água por três diferentes companhias fornecedoras ${ }^{72}$. A utilização de sistema de informação geográfica tem sido utilizada em medicina, sobretudo no campo da saúde pública na última década ${ }^{73,74}$. McKee et al. estudaram um surto comunitário de diarréia causado por Shigella sonnei no estado norteamericano da Carolina do Norte ${ }^{75}$. Estes autores conseguiram identificar o 
"epicentro" do surto por meio da relação temporo-espacial entre os casos, o que contribuiu para a interrupção da transmissão do agente.

Pretendemos explorar, neste projeto, a relação espacial entre o consumo global, ou seja, uso comunitário e hospitalar de antimicrobianos no Estado de São Paulo, indicadores socioeconômicos e de saúde e o perfil de resistência dos principais patógenos causadores de infecções relacionadas à assistência à saúde. 
2 Objetivos 


\section{OBJETIVOS}

1.1 Investigar a existência de dependência espacial na ocorrência de infecção da corrente sanguínea em UTI no estado de São Paulo causadas por bactérias multirresistentes (BMR).

1.2 Investigar a associação entre ocorrência de infecção da corrente sanguínea por BMR e consumo global de antimicrobianos no estado de São Paulo, indicadores socioeconômicos e de saúde. 
3 Método 


\section{MÉTODO}

\subsection{Tipo de estudo, área e população envolvidas}

Planejamos um estudo com caráter descritivo, ecológico e multinível envolvendo hospitais do estado de São Paulo notificantes de infecções hospitalares (IH) ao sistema de vigilância de IRAS da divisão de infecção hospitalar do Centro de Vigilância Epidemiológica da Secretaria de Saúde do Estado de São Paulo (DIH/CVE/SES) durante os anos de 2008 a 2011.

Os critérios para incluir os hospitais foram ter ao menos cinco leitos de UTI e ter notificado ao sistema em pelo menos três dos quatro anos do estudo.

O Estado de São Paulo tem uma área de $248.222 \mathrm{~km}^{2}$ distribuídas em 645 municípios e população de 41.262 milhões de habitantes segundo o censo do IBGE de 2010. A densidade demográfica do estado neste ano era de $166 \mathrm{hab} / \mathrm{km}^{2}$. Selecionamos 309 hospitais notificantes ao sistema de vigilância das infecções hospitalares da DIH/CVE/SES do estado de São Paulo em 105 municípios e que notificaram ao sistema durante os três anos do estudo.

Apresentamos, nas Figuras 1 e 2, respectivamente, as localizações geográficas, dos municípios representadas por área e dos hospitais, representadas por ponto.

A lista de hospitais incluídos no estudo é apresentada no Anexo 1. 


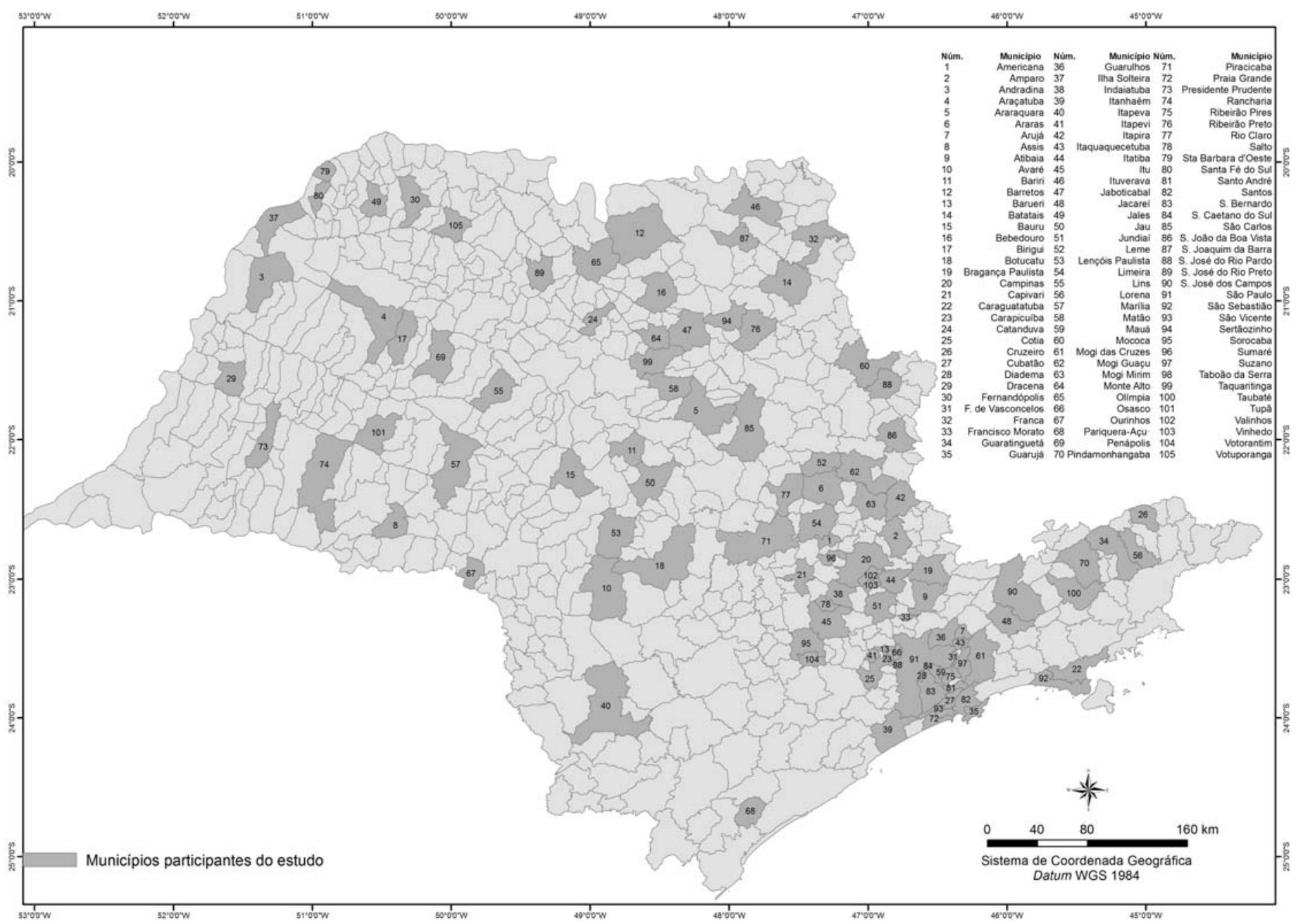

Figura 1 -

Distribuição dos

municípios

participantes do

estudo $(n=105)$. O

sistema de

coordenadas

geográficas utilizadas

foi com o Datum

World Geodetic

System (WGS 1984)

5roow

T

$4500 \mathrm{w}$ 


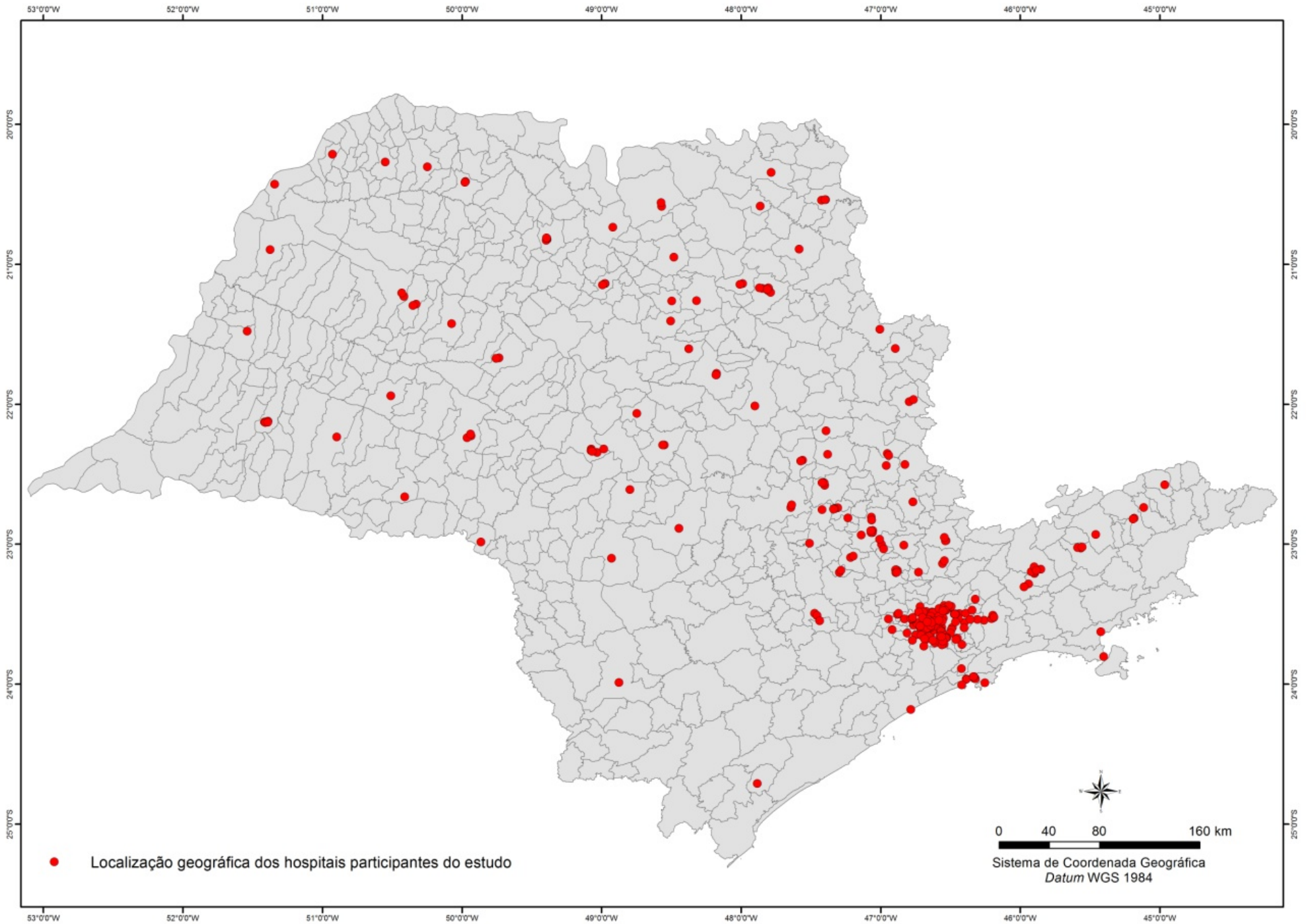

\section{Figura 2-}

Distribuição espacial dos hospitais

participantes do estudo $(n=309)$. 0 sistema de coordenadas geográficas

utilizadas foi com o

Datum World

Geodetic System (WGS 1984) 


\subsection{Variável dependente}

A DIH/CVE/SES mantém um sistema de vigilância de IH desde 2004 que publica anualmente as incidências de infecção da corrente sanguínea por bactérias multirresistentes. Estes dados estão disponíveis na web no endereço www.cve.saude.sp.gov ${ }^{11}$. Estabelecemos a incidência de infecção da corrente sanguínea (ICS) primária ou secundária, laboratorialmente confirmadas, ocorrida em unidade de terapia intensiva como variável dependente. A incidência anual foi calculada dividindo-se o número de infecções por patógeno multirresistente/ano pelo número total de pacientesdia de UTI no mesmo ano, somados todos os leitos de UTI do hospital participante. Foram incluídos dados notificados ao sistema entre os anos de 2008 e 2011 para descrição. Calculamos incidências, separadamente, para cada um dos diferentes agentes etiológicos e selecionamos apenas fenótipos de resistência de relevância epidemiológica. Os agentes selecionados e seus fenótipos de resistência são aqueles descritos no Quadro 1. 
Quadro 1 - Bactérias multirresistentes causadoras de infecção da corrente sanguínea primária ou secundária ocorridas em Unidades de Terapia Intensiva do Estado de São Paulo entre os anos de 2008 a 2011 e reportadas ao sistema de vigilância de infecções relacionadas à saúde da Divisão de Infecção Hospitalar do Centro de Vigilância Epidemiológica da Secretaria de Saúde do estado de São Paulo

Acinetobacter sp resistente a imipenem

Pseudomonas aeruginosa resistente a imipenem

Escherichia coli resistente à cefalosporina de terceira geração

Klebsiella pneumoniae resistente à cefalosporina de terceira geração

Enterococcus sp resistente à vancomicina

Staphylococcus aureus resistente à oxacilina

O critério diagnóstico de ICS primária é definido pela DIH/CVE/SES adaptado a partir dos critérios nacionais da Agência de Vigilância Sanitária $(\mathrm{ANVISA})^{76}$

Descrevemos, abaixo, os dois critérios utilizados para notificação de ICS primária no estado de São Paulo:

Critério 1:

Paciente com pelo menos um patógeno isolado em uma ou mais hemoculturas e o patógeno não está relacionado com uma infecção em outro sítio. 


\section{Critério 2:}

- Febre $\left(T \geq 38^{\circ} \mathrm{C}\right)$, calafrios ou hipotensão e qualquer um dos seguintes:

- Patógeno comumente contaminante de pele ${ }^{1}$ isolado de duas hemoculturas obtidas em duas punções diferentes e o microrganismo não está relacionado com infecção em outro sítio.

- Patógeno comumente contaminante de pele isolado de hemocultura em paciente com acesso venoso central e o médico institui terapia antimicrobiana adequada.

- Teste de antígeno positivo no sangue ${ }^{2}$ e o microrganismo não está relacionado com infecção em outro sítio.

As ICS secundárias são bacteremias diagnosticadas na vigência de um processo infeccioso em órgão/sítio específico exceto se este sítio for o acesso venoso central. Como exemplo, um paciente com critérios bem definidos de pneumonia e que tem uma bactéria patogênica isolada em sangue é classificado como portador de ICS secundária à pneumonia.

\footnotetext{
1 Microrganismos comumente contaminantes são aqueles residentes da flora normal (difteróides, Bacillus sp., Propionibacterium sp., estafilococos coagulase negativos ou Micrococcus sp).

2 Detecção de antígeno bacteriano, fúngico ou viral (Candida sp.; Herpes simplex, Varicella zoster, Haemophilus influenzae, Streptococcus pneumoniae, Neisseria meningitidis, estreptococos do grupo B) por teste diagnóstico rápido (contraimunoeletroforese, coagulação ou aglutinação em látex).
} 


\subsection{Variáveis independentes}

As variáveis independentes são descritas a seguir e estão sintetizadas e com sua posição hierárquica apresentada no Quadro 2. A posição hierárquica se refere ao modelo multinível utilizado na análise estatística.

\subsubsection{Variáveis socioeconômicas e indicadores de saúde}

A exploração de determinantes socioeconômicos e de indicadores de saúde baseou-se na premissa de que o padrão de riqueza de uma população pode levar à maior exposição individual a antimicrobianos e/ou à maior frequência a serviços de saúde abrindo caminho para colonização e consequente infecção por bactérias multirresistentes em doentes críticos, havendo um continuum entre estes fatores e o fenômeno da resistência no ambiente de terapia intensiva.

As variáveis socioeconômicas e indicadores de saúde de cada município foram obtidos a partir de dados do censo 2010 do Instituto Brasileiro de Geografia e Estatística (IBGE), dados do DATASUS (2010) e do Sistema de Análise de Dados do Estado de São Paulo (SEADE 2010). Inicialmente, exploramos um conjunto de 221 variáveis. Escolhemos, por conveniência, 16 dentre estas que representassem a condição socioeconômica dos municípios analisados assim como indicadores de acesso aos serviços de saúde e qualidade assistencial (Anexo 2). Submetemos o conjunto das 16 variáveis a uma matriz de correlação e 
excluímos uma entre duas variáveis com coeficiente de Pearson $\geq 0,5$. Ao final, permaneceram para análise quatro variáveis socioeconômicas e três indicadores de saúde que são descritos a seguir:

- Idade > 60 anos - é a proporção da população residente total com mais de sessenta anos por município. Os valores foram obtidos do censo de 2010 do IBGE.

- Proporção de domicílios com saneamento básico adequado segundo definição da Lei 11.445 de 2007 que estabelece as diretrizes nacionais para o saneamento básico, este é o "conjunto de medidas, infraestruturas e instalações operacionais de: abastecimento de água potável; esgotamento sanitário; limpeza urbana e manejo de resíduos sólidos; e, drenagem e manejo de águas pluviais urbanas" ${ }^{77}$. Os valores foram obtidos do censo de 2010 do IBGE.

- Índice de Gini - "Medida do desvio da distribuição do rendimento (ou do consumo) entre indivíduos ou famílias dentro de um país a partir de uma distribuição perfeitamente igual". Uma curva de Lorenz traça as percentagens acumuladas do rendimento total recebido em comparação com o número acumulado de beneficiários, começando pelo indivíduo ou família mais pobre. O índice de Gini mede a área entre a curva de Lorenz e uma linha hipotética de igualdade absoluta, expressa como percentagem da área máxima sob a linha. Um valor de 0 representa a igualdade absoluta, um valor de 1 a desigualdade absoluta" ${ }^{78}$. Os valores calculados para cada município incluído no estudo foram obtidos de pesquisa de orçamentos familiares realizada 
pelo IBGE nos anos de 2002 e 2003. A estimativa do consumo para a geração destes indicadores foi obtida utilizando o método de estimativa de pequenas áreas dos autores Elbers, Lanjouw e Lanjouw de 2002. Este método foi proposto pelo Banco Mundial e serviu de base para a construção do mapa da pobreza de 2008 elaborado pelo IBGE $^{79}$.

- Índice de desenvolvimento humano municipal - é uma medida que leva em conta a longevidade, escolaridade e renda da população avaliada. O primeiro componente é dado pela expectativa de vida ao nascer. O segundo, pela escolaridade de grupos de indivíduos definidos por faixa etária e o terceiro pela renda municipal per capita, ou seja, a renda média de cada residente de determinado município. Os valores foram obtidos do censo de 2010 do IBGE.

- Leitos públicos por $\mathbf{1 0 0 0}$ habitantes - valores obtidos do IBGE com ano de referência em 2009.

- Equipamentos de hemodiálise por 1000 habitantes - valores obtidos do IBGE com ano de referência em 2009.

- Coeficiente de mortalidade infantil (CMI) - "é calculado dividindo-se o número de óbitos de crianças menores de um ano pelos nascidos vivos naquele ano, em uma determinada área, e multiplicando-se por 1000 o valor encontrado" ${ }^{80}$. Este indicador foi obtido a partir dos dados publicados pelo Sistema Estadual de Análise de Dados (SEADE), fundação ligada à Secretaria Estadual de Planejamento e 
Desenvolvimento do Estado de São Paulo. Incluímos o CMI médio por município com base nos anos de 2006 a 2010 .

Os indicadores socioeconômicos e de saúde por município são apresentados na Tabela 13 (Anexo).

Quadro 2 - Classificação hierárquica das variáveis independentes investigadas na análise de regressão de Poisson como fatores associados à infecção da corrente sanguínea laboratorialmente confirmada em unidades de terapia intensiva do estado de São Paulo

\begin{tabular}{|c|c|c|}
\hline \multicolumn{3}{|c|}{ Variáveis independentes } \\
\hline Grupo & Nome & $\begin{array}{l}\text { Posição } \\
\text { hierárquica }\end{array}$ \\
\hline \multirow{6}{*}{ Socioeconômicas } & $\begin{array}{l}\text { Proporção de indivíduos com idade > } 60 \\
\text { anos }\end{array}$ & Distal \\
\hline & $\begin{array}{l}\text { Proporção de rendimento mensal } \\
\text { domiciliar per capita até } 1 / 2 \text { salário mínimo }\end{array}$ & Distal \\
\hline & $\begin{array}{l}\text { Proporção de domicílios com saneamento } \\
\text { adequado }\end{array}$ & Distal \\
\hline & Densidade demográfica & Distal \\
\hline & Índice de Gini & Distal \\
\hline & $\begin{array}{l}\text { Índice de desenvolvimento humano } \\
\text { municipal }\end{array}$ & Distal \\
\hline $\begin{array}{l}\text { Qualidade dos serviços de } \\
\text { saúde }\end{array}$ & Mortalidade infantil & Distal \\
\hline \multirow{3}{*}{$\begin{array}{l}\text { Acesso aos serviços de } \\
\text { saúde }\end{array}$} & Leitos públicos por 1000 habitantes & Distal \\
\hline & $\begin{array}{l}\text { Total de leitos (público+privado) por } 1000 \\
\text { habitantes }\end{array}$ & Distal \\
\hline & $\begin{array}{l}\text { Equipamentos de hemodiálise por } 1000 \\
\text { habitantes }\end{array}$ & Distal \\
\hline $\begin{array}{l}\text { Natureza administrativa } \\
\text { dos hospitais }\end{array}$ & $\begin{array}{l}\text { Pública } \\
\text { Privada } \\
\text { Filantrópica } \\
\text { Santas Casas }\end{array}$ & Medial \\
\hline $\begin{array}{l}\text { Número de leitos de UTI } \\
\text { de cada hospital }\end{array}$ & $\begin{array}{l}\text { Até } 15 \\
>15\end{array}$ & Medial \\
\hline $\begin{array}{l}\text { Consumo global de } \\
\text { antimicrobianos }\end{array}$ & $\begin{array}{l}\text { Dose diária definida de cada } \\
\text { antimicrobiano individualmente }\end{array}$ & Proximal \\
\hline
\end{tabular}




\subsubsection{Variáveis relacionadas à natureza do hospital}

Os hospitais foram divididos em quatro categorias segundo a sua natureza administrativa em público, privado, filantrópico e Santa Casa (Tabela 1). De uma maneira simplificada essas categorias representam o seguinte:

- Hospitais públicos - são aqueles geridos com recursos exclusivamente públicos em um regime de administração direta ou por meio de organizações sociais de saúde que são entidades de direito privado que por meio de contratos temporários de gestão administram hospitais públicos;

- Hospitais privados - são aqueles geridos com recursos privados oriundos diretamente de contrato com o paciente ou com empresas da área de saúde suplementar. Na maioria dos casos, estes hospitais formam a rede de empresas de saúde suplementar. Pode haver também hospitais contratados pelo SUS;

- Hospitais filantrópicos - foram agrupados nesta categoria, em sua maioria, grandes hospitais privados que revertem recurso público de renúncia fiscal em programas assistenciais pactuados com o governo. Em menor número são hospitais de caridade;

- Santas casas - são hospitais filantrópicos cuja natureza administrativa é privada, porém conveniados com o SUS recebendo recursos deste para atendimento público.

Os hospitais foram divididos ainda em duas categorias quanto ao número de leitos de terapia intensiva entre aqueles com até quinze leitos ou mais de quinze leitos. 
Tabela 1 - Distribuição dos hospitais, segundo sua natureza administrativa, notificantes ao sistema de vigilância de infecções relacionadas à assistência à saúde do Estado de São Paulo entre 2009 e 2011

\begin{tabular}{lcc}
\hline Natureza administrativa do hospital & N de hospitais & Proporção (\%) \\
\hline Pública & 86 & $28 \%$ \\
Privada & 126 & $41 \%$ \\
Filantrópica & 40 & $13 \%$ \\
Santa Casa & 57 & $18 \%$ \\
\hline
\end{tabular}

Dados da Divisão de Infecção Hospitalar do Centro de Vigilância Epidemiológica da Secretaria de Estado da Saúde de São Paulo

\subsubsection{Consumo de antimicrobianos}

Analisamos o consumo global (comunitário e hospitalar) de cada antimicrobiano no estado de São Paulo entre os anos 2009 e 2011. Obtivemos os dados de consumo por meio de auditoria de mercado realizada pela empresa IMS Health Brasil. Esta empresa detém base de dados de venda de antimicrobianos a pontos de distribuição (farmácias e unidades básicas de saúde) com cobertura de $98 \%$ para o estado de São Paulo.

Inicialmente, obtivemos os dados de consumo de 43 antimicrobianos e, após verificação da matriz de correlação, excluímos uma entre duas drogas que apresentavam índice de correlação de Pearson maior ou igual a 0,5 (Anexo 3). A escolha sobre quais drogas manter para análise ficou a critério do pesquisador. 
Catorze antibióticos foram incluídos no modelo final representando o consumo global de antibióticos no Estado de São Paulo: azitromicina, aztreonam, cefalotina, cefepime, cefoxitina, ceftazidima, ciprofloxacina, doxiciclina, eritromicina, imipenem, meropenem, norfloxacina, penicilina e roxitromicina.

O consumo foi expresso em dose diária definida (DDD)/1000 habitantes/ano segundo método Anatomical Therapeutic Chemical (ATC/DDD) da Organização Mundial da Saúde (OMS), modificado. Tal método encontra-se descrito na página www.whocc.no/atc_ddd_index acessada em 30/04/2011 ${ }^{81}$. A DDD expressa a dose diária de manutenção de uma droga utilizada em sua principal indicação num paciente adulto de $70 \mathrm{~kg}{ }^{82}$. Esta dose é tomada como uma unidade de medida e não necessariamente reflete a dose diária prescrita ou recomendada para diferentes indicações.

\subsection{Análise dos dados}

Inicialmente, procedemos a uma análise descritiva e exploratória dos dados. Descrevemos as incidências acumuladas de infecção da corrente sanguínea por patógeno por ano de análise (2008 a 2011). Logo após, apresentamos a descrição da natureza administrativa dos hospitais participantes do estudo, o número de hospitais participantes por município e o número de unidades de terapia intensiva por hospital. Apresentamos também, a distribuição espacial das incidências por patógeno por ano em mapas coropléticos. As incidências foram divididas em quartis. 


\subsubsection{Análise espacial}

\subsubsection{Organização dos dados espaciais}

Inicialmente, procedemos à análise espacial descritiva dos dados, por meio de análise de padrões de distribuição de pontos. Apresentamos um padrão pontual (conjunto de pontos $\mathrm{p}_{1}, \mathrm{p}_{2} \ldots \mathrm{p}_{\mathrm{n}}$ ) representando hospitais incluídos no estudo. A coordenada geográfica de cada hospital foi obtida pelo programa Google Earth ${ }^{\mathrm{TM}}$ usando como referência seu código de endereçamento postal.

A base geográfica sobre a qual apresentamos os pontos é o mapa do Estado de São Paulo cujo limite foi estabelecido pelas coordenadas apresentadas na Tabela 2.

Tabela 2 - Coordenadas geográficas e planas definidoras da área analisada neste estudo

\begin{tabular}{|c|c|c|c|c|}
\hline \multirow{2}{*}{ Limites } & \multicolumn{2}{|c|}{ Coordenadas de longitude (X) } & \multicolumn{2}{|c|}{ Coordenadas de latitude $(\mathrm{Y})$} \\
\hline & Geográfica & Plana & Geográfica & Plana \\
\hline Norte & $19^{\circ} 46^{\prime} 50 " S$ & -20.113401 & $50^{\circ} 28^{\prime} 39^{\prime \prime O}$ & -50.118759 \\
\hline Sul & $25^{\circ} 19^{\prime} 4^{\prime \prime} S$ & -23.250146 & $48^{\circ} 5^{\prime} 55^{\prime \prime} \mathrm{O}$ & -72.23912 \\
\hline Leste & $22^{\circ} 40^{\prime} 45^{\prime \prime} S$ & -23.720286 & $44^{\circ} 9^{\prime} 32^{\prime \prime O}$ & -74.79218 \\
\hline Oeste & $22^{\circ} 26^{\prime} 52^{\prime \prime} S$ & -22.640347 & $53^{\circ} 6^{\prime} 29^{\prime \prime} \mathrm{O}$ & -52.960375 \\
\hline
\end{tabular}

\subsubsection{Análise exploratória de dados espaciais}

Nosso interesse primário, nesta fase exploratória, foi verificar se a variável dependente deste estudo (ocorrência de infecção da corrente 
sanguínea (ICS) causada por bactérias multirresistentes) exibia algum padrão sistemático ou se tem distribuição aleatória. Uma vez que a cada hospital estão associadas taxas de incidência para cada um dos microorganismos analisados e que cada hospital representa um aglomerado de pacientes, a análise de existência de dependência espacial foi feita por meio do cálculo dos índices globais de Moran (índice de autocorrelação espacial).

O índice mede quanto o valor observado de um atributo (p.ex, ICS) numa região ou ponto é independente dos valores desta mesma variável nas localizações vizinhas. O índice varia da autocorrelação absoluta de 1 (direta) a -1 (inversa) sendo zero a ausência completa de autocorrelação ${ }^{83}$. Se houver autocorrelação espacial positiva, assumimos que existe dependência espacial do fenômeno estudado. Nós utilizamos, neste estudo, o índice global de Moran I, dado pela fórmula:

$$
I=\frac{\mathrm{n} \sum_{i=1}^{n} \sum_{i=1}^{n} w_{i j}\left(y_{i}-\bar{y}\right)\left(y_{j}-\bar{y}\right)}{\left(\sum_{i=1}^{n}\left(y_{i}-\bar{y}\right)^{2}\right) \sum \sum_{i \neq i} w_{i j}}
$$

na qual,

$n=$ número de pontos analisados (em nosso estudo, UTI individualmente)

$Y i=$ valor do atributo considerado no ponto $i$ (em nosso estudo, incidência de ICS para cada patógeno individualmente)

$\bar{y}=$ valor médio do atributo na região do estudo

$W i j=$ pesos atribuídos conforme a conexão entre as áreas $i$ e $j$ 
A fim de calcularmos o índice global de Moran, construímos uma matriz de vizinhança utilizando o programa GEODA ${ }^{\mathrm{TM}}$. Adotamos como critério de vizinhança os oito vizinhos (hospitais) mais próximos independente da distância entre eles. Esta escolha foi baseada no fato de haver extensas áreas do estado de São Paulo sem hospitais com UTI notificantes ao sistema de vigilância da DIH/CVE. A probabilidade foi calculada numa base de 999 permutações.

O cálculo do índice foi realizado utilizando o programa $R$ versão ¡386 3.0.1.

\subsubsection{Análise estatística}

\subsubsection{Modelo hierárquico}

Os modelos de regressão múltipla são frequentemente utilizados para a investigação de fatores de risco em eventos relacionados à saúde como a ocorrência de doenças ou a mortalidade por determinada doença ${ }^{84}$. Tais modelos partem do pressuposto que todas as variáveis envolvidas tem o "mesmo potencial" sobre o desfecho ou, colocado de outra forma, estão no mesmo "nível hierárquico". No entanto, o processo saúde doença compõe uma teia de relações de fatores determinantes de diferentes dimensões. Dentro desta lógica, alguns fatores podem estar relacionados de maneira mais direta (proximal) ao desfecho e outros (distais ou mediais) podem atuar em cadeia influenciando fatores proximais. Esta forma de organizar as variáveis hierarquicamente dentro de uma ordem temporal ou de plausibilidade é uma estratégia para dar conta da complexidade das inter- 
relações de variáveis contribuintes para eventos em saúde e utilizam modelos conhecidos como hierárquicos ou multinível. Por exemplo, há estudos de causas de diarreia infecciosa em crianças de países de baixa renda per capita utilizando modelos hierarquizados que levam em conta fatores ou determinantes sociais como educação dos pais, nível de emprego e renda salarial familiar ${ }^{85}$. Tais fatores atuam distalmente e influenciam fatores intermediários e proximais ao desfecho como baixo peso ao nascer, desnutrição e acesso a serviços de saúde.

Assumindo que fatores socioeconômicos, acesso e qualidade da assistência à saúde contribuem para a ocorrência de resistência bacteriana dentro de uma população, investigamos a relação entre indicadores de desenvolvimento social, econômico e de saúde dos municípios e a incidência de infecção por bactérias multirresistentes nas unidades de terapia intensiva neles localizadas. O nível hierárquico das variáveis analisadas está descrito no Quadro 2. O consumo global dos diferentes antimicrobianos, ou seja, comunitário e hospitalar foi assumido como variáveis proximais.

Para cada antibiótico foram ajustados modelos multinível, usando a variável incidência de infecção da corrente sanguínea como desfecho, aninhada nas variáveis "município" e "hospital". O desfecho foi medido uma vez por ano, em 2009, 2010 e 2011. Em todos os modelos, o logaritmo do número esperado de casos, calculado por padronização indireta, foi usado como "offset" para expressar os casos em termos do risco relativo (RR) ${ }^{86}$. Todas as covariáveis foram centradas na média. Inicialmente foram incluídas 
as covariáveis demográficas e selecionou-se o modelo com menor WAIC ${ }^{87}$. A esse modelo se acrescentaram covariáveis hospitalares (natureza administrativa e número de leitos de UTI) e selecionou-se o modelo com menor WAIC, mantendo todas as covariáveis demográficas. Finalmente, acrescentaram-se covariáveis relacionadas aos antibióticos e selecionou-se o modelo com menor WAIC, mantendo todas as covariáveis demográficas e hospitalares.

\subsubsection{Análise bayseana}

Dado que a proporção de zeros nos desfechos variou entre 34\% para Staphylococcus aureus resistentes à oxacilina e 85\% para Enterococcus sp resistentes à vancomicina, a verosimilhança foi modelada com base em uma distribuição de Poisson inflada por zeros ${ }^{86}$. Os modelos foram ajustados seguindo a abordagem INLA, especificando prioris não informativas para as variáveis "município" e "hospital" $(\operatorname{Normal}(0,1 / \sigma 2), 1 / \sigma 2=1 e-6){ }^{86}$. As análises foram feitas no software $R$ 3.2.1, usando os pacotes INLA 0.0$1432754561^{88}$ e INLAOutputs $0.0 .2^{89}$. 
4 Resultados 


\section{RESULTADOS}

\subsection{Descrição dos hospitais incluídos}

Apresentamos incialmente, a distribuição do número de hospitais incluídos por município (Tabela 3), assim como a sua distribuição por número de leitos totais e leitos de UTI (Tabela 4). O município de São Paulo concentra $29 \%$ de todos os hospitais incluídos na análise e $1 / 6$ está em grandes centros urbanos ou cidades com pelo menos 300.000 habitantes.

Tabela 3 - Número de hospitais notificantes segundo município. Sistema de vigilância de infecções relacionadas à assistência à saúde do Estado de São Paulo entre 2009 e 2011

\begin{tabular}{cc}
\hline Número de municípios (\%) & Número de hospitais \\
\hline 1 & 99 \\
9 & $6-9$ \\
33 & $2-5$ \\
62 & 1 \\
\hline
\end{tabular}

Dados da Divisão de Infecção Hospitalar do Centro de Vigilância Epidemiológica da Secretaria de Estado da Saúde de São Paulo 
Tabela 4 - Distribuição dos hospitais, segundo número de leitos de unidade de terapia intensiva (UTI), notificantes ao sistema de vigilância de infecções relacionadas à assistência à saúde do estado de São Paulo entre 2008 e 2011

\begin{tabular}{ccc}
\hline N de hospitais & N de leitos de UTI & Proporção (\%) \\
\hline 14 & 5 & $5 \%$ \\
147 & $6-10$ & $48 \%$ \\
95 & $11-20$ & $31 \%$ \\
30 & $21-30$ & $10 \%$ \\
14 & $31-40$ & $5 \%$ \\
6 & $41-70$ & $2 \%$ \\
3 & $>100$ & $1 \%$ \\
\hline
\end{tabular}

Dados da Divisão de Infecção Hospitalar do Centro de Vigilância Epidemiológica da Secretaria de Estado da Saúde de São Paulo 
As incidências de infecção por patógenos multirresistentes são apresentadas na Tabela 5. Embora haja um aumento na proporção de multirresistentes entre Escherichia coli, Klebsiella pneumoniae e Acinetobacter sp entre 2005 e 2010, conforme apresentamos na introdução, apenas este último mostra aumento da incidência de infecção no período do estudo.

Tabela 5 - Incidência de infecção da corrente sanguínea/1000 pacientes-dia (percentil 90) segundo patógeno multirresistente em unidades de terapia intensiva ( $n=$ número de UTIs reportadas) do estado de São Paulo, 2008-2011

\begin{tabular}{|c|c|c|c|c|c|}
\hline $\begin{array}{l}\text { Patógeno resistente ( } \mathrm{n} \text { de } \\
\text { patógenos resistentes } \\
\text { reportados) }\end{array}$ & $\begin{array}{c}2008 \\
(n=308) \\
\text { p90 }\end{array}$ & $\begin{array}{c}2009 \\
(n=323) \\
\text { p90 }\end{array}$ & $\begin{array}{c}2010 \\
(n=309) \\
\text { p90 }\end{array}$ & $\begin{array}{c}2011 \\
(\mathrm{n}=308) \\
\mathrm{p} 90\end{array}$ & $\begin{array}{l}\text { Valor } \\
\text { de } p\end{array}$ \\
\hline $\begin{array}{l}\text { Acinetobacter sp resistente a } \\
\text { carbapenem (3.065) }\end{array}$ & 1,32 & 1,25 & 1,56 & 1,61 & $<0,0001(+)$ \\
\hline $\begin{array}{l}\text { Pseudomonas aeruginosa } \\
\text { resistente a carbapenem } \\
(1.396)\end{array}$ & 0,84 & 0,84 & 0,71 & 0,64 & $0,001(-)$ \\
\hline $\begin{array}{l}\text { Escherichia coli resistente a } \\
\text { cefalosporina de terceira } \\
\text { geração }(613)\end{array}$ & 0,40 & 0,42 & 0,35 & 0,36 & $0,02(-)$ \\
\hline $\begin{array}{l}\text { Klebsiella pneumoniae } \\
\text { resistente a cefalosporina de } \\
\text { terceira geração }(2.960)\end{array}$ & 1,57 & 1,57 & 1,33 & 1,21 & $<0,0001(-)$ \\
\hline $\begin{array}{l}\text { Staphylococcus aureus } \\
\text { resistente à oxacilina ( } 5.708)\end{array}$ & 3,37 & 2,92 & 2,89 & 2,72 & 0,46 \\
\hline $\begin{array}{l}\text { Enterococcus sp resistente à } \\
\text { vancomicina ( } 650)\end{array}$ & 0,28 & 0,26 & 0,32 & 0,26 & 0,98 \\
\hline
\end{tabular}




\subsection{Dados espaciais}

A seguir apresentamos a distribuição espacial das incidências de infecção da corrente sanguínea por patógeno, Figuras 3 a 8 . Os círculos preenchidos representam o intervalo de valores dentro do qual se encontra a incidência de infecção da corrente sanguínea por patógeno em cada unidade de terapia intensiva.

$\mathrm{Na}$ Tabela 6, apresentamos o índice de autocorrelação espacial global de Moran calculado para cada patógeno para os quatro anos do estudo.

Os mapas destas figuras são reapresentados a partir da página 94 em maior dimensão. 
Figura 3 - Distribuição espacial das incidências de ICS por Acinetobacter sp resistente a carbapenêmico nas UTI do estado de São Paulo nos anos 2008 a 2011
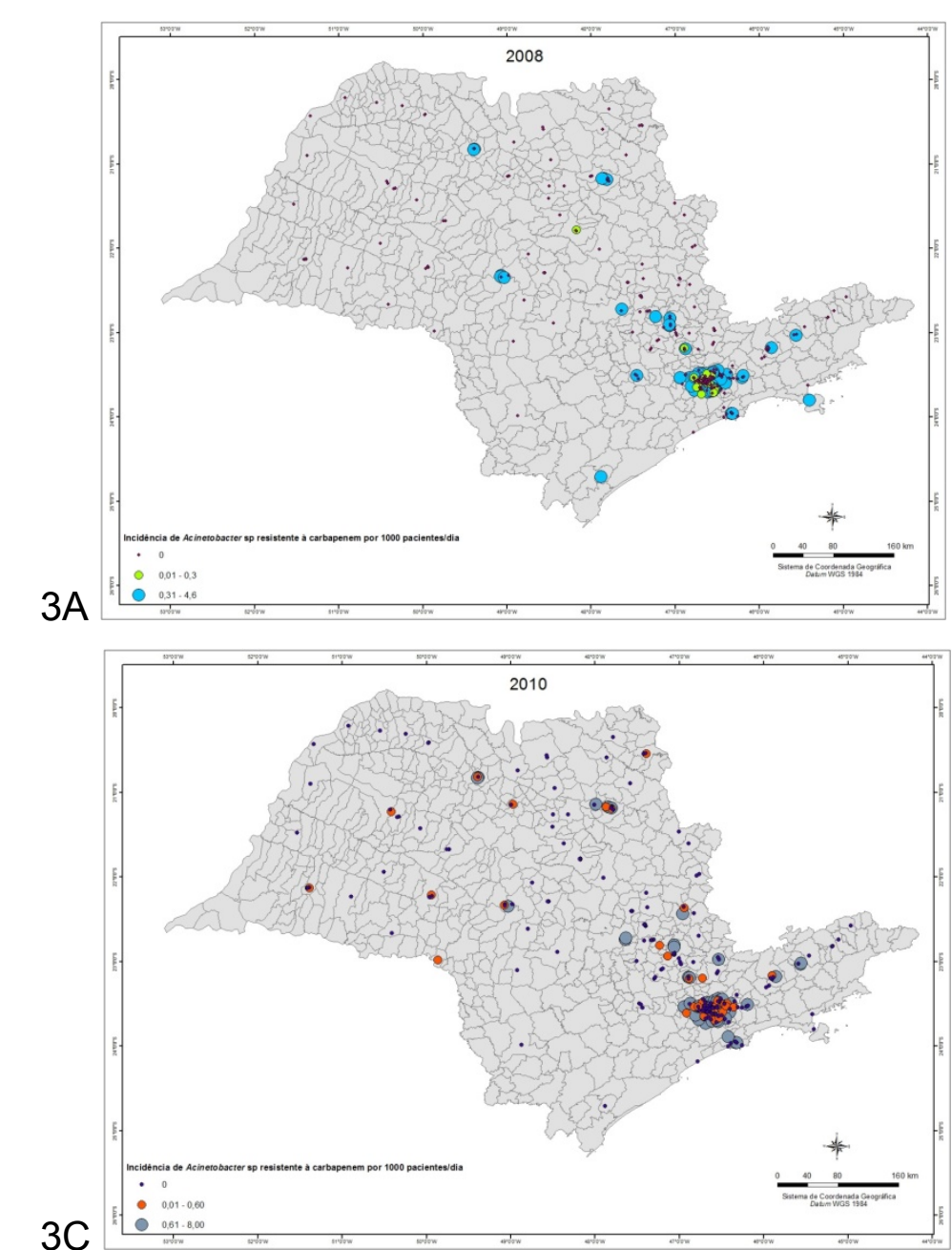

3B

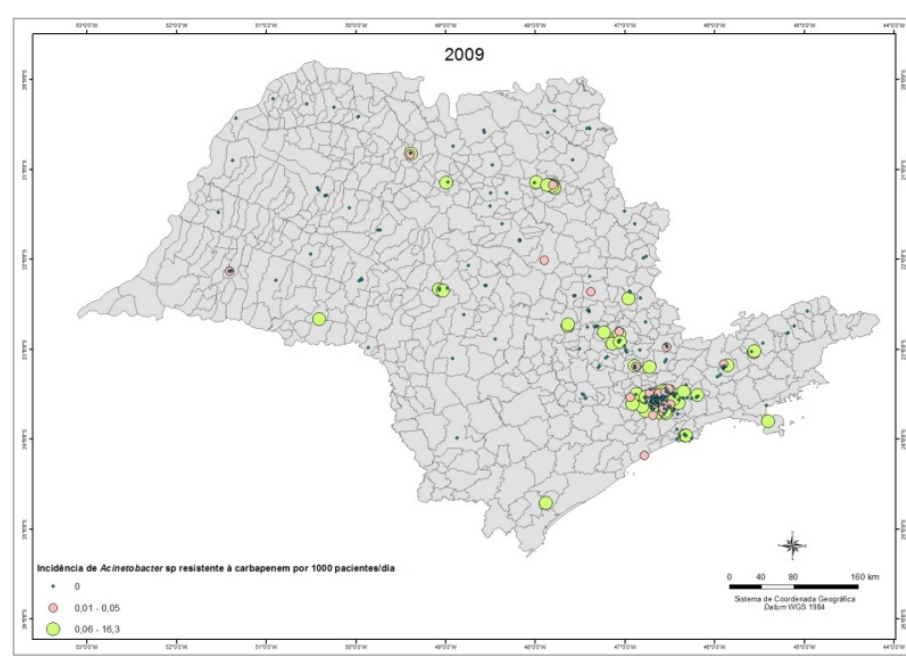

$3 \mathrm{D}$

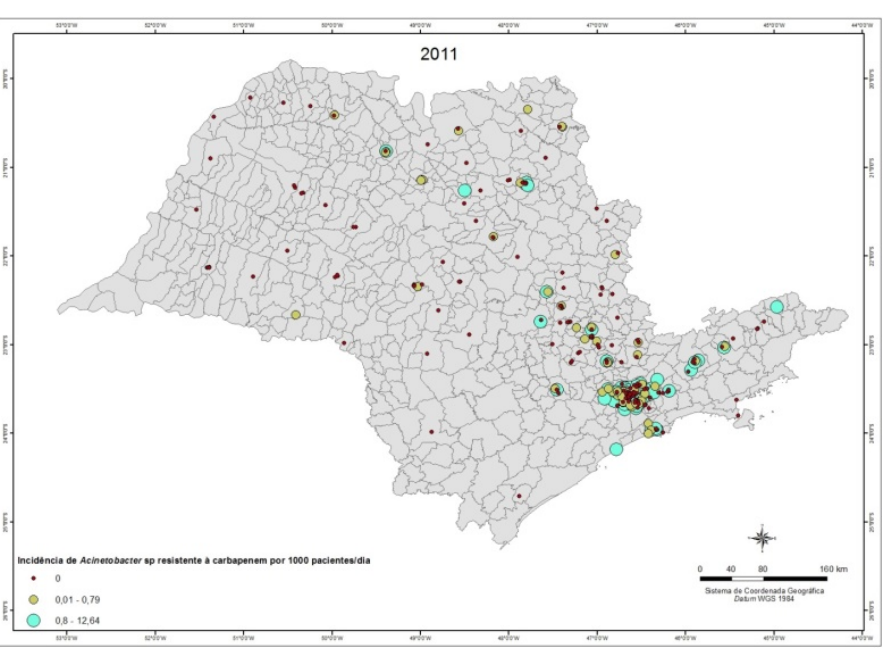

ICS (infecção da corrente sanguínea), UTI (unidade de terapia intensiva) 
Figura 4 - Distribuição espacial das incidências de ICS por Pseudomonas aeruginosa resistente a carbapenêmicos em UTIs do estado de São Paulo nos anos 2008 a 2011
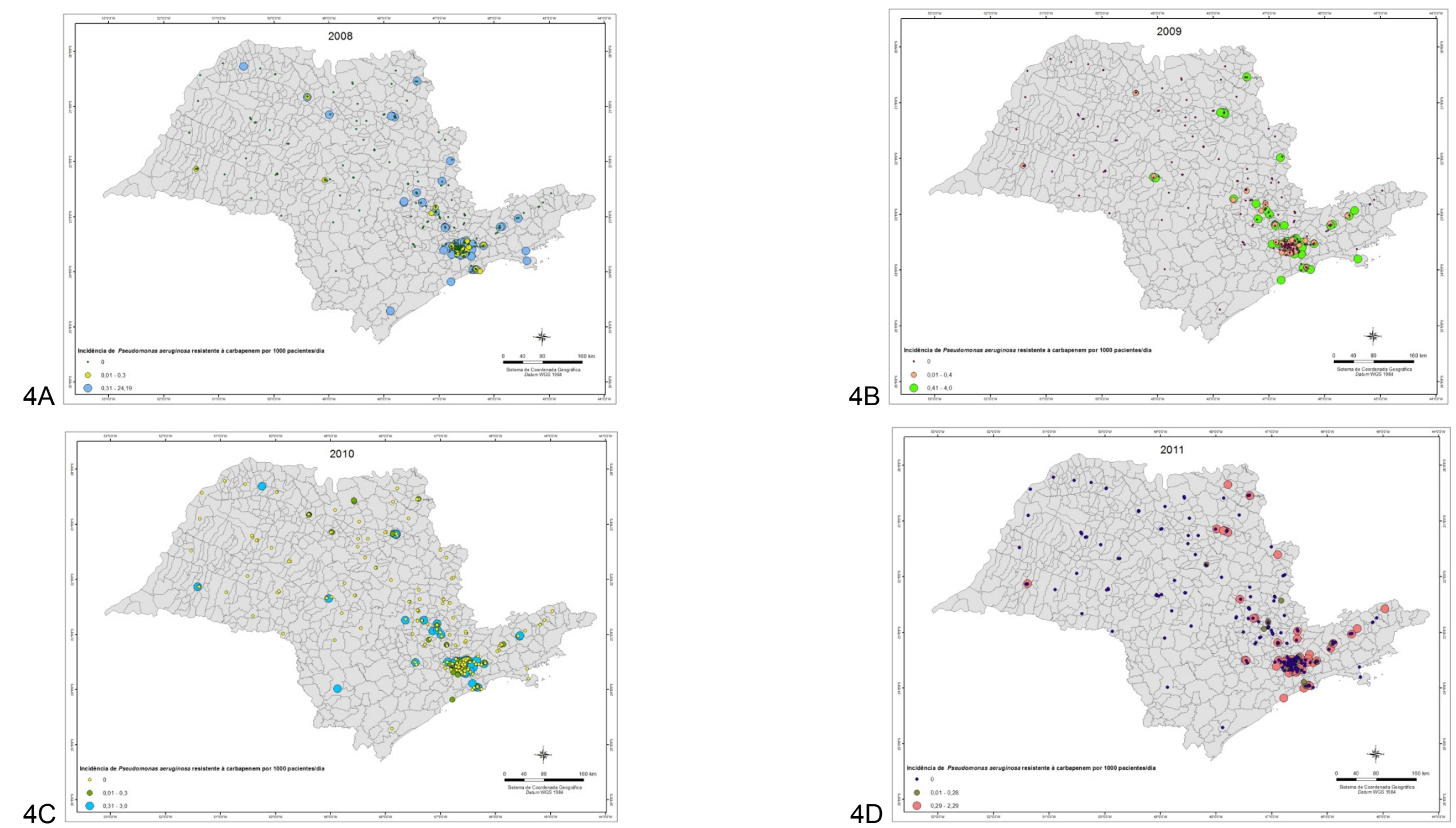

ICS (infecção da corrente sanguínea), UTI (unidade de terapia intensiva). 
Figura 5 - Distribuição espacial das incidências de ICS por Escherichia coli resistente a cefalosporinas de terceira geração em UTIs do estado de São Paulo nos anos 2008 a 2011

$5 \mathrm{~A}$

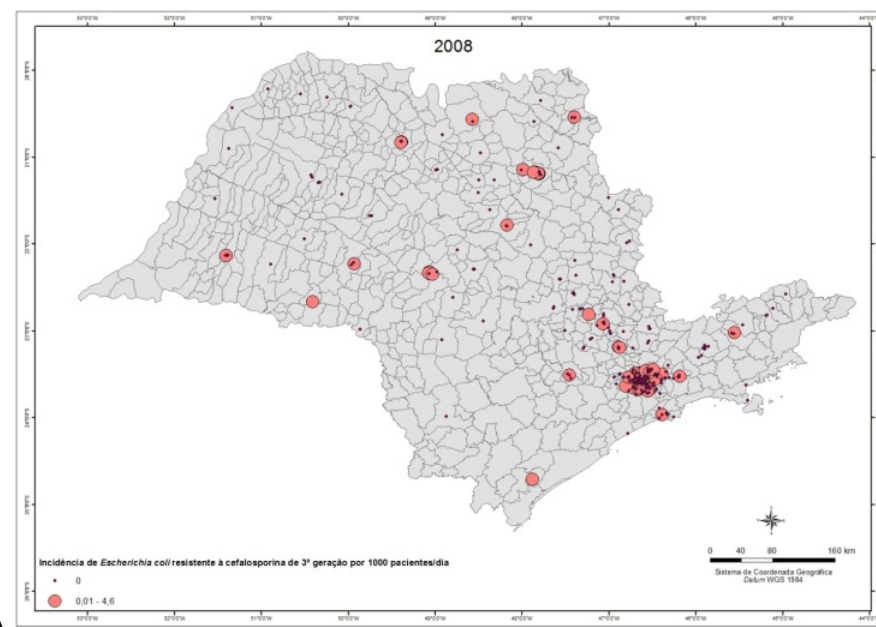

$5 \mathrm{C}$

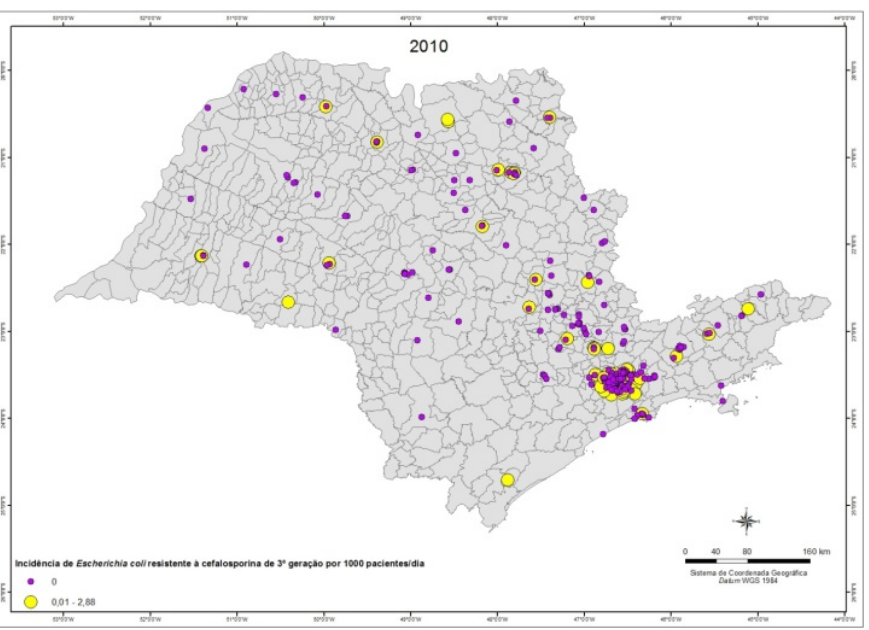

$5 \mathrm{~B}$

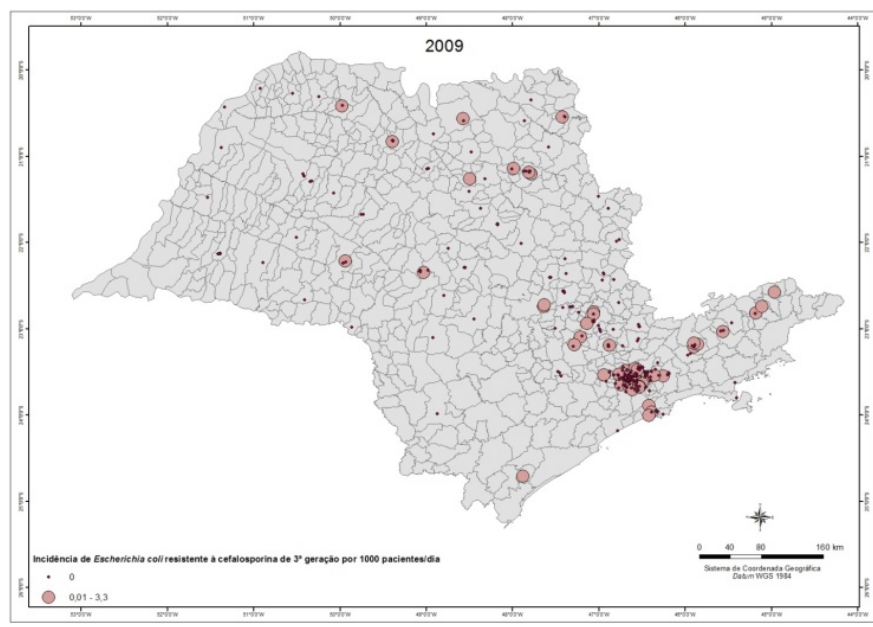

$5 \mathrm{D}$

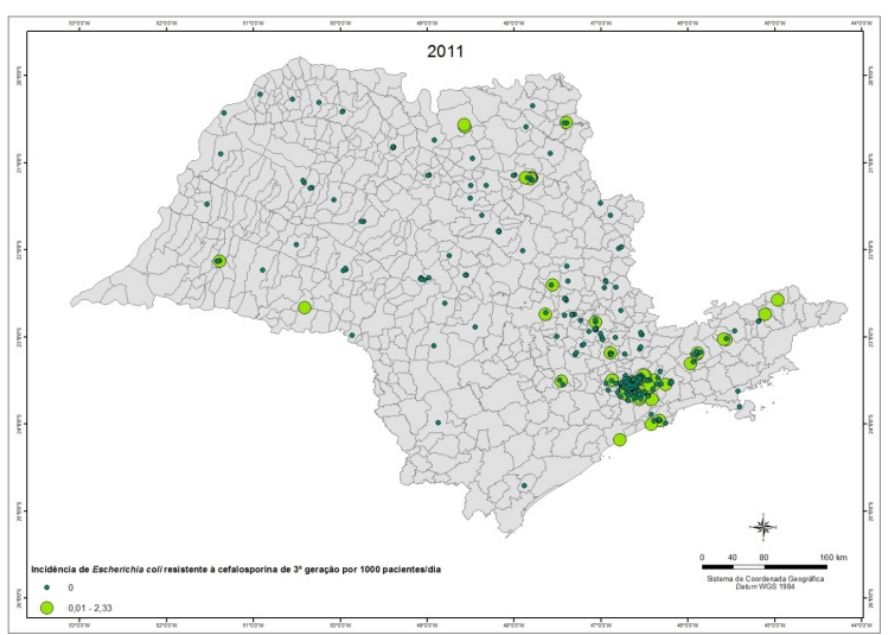

ICS (infecção da corrente sanguínea), UTI (unidade de terapia intensiva). 
Figura 6 - Distribuição espacial das incidências de ICS por Klebsiella pneumoniae resistente a cefalosporinas de terceira geração em UTIs do estado de São Paulo nos anos 2008 a 2011
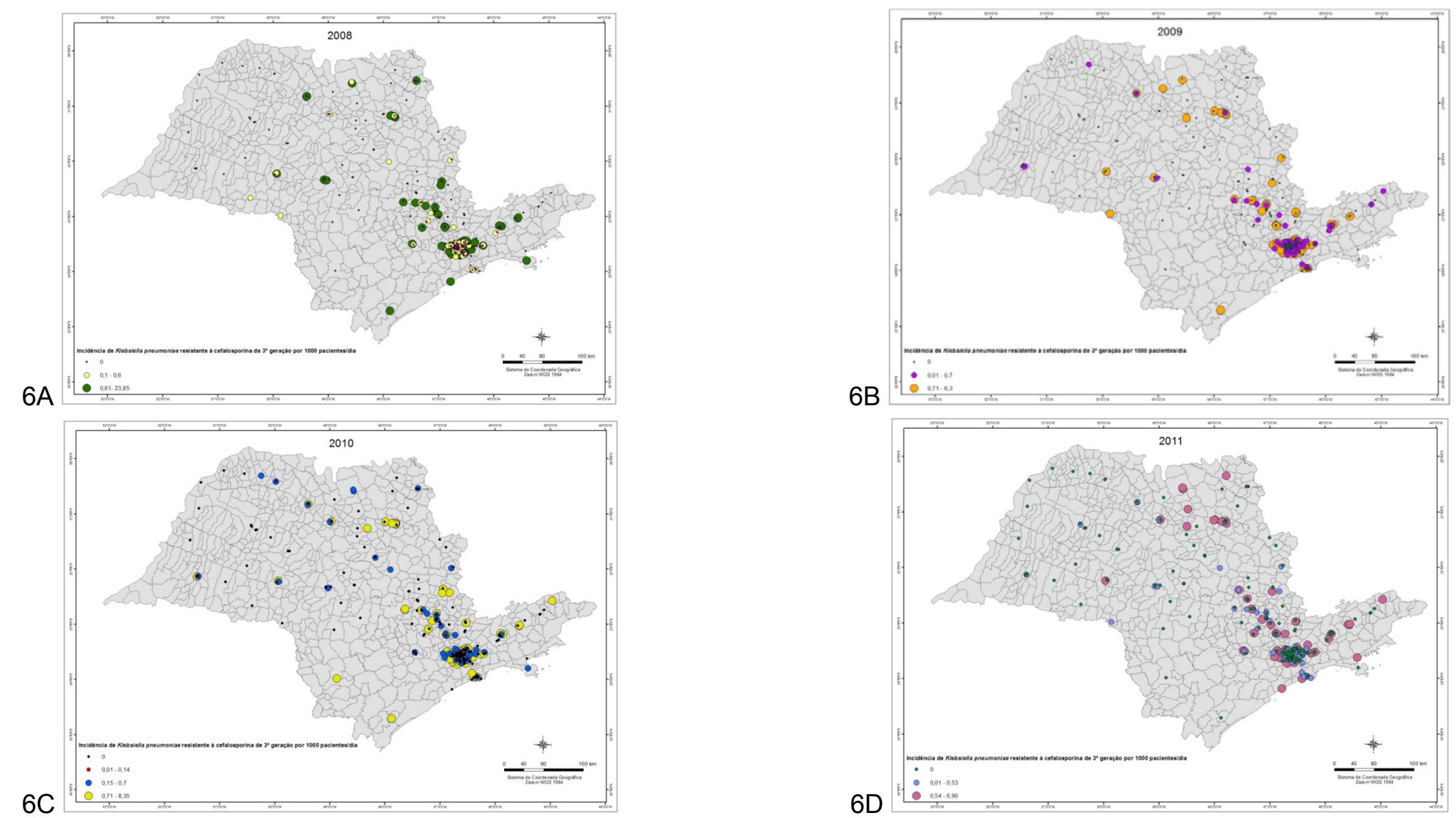

ICS (infecção da corrente sanguínea), UTI (unidade de terapia intensiva). 
Figura 7 - Distribuição espacial das incidências de ICS por Staphylococcus aureus resistente à oxacilina em UTIs do estado de São Paulo nos anos 2008 a 2011
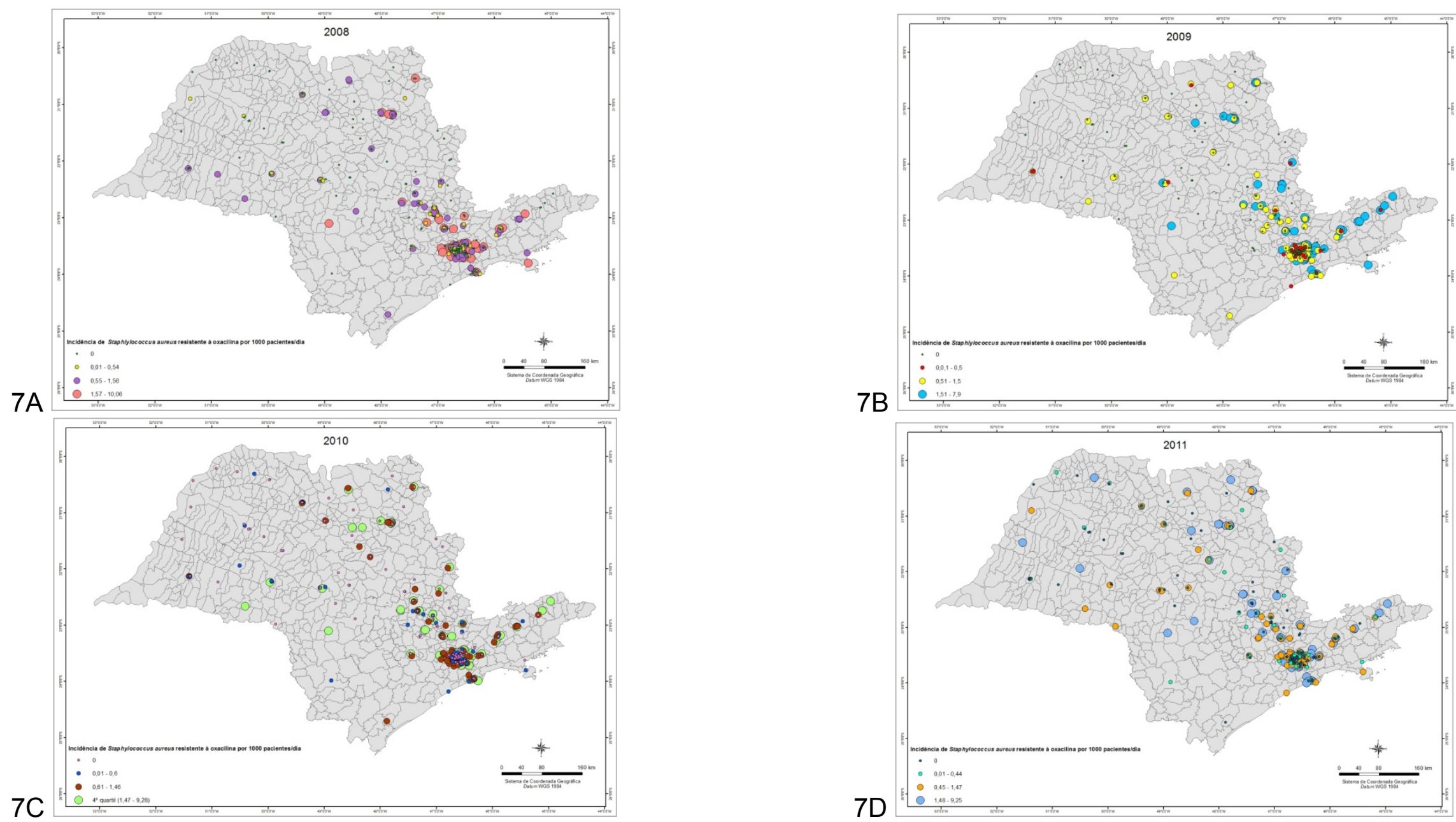

ICS (infecção da corrente sanguínea), UTI (unidade de terapia intensiva). 
Figura 8 - Distribuição espacial das incidências de ICS por Enterococcus sp resistente à vancomicina em UTIs do estado de São Paulo nos anos de 2008 a 2011
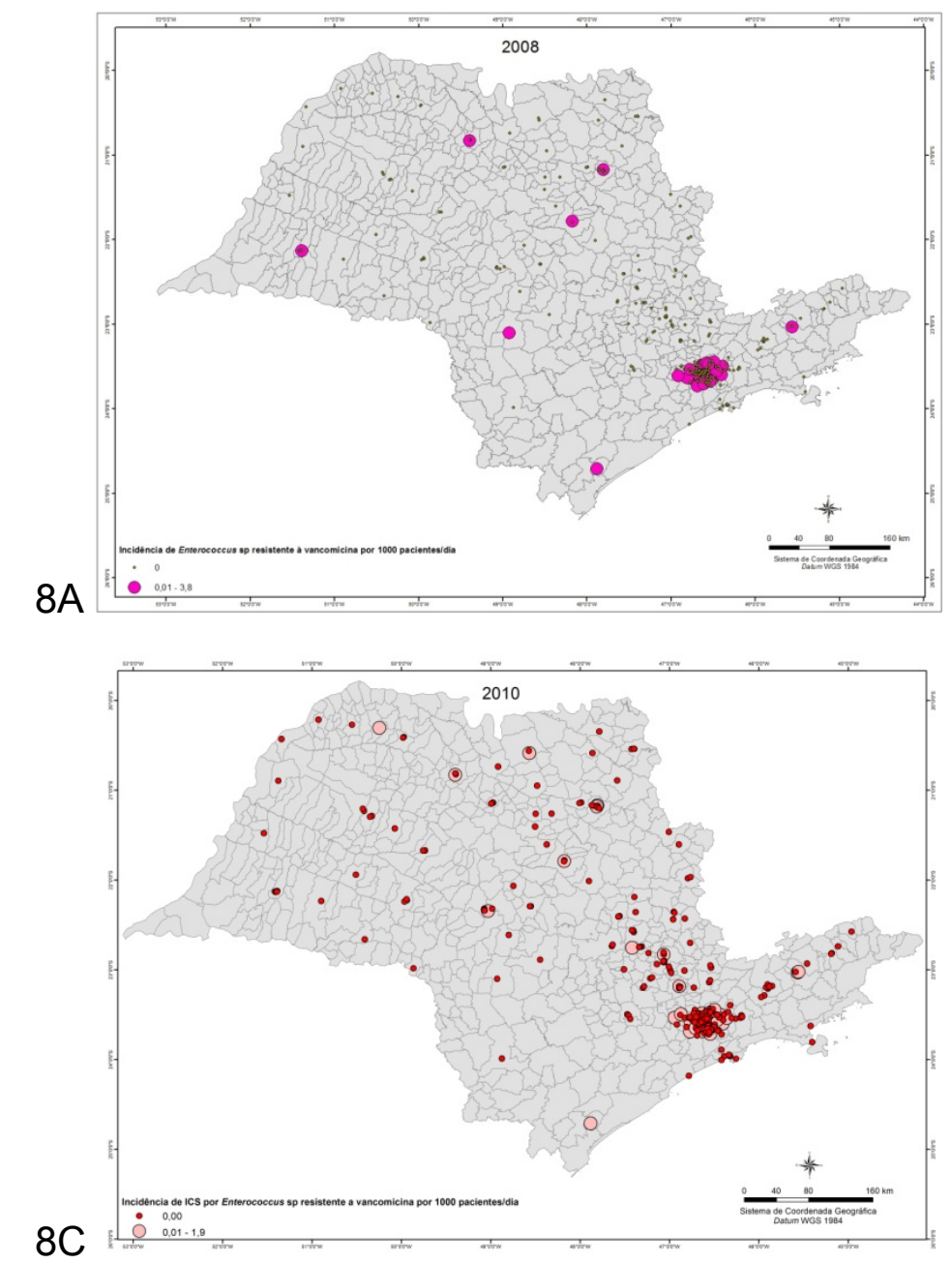

ICS (infecção da corrente sanguínea), UTI (unidade de terapia intensiva).
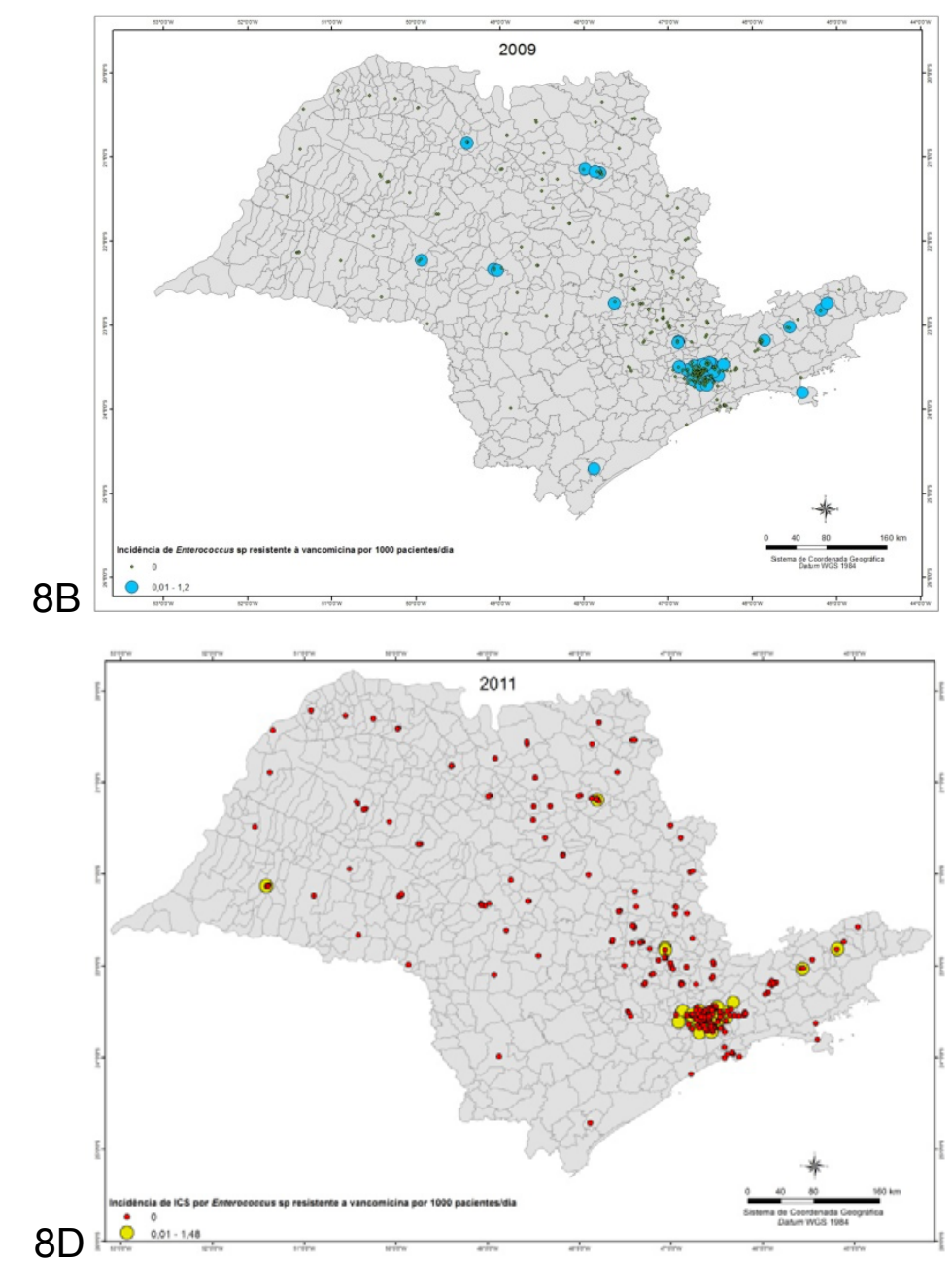
Tabela 6 - Análise de dependência espacial das incidências de ICS por bactérias multirresistentes em UTIs do estado de São Paulo nos anos de 2008 a 2011. A estimativa foi feita pelo cálculo do índice global de Moran utilizando-se matriz de vizinhança pelo método do vizinho mais próximo (oito vizinhos). A probabilidade foi calculada numa base de 999 permutações

\begin{tabular}{|c|c|c|c|c|c|c|c|c|}
\hline \multirow{2}{*}{ Patógeno } & \multicolumn{2}{|l|}{2008} & \multicolumn{2}{|l|}{2009} & \multicolumn{2}{|l|}{2010} & \multicolumn{2}{|l|}{2011} \\
\hline & Índice de Moran & $p$ & Índice de Moran & $p$ & Índice de Moran & $p$ & Índice de Moran & $p$ \\
\hline Acinetobacter sp & 0,06 & 0,01 & 0,03 & 0,11 & 0,03 & 0,09 & 0,06 & 0,02 \\
\hline Pseudomonas aeruginosa & 0,10 & 0,00 & 0,08 & 0,00 & 0,07 & 0,01 & 0,09 & 0,01 \\
\hline Escherichia coli & 0,00 & 0,40 & 0,01 & 0,29 & 0,02 & 0,08 & 0,01 & 0,31 \\
\hline Klebsiella pneumoniae & 0,08 & 0,01 & 0,02 & 0,18 & 0,04 & 0,05 & 0,07 & 0,01 \\
\hline Staphylococcus aureus & 0,11 & 0,00 & 0,04 & 0,07 & 0,04 & 0,05 & 0,01 & 0,00 \\
\hline Enterococcus sp & 0,04 & 0,05 & 0,03 & 0,09 & 0,02 & 0,12 & 0,05 & 0,04 \\
\hline
\end{tabular}

ICS- infecção da corrente sanguínea. 


\subsection{Análise estatística}

A seguir, apresentamos os resultados da análise de regressão de Poisson. A variável independente "natureza administrativa do hospital" foi dividida em quatro categorias como Santa Casa, hospital público, hospital privado e hospital filantrópico, sendo esta última considerada a categoria de base ou de referência.

Tabela 7 - Resultado da análise de fatores associados à infecção da corrente sanguínea por Acinetobacter sp resistente aos carbapenêmicos em unidades de terapia intensiva do Estado de São Paulo nos anos de 2008 a 2011

\begin{tabular}{lccc}
\hline Variável & RR & \multicolumn{2}{c}{ IC 95\% } \\
\hline Intercepto & 0,33 & 0,28 & 0,44 \\
Equipamentos de hemodiálise/1000 habitantes & 1,08 & 0,89 & 1,06 \\
Natureza administrativa & & & \\
Categoria de base & & & \\
$\quad$ Hospital filantrópico & 1 & & \\
$\quad$ Hospital privado & 1,11 & 0,73 & 1,11 \\
$\quad$ Hospital público & 2,23 & 1,50 & 2,29 \\
$\quad$ Santa Casa & 0,24 & 0,13 & 0,24 \\
\hline
\end{tabular}

$\mathrm{RR}$ - risco relativo; IC - intervalo de credibilidade. 
Tabela 8 - Resultado da análise de fatores associados à de infecção da corrente sanguínea por Pseudomonas aeruginosa resistente aos carbapenêmicos em unidades de terapia intensiva do Estado de São Paulo nos anos de 2008 a 2011

\begin{tabular}{lccc}
\hline Variável & RR & \multicolumn{2}{c}{ IC 95\% } \\
\hline Intercepto & 0,90 & 0,61 & 1,30 \\
Equipamentos de hemodiálise/1000 habitantes & 0,86 & 0,70 & 1,03 \\
$\begin{array}{l}\text { Natureza administrativa } \\
\text { Categoria de base }\end{array}$ & & & \\
$\quad$ Hospital filantrópico & 1 & & \\
$\quad$ Hospital privado & 0,94 & 0,61 & 1,44 \\
$\quad$ Hospital público & 1,76 & 1,14 & 2,71 \\
$\quad$ Santa Casa & 0,29 & 0,16 & 0,53 \\
Uso de azitromicina & 0,94 & 0,76 & 1,14 \\
\hline
\end{tabular}

$\mathrm{RR}$ - risco relativo; IC - intervalo de credibilidade.

Tabela 9 - Resultado da análise de fatores associados à infecção da corrente sanguínea por Escherichia coli resistente às cefalosporinas de terceira geração em unidades de terapia intensiva do Estado de São Paulo nos anos de 2008 a 2011

\begin{tabular}{lccc}
\hline Variável & RR & \multicolumn{2}{c}{ IC 95\% } \\
\hline Intercepto & 0,86 & 0,47 & 1,49 \\
Leitos públicos & 1,54 & 0,89 & 1,23 \\
Natureza administrativa & & & \\
Categoria de base & & & \\
$\quad$ Hospital filantrópico & 1 & & \\
$\quad$ Hospital privado & 1,00 & 0,56 & 1,81 \\
$\quad$ Hospital público & 1,97 & 1,11 & 3,55 \\
$\quad$ Santa Casa & 0,71 & 0,36 & 1,41 \\
\hline
\end{tabular}

$\mathrm{RR}$ - risco relativo; IC - intervalo de credibilidade. 
Tabela 10 - Resultado da análise de fatores associados à infecção da corrente sanguínea por Klebsiella pneumoniae resistente às cefalosporinas de terceira geração em unidades de terapia intensiva do Estado de São Paulo nos anos de 2008 a 2011

\begin{tabular}{lccc}
\hline Variável & RR & \multicolumn{2}{c}{ IC 95\% } \\
\hline Intercepto & 0,76 & 0,51 & 1,10 \\
População com idade $\geq 60$ anos & 0,88 & 0,73 & 1,05 \\
Natureza administrativa & & & \\
Categoria de base & & & \\
$\quad$ Hospital filantrópico & 1 & & \\
$\quad$ Hospital público & 0,85 & 0,57 & 1,26 \\
$\quad$ Hospital privado & 1,69 & 1,13 & 2,53 \\
$\quad$ Santa Casa & 0,55 & 0,34 & 0,90 \\
Uso de ceftazidima & 0,83 & 0,62 & 1,06 \\
\hline
\end{tabular}

$\mathrm{RR}$ - risco relativo; IC - intervalo de credibilidade.

Tabela 11 - Resultado da análise de fatores associados à infecção da corrente sanguínea por Staphylococcus aureus resistente à meticilina em unidades de terapia intensiva do Estado de São Paulo nos anos de 2008 a 2011

\begin{tabular}{lccc}
\hline Variável & RR & \multicolumn{2}{c}{ IC 95\% } \\
\hline Intercepto & 1,01 & 0,79 & 1,30 \\
Índice de Gini & 0,83 & 0,75 & 0,91 \\
Natureza administrativa & & & \\
Categoria de base & & & \\
$\quad$ Hospital filantrópico & 1 & 0,57 & 1,02 \\
$\quad$ Hospital privado & 0,76 & 0,92 & 1,68 \\
$\quad$ Hospital público & 1,24 & 0,53 & 1,05 \\
$\quad$ Santa Casa & 0,75 & 1,06 & 1,25 \\
Uso de penicilina & 1,15 & & \\
\hline
\end{tabular}

$\mathrm{RR}$ - risco relativo; IC - intervalo de credibilidade. 
Tabela 12 - Resultado da análise de fatores associados à infecção da corrente sanguínea por Enterococcus $\mathrm{sp}$ resistente à vancomicina em unidades de terapia intensiva do Estado de São Paulo nos anos de 2008 a 2011

\begin{tabular}{lccc}
\hline Variável & RR & \multicolumn{2}{c}{ IC 95\% } \\
\hline Intercepto & 0,46 & 0,22 & 0,91 \\
Leitos públicos & 1,13 & 0,93 & 1,40 \\
Natureza administrativa & & & \\
Categoria de base & & & \\
$\quad$ Hospital filantrópico & 1 & 0,46 & 1,67 \\
$\quad$ Hospital privado & 0,87 & 1,04 & 3,74 \\
$\quad$ Hospital público & 1,95 & 0,11 & 0,84 \\
$\quad$ Santa Casa & 0,31 & 0,33 & 1,13 \\
Uso de amicacina & 0,65 & & \\
\hline
\end{tabular}

$\mathrm{RR}$ - risco relativo; IC - intervalo de credibilidade. 
$\mathrm{Na}$ Figura 8, abaixo, apresentamos a variação dos onze antimicrobianos mais vendidos no estado de São Paulo no período do estudo. Assumimos que a venda aproxima-se do consumo em cada ano. $\mathrm{O}$ consumo é apresentado por dose diária definida por milhões de habitantes por ano.

Figura 9 - Dados dos onze antimicrobianos mais consumidos no estado de São Paulo no período de 2008 a 2011 em milhões de DDD. DDD (dose diária definida)

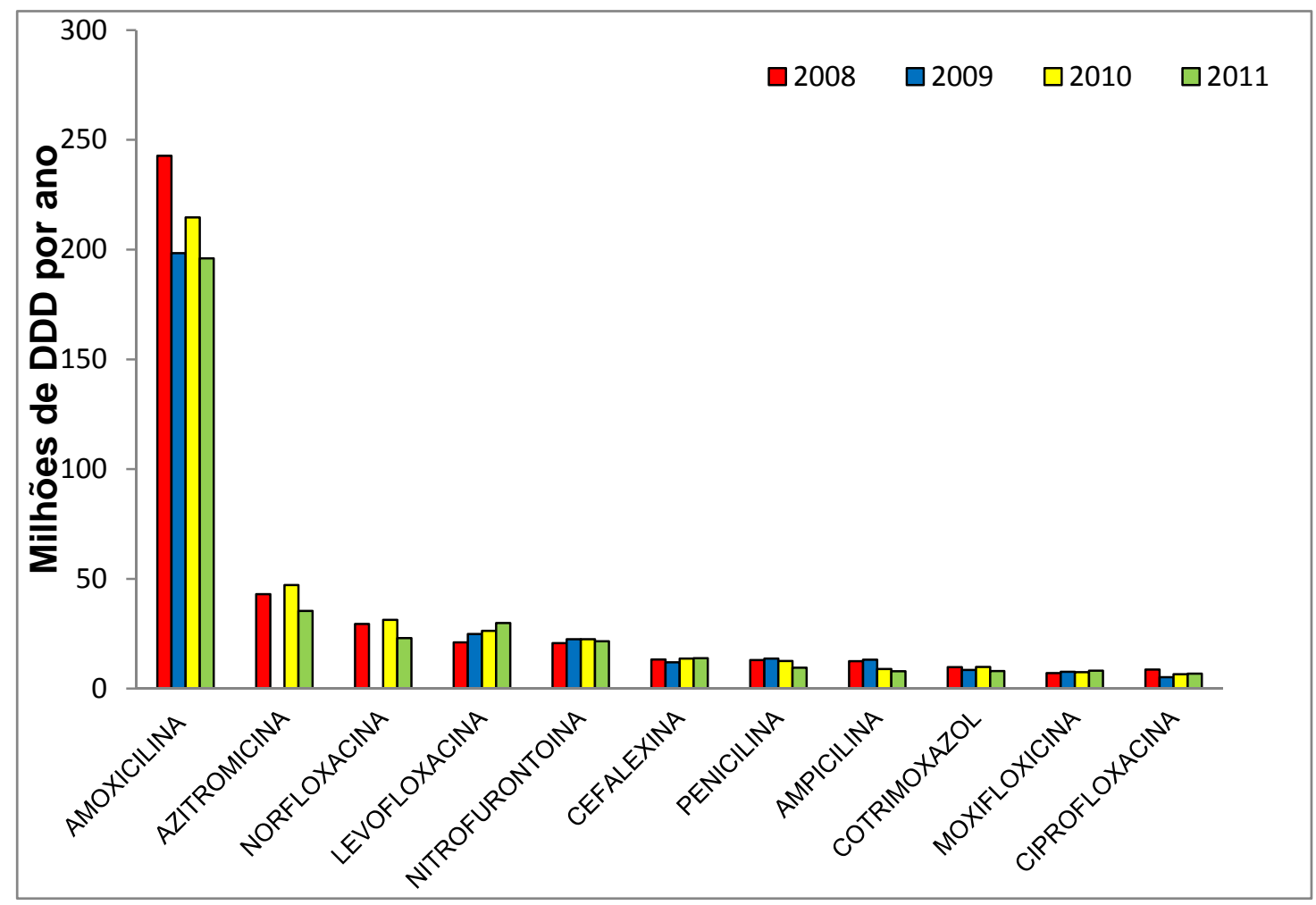


5 Discussão 


\section{DISCUSSÃO}

Neste estudo, testamos a hipótese de que o consumo global de antimicrobianos e indicadores socioeconômicos e de qualidade de assistência à saúde estão diretamente relacionados com a incidência de infecções causadas por bactérias resistentes a estas drogas em unidades de terapia intensiva. Identificamos associação direta entre consumo global de penicilina e inversa com índice de Gini no estado de São Paulo e infecção da corrente sanguínea causada por Staphylococcus aureus resistente à oxacilina. Essa relação com índice de Gini demonstra que, quanto maior a desigualdade social, menor a incidência de infecção por MRSA na unidade de terapia intensiva. De maneira interessante, outra investigação conduzida por nosso grupo com o objetivo de avaliar fatores determinantes para o consumo de antimicrobianos na rede de farmácias privadas do estado de São Paulo, encontrou associação direta entre altos índices de Gini e maior consumo de penicilinas (dados não publicados). As penicilinas naturais são antibióticos de uso predominantemente parenteral e, na maioria das vezes, administradas em ambiente hospitalar ou de assistência à saúde. Para os demais agentes etiológicos estudados, não observamos o consumo global (comunitário e hospitalar) de antimicrobianos ou de variáveis socioeconômicas, de acesso e qualidade da assistência à saúde como determinantes da infecção da corrente sanguínea em unidades de terapia intensiva do estado de São Paulo. Observamos maior incidência de 
Enterococcus resistente à vancomicina (VRE), Pseudomonas aeruginosa resistente a carbapenens, Acinetobacter sp resistente a carbapenens e Escherichia coli resistente a cefalosporinas de terceira geração em hospitais públicos comparados a hospitais filantrópicos e menor incidência de VRE, Klebsiella pneumoniae resistente a cefalosporinas de terceira geração, Pseudomonas aeruginosa resistente a carbapenens, Acinetobacter $\mathrm{sp}$ resistente a carbapenens e Escherichia coli resistente a cefalosporinas de terceira geração em Santas Casas comparadas a hospitais filantrópicos. Por fim, observamos maior incidência de Klebsiella pneumoniae resistente a cefalosporinas de terceira geração em hospital privado comparado a hospital filantrópico. Estabelecemos a filantropia como categoria de base em razão de representar menores incidências de infecção da corrente sanguínea e boa disponibilidade de recursos diagnósticos e, portanto, menor risco de subnotificação ao sistema de vigilância de infecções hospitalares do estado de São Paulo.

As associações entre Santas Casas com menores incidências de infecção por multirresistente é um fenômeno que precisa ser melhor compreendido. Uma hipótese é que esta associação seja um marcador da desigualdade como apontado pelo índice de Gini para MRSA. Explorando a distribuição destes hospitais, observamos que entre as cinquenta e sete Santas Casas do estado de São Paulo, vinte e sete (47\%) são o único hospital do município onde estão localizadas e quinze (26\%) estão em municípios com dois hospitais. No entanto, o índice de Gini médio $(0,42)$ dos municípios cujo único hospital é uma Santa Casa é igual à média dos 
demais municípios incluídos no estudo (dados não apresentados nos resultados). Igualmente, não observamos diferença no IDH médio $(0,77)$ dos dois grupos de municípios sendo, portanto, difícil atribuir este achado à desigualdade. Alternativamente, pode haver menor recurso laboratorial para identificação de patógenos resistentes por este grupo de hospitais, o que necessita de confirmação em análise futura da capacidade técnica dos laboratórios do estado de São Paulo. Por este prisma, a carência de recurso laboratorial poderia estar relacionada à maior desigualdade social e explicar a relação observada com o índice de Gini.

Desde o início do que conhecemos como era antibiótica, inaugurada com o uso clínico da penicilina, observa-se o aumento da incidência de infecções causadas por bactérias resistentes, principalmente em hospitais. Este fenômeno assume grande importância na saúde pública em razão do grande impacto na morbidade e mortalidade de pacientes críticos infectados por patógenos mutlirresistentes ${ }^{90}$. A cada novo lançamento no mercado de droga ou de classe de drogas para uso clínico segue-se a identificação de bactérias com perfil fenotípico de resistência à nova droga. Embora, em relatos anteriores, sobretudo em situações epidêmicas e de surtos, pareça claro haver uma relação entre consumo e seleção de resistentes, os fatores que determinam a resistência são provavelmente múltiplos e com imbricada relação e não são completamente compreendidos. A maioria das sociedades de profissionais ligados à infectologia recomenda em suas diretrizes o uso racional de antimicrobianos como medida de prevenção da seleção de bactérias resistentes a essas drogas ${ }^{91,92,93}$. A Organização Mundial da 
Saúde em página da internet publicada em Fact Sheet número 194 com última atualização em abril de 2015 afirma que apesar de a resistência bacteriana ser um fenômeno natural, ela é acelerada pela atividade humana incluindo consumo humano de antimicrobianos assim como na produção animal e recomenda intervenções governamentais com formulação de politicas públicas com o objetivo de mitigar consequências indesejadas desta atividade ${ }^{94}$. No Brasil, a Resolução de Diretoria Colegiada (RDC) número 44 de 2010 da Agência Nacional de Vigilância Sanitária (ANVISA) impôs restrição da venda de antimicrobianos nas farmácias mediante apresentação de receita médica com sua retenção. O impacto desta medida variou nas diferentes regiões do país, como demonstrado por ${ }^{95}$, provavelmente em razão de fatores socioeconômicos. Desta maneira, assumimos neste estudo, por hipótese, que o consumo global (comunidade e hospital) de antimicrobianos guarda uma relação de causalidade importante na seleção de bactérias resistentes levando ao aumento da incidência de infecções de corrente sanguínea nas unidades de terapia intensiva. Assumimos ainda que outros fatores concorrentes que representam a relação do hospedeiro com o ambiente que o cerca, representados por indicadores sociais e de qualidade de assistência à saúde, contribuem para a ocorrência deste fenômeno.

modelo teórico que escolhemos para testar nossa hipótese leva em conta a contribuição das variáveis independentes atuando em diferentes níveis. Trata-se de um modelo hierárquico multinível. Analisamos como determinantes de resistência variáveis socioeconômicas como índice de Gini, proporção de indivíduos com mais de sessenta anos, índice de 
desenvolvimento humano e cobertura de saneamento básico adequado, variáveis de acesso aos serviços de saúde como número de leitos públicos e número de equipamentos de hemodiálise por 1000 habitantes, além de variáveis que representam acesso e qualidade dos serviços de saúde como coeficiente de mortalidade infantil. A natureza administrativa dos hospitais assim como sua complexidade estimada pelo número de leitos de UTI foram avaliadas. Assumimos que tais variáveis contribuem em alguma medida para o desfecho investigado, i.e. infecção da corrente sanguínea laboratorialmente confirmada, mas não de maneira direta e sim como determinantes distais (socioeconômicas, qualidade e acesso a serviços de saúde) e mediais (natureza administrativa e números de leitos de UTI). O consumo de antimicrobianos foi investigado como determinante proximal, ou seja, com potencial relação causal mais direta. Os modelos hierárquicos multinível possibilitam a análise da interrelação dos determinantes de maneira mais robusta. Neste modelo, assumimos que os fatores socioeconômicos (nível hierárquico distal) podem interferir direta ou indiretamente nos fatores determinantes de hierarquia mais proximal ao desfecho como frequentar serviços de saúde, nível de resolução de problemas de saúde e o próprio consumo de antimicrobianos, criando assim uma cadeia de fatores determinantes interdependente. Levamos em conta também a relação temporal entre os determinantes analisados, uma vez que os dados de consumo de antibiótico (2008 a 2010) antecedem os dados de infecção da corrente sanguínea laboratorialmente confirmada. 
Um problema com o qual nos deparamos já na fase exploratória de análise dos dados foi o fato de que a variável dependente apresentava uma grande proporção de valores iguais a zero que variou de $34 \%$ a $85 \%$ entre os seis desfechos medidos. Portanto, dispúnhamos de modelos inflados de zero para análise. Nesta circunstância, a utilização de regressões múltiplas da estatística frequentista clássica e mesmo a utilização de modelos de regressão espacial não conseguiram dar conta de explicar a variabilidade do desfecho e sua relação com as variáveis independentes uma vez que violaram o pressuposto de apresentar distribuição gaussiana dos resíduos (dados não apresentados). Por esta razão, optamos por utilizar a estatística bayseana.

Um ponto forte de nosso estudo é o fato de avaliar a associação entre consumo de antimicrobiano e ocorrência de resistência bacteriana por meio de um estudo multinível envolvendo uma grande população e explorando a relação entre determinantes sociais, de organização dos serviços e saúde e consumo de antimicrobianos com um desfecho de ocorrência limitada a um espaço considerado dos mais críticos de assistência que é a unidade de terapia intensiva. A maioria dos estudos que avalia essa associação envolve pequenas populações, como unidades de terapia intensiva (uma ou um pequeno número de unidades) e são estudos de intervenção do tipo quasiexperimental com série temporal interrompida ou estudos observacionais de coorte ou caso-controle relacionados a surtos de infecção por bactérias multirresistentes. Na maioria dos estudos, o consumo e o desfecho (aquisição de bactérias resistentes) são avaliados dentro do 
ambiente hospitalar ou de assistência à saúde. Dois estudos ecológicos avaliaram a relação entre uso de antibióticos e resistência ${ }^{70,71}$. Uma revisão sistemática avaliou intervenções dentro dos hospitais com o objetivo de se reduzir a incidência de infecção e/ou colonização por bactérias multirresistentes a partir da restrição do uso de antimicrobianos. Pelo menos 16 estudos incluídos apresentavam metodologia considerada adequada para medir o tamanho do efeito da intervenção e sua sustentabilidade ao longo do tempo e tinham um desfecho microbiológico bem definido. Cinco estudos avaliavam restrição de uso e impacto em Clostridium difficile. Dez estudos avaliaram impacto sobre bacilos Gram negativos, três sobre Enterococcus resistente à vancomicina e dois sobre Staphylococcus aureus resistente à meticilina (MRSA). Quatro estudos apresentaram associação positiva entre uso e resistência, oito apresentaram fraca associação e quatro associação negativa. A evidência mais consistente foi demonstrada pelas cinco intervenções que propuseram restrição de uso de antimicrobianos para redução da incidência de diarréia por Clostridium difficile. As intervenções foram relativamente homogêneas, abrangendo todo o hospital e todas restringiam uso de cefalosporinas e clindamicina. Seus resultados mostraram alteração da direção da reta em análises de regressão com significância estatística. Os resultados dos dez estudos envolvendo bacilos Gram negativos (BGN) foram menos consistentes. Eles foram mais heterogêneos em termos de característica da unidade sob intervenção e em relação ao tipo de intervenção. Essas intervenções variaram e compreenderam redução de tempo de tratamento, avaliação pós-prescrição 
com mudança de antimicrobiano, uso rodiziado de classes de antimicrobianos em unidade de terapia intensiva neonatal. Apesar de ter havido mudança na direção da reta de regressão em todos os estudos envolvendo BGN, apenas um foi estatisticamente significativo. Os dados para bactérias Gram positivas foram mais limitados. Um estudo demonstrou associação entre restrição de ceftazidima numa unidade de oncohematologia e a taxa de colonização por VRE. Por outro lado, a restrição do uso de cefalosporinas não mostrou qualquer associação com colonização por este agente. Da mesma forma, o estudo que avaliou restrição do uso de vancomicina mostrou não mostrou resultados significativos na colonização por VRE, apesar de ter demonstrado uma tendência de queda. Dois estudos desta revisão testaram efeito da restrição de cefalosporinas na redução da prevalência de MRSA sendo o efeito demonstrado em apenas um deles ${ }^{70}$.

Um estudo ecológico avaliou a associação entre consumo de antimicrobianos em pacientes ambulatoriais e sua relação com a proporção de bacteremias por Streptococcus pneumoniae não sensíveis à penicilina e à eritromicina e Escherichia coli resistente à fluorquinolona. Participaram deste estudo 32 países europeus e os dados de consumo e resistência foram fornecidos por dois sistemas de vigilância, European Surveillance of Antimicrobial Consumption (ESAC) e o European of Antimicrobial Resistance Surveillance System (EARSS) entre os anos de 2000 e 2005. Da mesma forma que o nosso estudo, o consumo de antimicrobiano foi calculado em dose diária definida (DDD) segundo metodologia da Organização Mundial da Saúde, porém o nível de agregação foi o país e o cenário de consumo foi a 
população atendida em nível ambulatorial nas redes de saúde dos países participantes. $O$ desfecho analisado também levou em conta a proporção de resistência e não a incidência de bacteremias. Além disso, foram selecionadas apenas algumas classes de antimicrobiano para avaliação no impacto da resistência. Pelo menos para Streptococcus pneumoniae não sensíveis à penicilina a variação de consumo de penicilina coincide com a resistência a esta droga no país, de maneira estável ao longo do tempo. É importante notar que variáveis que pudessem explicar, pelo menos em parte, o comportamento epidemiológico destas infecções não foram levados em consideração, como por exemplo, políticas nacionais de vacinação antipneumocócica ${ }^{71}$.

Outro estudo, que avalia consumo de antimicrobianos e seleção de bactérias resistentes na comunidade, verificou se a resistência de S.pneumoniae à azitromicina era maior em comunidades tratadas em massa para tracoma, comparada com comunidades não tratadas (controle). A Organização Mundial da Saúde (OMS) recomenda tratamento com antibiótico em massa e a maioria dos programas faz o tratamento anualmente. Neste estudo, 12 subkebeles na Etiópia (cada um composto por seis comunidades) foram randomizadas para receber tratamento em massa com azitromicina para crianças com idade entre um e 10 anos, nos meses zero, três, seis e nove. Doze subkebeles controle receberam tratamento no mês 12. Em cada comunidade, foi escolhida uma unidade sentinela para monitorização de tracoma, de cujos pacientes foram coletados swab de nasofaringe (10 crianças em cada unidade, antes e após tratamento no 
grupo tratado, e apenas no mês 12 - antes do tratamento - no grupo controle). A suscetibilidade das cepas de S. pneumoniae foi avaliada pelo método de Etest. Em todos os isolados resistentes, foram pesquisados os genes mefA e ermB, que são os responsáveis pela grande maioria dos casos de resistência à azitromicina. Foram estimadas as prevalências de S.pneumoniae e proporção de resistência. $\mathrm{O}$ desfecho pesquisado foi a comparação da prevalência de resistência no mês 12 (grupo tratado $x$ controle) e nos meses zero e 12 (grupo tratado apenas). Crianças das comunidades tratadas com azitromicina apresentaram maior risco de S.pneumoniae resistente a macrolídeo - Odds ratio (OR): 13,2 (IC 95\%: 5,531,9). Houve aumento significativo nas resistências à clindamicina e à tetraciclina após tratamento em massa, e não foi observada resistência à penicilina. Não houve diferença significativa na detecção dos genes de resistência no grupo tratado (pré e pós) e em comparação ao controle ${ }^{96}$. Uma limitação importante para a comparação destes estudos de intervenção é sua heterogeneidade metodológica ${ }^{70}$. A maioria dos estudos utiliza séries temporais interrompidas sem comparação com um grupo controle o que torna difícil de assumir que a mudança observada no desfecho não ocorreria independente da intervenção. O número de observações antes e após a intervenção precisa ser equilibrado e o mínimo aceitável é de três pontos de observação. O ideal é que haja 24 pontos de observação tornando possível avaliar eventual sazonalidade do fenômeno observado ${ }^{97}$.

Diferentemente dos estudos acima, que avaliaram a associação de uso e resistência em contextos restritos de ambiente hospitalar ou de 
comunidade, nós investigamos a transversalidade do fenômeno, ou seja, se o consumo global de antimicrobianos (comunidade e hospital) somado a determinantes socioeconômicos e de qualidade de assistência poderiam interferir em um desfecho circunscrito à unidade de terapia intensiva. No entanto, não encontramos, em nosso estudo, relação direta significativa entre consumo global de antimicrobianos e incidência de infecção primária da corrente sanguínea por bactérias multirresistentes em unidades de terapia intensiva. Nossas hipóteses, a partir destes resultados, são, primeiro, que a seleção de patógenos resistentes na unidade de terapia intensiva provavelmente se dá a partir do consumo destas drogas no próprio ambiente de terapia intensiva ou no contexto de assistência à saúde (e.g, consumo por pacientes internados fora da unidade de terapia intensiva ou que frequentam serviços de saúde sistematicamente, como hospital-dia, clínicas de hemodiálise, clínicas de quimioterapia, instituições asilares de longa permanência), segundo, que uma vez selecionados, a disseminação destes agentes por meio da transmissão cruzada seja o grande responsável pela rapidez do aumento de muitos destes patógenos.

Outros estudos ecológicos que exploraram esta associação reforçam nossa primeira hipótese. Na Alemanha, $85 \%$ do consumo de antibióticos é em animais, $85 \%$ do consumo de antibióticos em humanos ocorre fora do ambiente hospitalar e $85 \%$ dos antibióticos prescritos no hospital o são fora da unidade de terapia intensiva. Por outro lado, os antibióticos administrados aos pacientes críticos de terapia intensiva são de mais largo espectro. 
Um exemplo que reforça nossa segunda hipótese é a experiência de Israel em relação à epidemia de enterobactérias produtoras de Klebsiella pneumoniae carbapenemase (KPC) ${ }^{98}$. publicaram um estudo relatando o controle da disseminação deste agente por meio de medidas de bloqueio da transmissão cruzada. Em 2006, o sistema de saúde de Israel se deparou com a disseminação em todo o país de um clone predominante de Klebsiella pneumoniae ST-258, provavelmente introduzido no país no final de 2005 oriundo dos Estados Unidos. O esforço individual dos hospitais em conter este agente não alcançou bom êxito e em março de 2007 o país apresentava uma incidência de 55,5 casos/100.000 pacientes-dia. Vários relatos demonstravam mortalidade bruta entre $44 \%$ e $70 \%$, com mortalidade atribuída para bacteremia de $50 \%$. Neste momento, o ministério da saúde de Israel (MSI) lançou um plano de controle da disseminação deste agente em nível nacional com três pilares: a) notificação compulsória de todos os casos de infecção e/ou colonização por enterobactérias resistentes a carbapenem $(\mathrm{ERC}) ; \mathrm{b})$ isolamento com precauções de contato para pacientes infectados ou colonizados por ERC em quartos privativos e ou coortes; c) equipe de enfermagem dedicada para cuidar destes pacientes. A equipe escalada não poderia ter contato físico com pacientes externos à coorte. Além disso, foi criada uma força tarefa dentro do MSI com pessoal dedicado à organização, análise e divulgação dos dados coletados. Por ocasião do lançamento do plano nacional, equipes revestidas de autoridade sanitária visitaram os diretores dos hospitais e estabeleceram acordos para cumprimento das normas estabelecidas. Ao longo do primeiro ano, equipes do MSI visitavam 
hospitais aleatoriamente, conversavam com diretores e profissionais de saúde, monitoravam a adesão ao plano e devolviam dados epidemiológicos. O uso racional de antimicrobianos não foi nominado como um dos pilares deste plano, antes ele se baseava na observação de disseminação de um mesmo clone muito provavelmente facilitada pela transmissão cruzada por meio das mãos dos profissionais de saúde. As medidas de barreira implantadas e o monitoramento intensivo da adesão a estas barreiras tiveram impacto positivo com redução de $80 \%$ na incidência de infecção por ERC (55,5 casos por 100.000 pacientes-dia para 11,7 casos, $p<0,001)$. Assim, as medidas mais eficazes para o controle da disseminação de bactérias multirresistentes e, consequentemente, redução da incidência de infecção por estes patógenos estão associados às boas práticas de prevenção de infecção e medidas de bloqueio de transmissão cruzada ${ }^{99}$.

O controle de uso de antimicrobianos no âmbito hospitalar como medida de prevenção de bactérias resistentes, embora recomendado pelas sociedades científicas, permanece com seu papel pouco compreendido. A maioria dos estudos que avalia medidas de prevenção de resistência bacteriana em serviços de saúde envolve múltiplas intervenções. Uma revisão integrativa publicada em 2011 avaliou quais medidas de prevenção de infecções relacionadas à assistência à saúde (IRAS) tinham impacto na redução de MRSA, Enterococcus sp resistente à vancomicina, enterobactéria resistente às cefalosporinas de terceira geração e Clostridium difficile. Foram incluídos, nesta revisão, estudos que tivessem foco na redução da incidência do agente resistente e não numa determinada 
síndrome infecciosa, que apresentassem uma medida de intervenção e cujos desenhos fossem grupos randomizados ou quasiexperimental com análise antes/depois da intervenção. Entre os 1.382 artigos recuperados, 47 foram revisados e 32 incluídos na análise. Todos os 32 estudos originais incluídos apresentava um desenho quasiexperimental. Vinte e sete $(84,4 \%)$ usaram séries temporais interrompidas, 3 (9,4\%) pré e pós-intervenção sem grupo controle e $2(6,3 \%)$ pré e pós-intervenção com grupo controle. As intervenções consistiam na implantação de "pacotes" de medidas, que na maioria das vezes, envolviam um programa robusto de higiene de mãos, apoio administrativo, monitoramento de pacientes colonizados e infectados com instituição de medidas de barreira (precauções de contato e isolamento) e controle do uso de antimicrobianos. Agrupando as medidas comuns a todos os estudos temos, medida administrativa (56\%), educação e treinamento $(62 \%)$, vigilância microbiológica $(53 \%)$ de colonizados e/ou infectados, instalação de precauções de contato (75\%), monitoramento da limpeza hospitalar (25\%), descolonização de pacientes $(28 \%)$ e controle de antimicrobianos (25\%). Os estudos aplicaram entre 2 e 5 destas intervenções. De uma maneira geral, houve redução das incidências de infecção/colonização por patógenos resistentes em todos os estudos. Entretanto os métodos aplicados (a maioria com séries temporais interrompidas) tornam difícil a generalização das conclusões. Além disso, como as intervenções incluem um "pacote" de medidas é difícil avaliar a contribuição individual dos diferentes componentes. Não é possível excluir o impacto do "efeito Hawthorne" sempre que um pacote de medidas é 
instituído com o objetivo de melhorar ou otimizar um processo de trabalho. Ensaios controlados e randomizados são escassos no campo das intervenções para controle de IRAS. Muitos estudos que apresentam como objetivo o controle de agentes multirresistentes estão relacionados a controle de surtos. A maioria dos relatos de surto e estudos de intervenção é escrita e apresentada de maneira não padronizada o que dificulta a sua comparação (www.outbreak-database.com). Há propostas na literatura de padronização destes estudos, como por exemplo, as recomendações do Outbreak Reports and Intervention Studies of Nosocomial Infections (ORION) ${ }^{100}$.

De maneira interessante, em nosso estudo, o único patógeno que tem sua incidência elevada diretamente relacionada com o consumo de antimicrobiano e inversamente relacionada ao índice de Gini é o Staphylococcus aureus resistente à oxacilina. Poderíamos supor que essa relação devesse aumentar a ocorrência também de infecções comunitárias por Staphylococcus aureus resistente à oxacilina, CA-MRSA da sigla em inglês Community Associated Methicillin Resistant Staphylococcus aureus. No entanto, este não é um patógeno frequente no Brasil. Em um estudo de revisão publicado em $2015{ }^{101}$ foram identificados 21 pacientes em relatos de casos de infecção no país descritos em artigos selecionados entre 2007 e 2013. Em outro estudo, Witzel et al. encontraram 16,5\% de prevalência de colonização nasal por MRSA em 302 homens vivendo em uma instituição prisional no Brasil. Os fatores associados foram comportamento sexual (homens que fazem sexo com homens), uso de drogas inalatórias, doença 
de pele e pulmonar. O uso prévio de antimicrobianos não foi avaliado ${ }^{102}$. Bonesso et al. estudaram a prevalência de CA-MRSA entre pacientes com infecções comunitárias de pele e partes moles. Entre 127 pacientes avaliados, houve caracterização molecular de MRSA em $10 \%$ dos casos. Os fatores associados à aquisição de MRSA neste estudo foram uso prévio de ciprofloxacina e trabalhar em ambiente de assistência à saúde ${ }^{103}$. No Reino Unido, um estudo ecológico analisando a distribuição espacial de CA-MRSA e HA-MRSA (hospital acquired methicillin Staphylococcus aureus) encontrou associação com infecção por este agente e indicadores sociais de pobreza ${ }^{104}$, apontando para a mesma direção dos nossos achados.

Independente da relação entre uso de antimicrobianos e "seleção de resistência, há, pelo menos, duas outras razões importantes para se defender o uso racional destas drogas em qualquer nível de assistência, da primária à quaternária. São elas, a prevenção de eventos adversos relacionados e custo elevado. Levando-se em conta que os antimicrobianos representam $50 \%$ do consumo de farmácias hospitalares, o seu uso racional tem $\mathrm{o}$ potencial de prevenir um grande número de eventos adversos decorrentes de seu uso desnecessário. É possível, por meio da implantação de uma política de uso racional de antimicrobianos, obter redução do tempo de uso e custo, sem impacto negativo sobre a qualidade da assistência. Meyer et al. ${ }^{105}$ avaliaram o impacto de uma intervenção para o tempo de uso de antimicrobianos para tratamento de pneumonia em unidade de terapia intensiva neurocirúrgica. $\mathrm{O}$ tempo de uso de antimicrobianos assim como o custo decorrente deste foi analisado por meio de séries temporais 
interrompidas. Após a implantação de diretrizes para uso de antimicrobianos no tratamento de pneumonia, houve redução da média do tempo de tratamento de pneumonia hospitalar de 15 para 7 dias e de pneumonia comunitária de 10 para 5 dias. Consequentemente, houve redução significativa do consumo das seguintes drogas ou classe de drogas: cefalosporinas de segunda geração, carbapenens, imidazólicos, penicilinas com inibidor de beta-lactamase e glicopeptídeos. O custo global com antimicrobianos/paciente-dia também foi reduzido de maneira significativa de 13,6 euros/paciente-dia antes para 7,31 euros/paciente-dia após a intervenção. Não foi observada diferença na taxa de mortalidade por pneumonia neste período.

O consumo global de antimicrobianos provavelmente atua como um "selecionador" de bactérias resistentes na comunidade como componente de uma cadeia complexa de determinantes de resistência. Ainda são necessários estudos que levem em conta essa complexidade, avaliando a interação de fatores biológicos (consumo humano de antimicrobianos e na agropecuária), distribuição espacial do fenômeno, mobilidade dos indivíduos colonizados e/ou infectados, aspectos etnográficos e hierarquia da rede de assistência à saúde. Além disso, é possível que as formas de seleção e disseminação guardem grande variabilidade entre as diferentes bactérias em razão de seus nichos e repertórios genéticos conferindo vantagens ecológicas peculiares para cada espécie. Neste sentido, os recentes avanços no conhecimento do microbioma poderão trazer luz sobre os fatores mais relevantes para a seleção e disseminação destes agentes. Reforçando 
a hipótese da dinâmica diversa de seleção e transmissão entre os agentes, um estudo de vigilância de infecção por bactérias resistentes em unidades de terapia intensiva na Alemanha entre 2000 e 2011 não observou aumento na incidência de infecções por MRSA (4,2/1000 pacientes-dia em 2011), mas por outro lado, detectou aumento de cinco vezes na incidência de klebsiella pneumoniae e Escherichia coli resistentes a cefalosporinas de terceira geração no mesmo período. Houve aumento significativo de Enterococcus sp resistente à vancomicina $(0,1$ a $0,8 / 1000$ pacientes-dia) mas não foi demonstrada correlação com o uso prévio desta droga $(p=0,19)$. Outras variáveis socioeconômicas ou culturais podem desempenhar algum papel. O pesado uso de antimicrobianos em animais, seja na medicina veterinária clínica, seja na pecuária como promotor de crescimento ou como "profiláticos" na proteção infecciosa de rebanhos ainda não tem seu impacto medido sobre a seleção de resistentes para a saúde humana. As possibilidades de interação são multiplas, com aquisição de bactérias resistentes via transmissão cruzada inter-espécies (animal-humana) por manipulação direta de animais (profissionais da pecuária, da medicina veterinária, cuidados gerais de animais domésticos), consumo de carne "contaminada", manipulação de alimentos contaminados, convívio doméstico com animais colonizados ou infectados. O papel destas interações ainda é pouco explorado. Leistner et al investigaram a disseminação de Escherichia coli no âmbito da comunidade e os fatores associados a essa disseminação por meio de um estudo de caso-controle compreendido no período de maio de 2011 a janeiro de 2012. Os casos foram definidos como pacientes 
colonizados por Escherichia coli comunitária produtora de beta-lactamase de espectro estendido (ESBL) identificada em período menor que 72 horas após a admissão hospitalar. Os controles foram definidos como pacientes colonizados por Escherichia coli comunitária não produtora de betalactamase de espectro estendido (ESBL) identificada em período menor que 72 horas após a admissão hospitalar. O status de colonizado era definido por meio de swab retal obtido à admissão. A produção de ESBL foi definida pela identificação genes codificadores destas enzimas por meio de reação em cadeia da polimerase e sequenciamento genético. Casos e controles responderam a um questionário que explorava hábitos alimentares, viagens, situação domiciliar, língua mais comum falada em casa (língua-mãe). Foram analisados 85 casos e 170 controles. O uso de língua asiática em casa (OR $=13,4 ; \mathrm{IC} 95 \%$ 3.3-53.8; $p<0,001)$ e o consumo de carne de porco (> de 3 refeições por semana, OR = 3,5; IC 95\% 1,8 - 6,6; $p<0,001$ ) foram os dois fatores independenetemente associados com colonização por Escherichia coli produtora de ESBL após análise por meio de regressão logística. $\mathrm{O}$ consumo de aves e o uso prévio de antimicrobianos não foram associados à colonização. Em outro estudo, Spoor et al demonstraram por meio de estudo filogenético que a emergência de dois clones de MRSA que afetam humanos foram transferidos de hospedeiro bovino pelo major bovine Staphylococcus aureus complex, CC97 ${ }^{106}$. Um desses clones foi isolado em infecções humanas em quatro diferentes continentes. Diante dos achados desses estudos, é provável que o gado de corte atue como reservatório de patógenos com implicações em saúde pública. 
Uma limitação do nosso estudo foi não conseguir avaliar o desempenho dos laboratórios clínicos envolvidos na identificação dos patógenos multirresistentes. Os laboratórios clínicos de cada instituição, provavelmente, dispõem de recurso tecnológico diverso para identificação fenotípica e/ou genotípica de resistência bacteriana. A Divisão de Infecção Hospitalar do Centro de Vigilância Epidemiológica da Secretaria de Saúde do Estado de São Paulo, responsável pelo sistema de vigilância de infecções em unidades de terapia intensiva aplicou um questionário em 2008 aos laboratórios clínicos que atendem aos hospitais que reportam ao sistema de vigilância (dados não publicados). A taxa de reposta foi de $98,7 \%$ entre os hospitais que tem unidades de terapia intensiva, representando 236 laboratórios. Oitenta e oito por cento dos laboratórios afirmaram seguir as normas do Clinical and Laboratory Standards Institute (CLSI), que é a padronização norte-americana de referência para a qualidade dos processos laboratoriais. A mesma proporção afirmou dispor de protocolos internos de controle de qualidade e $72 \%$ afirmaram participar de algum programa externo de avaliação da qualidade.

Em resumo, a associação entre o consumo de antimicrobianos, fatores socioeconômicos e de acesso e qualidade da assistência à saúde e incidência de infecção primária da corrente sanguínea causada por bactérias resistentes a múltiplas drogas em unidades de terapia intensiva não foi observada em nosso estudo, exceto para Staphylococcus aureus resistente à oxacilina. Esforços no sentido de se reduzir a incidência destas infecções devem estar focados em medidas de prevenção de infecção como proteção 
do sítio de inserção, adequadas antissepsia da pele e desinfecção das conexões ao manipular o sistema de infusão, além da redução da transmissão cruzada dentro das unidades de terapia intensiva a partir de um robusto programa de higiene das mãos entre profissionais de saúde. Os achados do estudo não invalidam todos os esforços empreendidos na busca por sedimentar uma cultura médica de uso racional de antimicrobianos uma vez que há impacto positivo desta prática na redução de eventos adversos resultantes do uso destas drogas e redução de gastos desnecessários. Estudos que deem conta da complexidade causal e interação dos fenômenos de "seleção" e "disseminação" de resistentes são necessários tanto na comunidade quanto no ambiente de assistência à saúde. 
6 Conclusão 


\section{CONCLUSÃO}

1. Observamos que, embora não de maneira uniforme, a maioria dos patógenos estudados, nos diferentes anos, forma agrupamentos geográficos, ou seja, não estão distribuídos aleatoriamente no espaço estudado.

2. Não observamos, neste estudo, relação entre consumo de antimicrobianos na comunidade e infecção por patógenos multirresistentes em pacientes críticos tratados em unidades de terapia intensiva (UTI), exceto entre uso de penicilina e infecção por MRSA.

3. Observamos relação entre maior concentração de renda e menor incidência de infecção por MRSA.

4. Observamos associação entre baixas incidências de infecção por patógenos multirresistentes e Santas Casas, o que pode ser um marcador de desigualdade social confirmando o achado descrito acima da relação entre alto índice de Gini (maior concentração de renda) e menor incidência de MRSA ou, alternativamente, se constituir em fragilidade do diagnóstico laboratorial.

5. Há necessidade de estudos que explorem esta relação observada entre maior concentração de renda e categoria do hospital (Santa Casa) com menores incidências de infecção por patógenos multirresistentes em UTI. 
7 Referências 


\section{REFERÊNCIAS}

01 Rice WR, Chippindale AK. Sexual recombination and the power of natural selection. Science. 2001;294(5542):555-9.

02 Mandell GL. Mandell, Bennett and Dolin's Principles and Practice of Infectious Diseases. 6th ed. Churchill Livingstone: Elsevier; 2005.

03 Ligon BL. Sir Alex Fleming: Scottish researcher who discovered penicillin. Semin Pediatr Infect Dis. 2004;15(1):58-64.

04 Ligon BL. Sir Howard Walter Florey - The force behind the development of penicillin. Semin Pediatr Infect Dis. 2004;15(2):109-14.

05 Chambers HF. The changing epidemiology of Staphylococcus aureus? Emerg Infect Dis. 2001;7(2):78-82.

06 Panlilio AL, Culver DH, Gaynes RP, Banerjee S, Henderson TS, Tolson JS, Martone WJ. Methicillin-resistant Staphylococcus aureus in U.S. hospitals, 1975-1991. Infect Control Hosp Epidemiol. 1992;13(10):582-6.

07 Edwards JR, Peterson KD, Andrus ML, Tolson JS, Goulding JS, Dudeck MA, Mincey RB, Pollock DA, Horan TC; NHSN Facilities. National Healthcare Safety Network (NHSN) Report, data summary for 2006, issued June 2007. Am J Infect Control. 2007;35(5):290-301.

08 Hiramatsu K, Hanaki H, Ino T, Yabuta K, Oguri T, Tenover FC. Methicillin-resistant Staphylococcus aureus clinical strain with reduced vancomycin susceptibility. J Antimicrob Chemother. 1997;40(1):135-6. 
09 Oliveira GA, Dell'Aquila AM, Masiero RL, Levy CE, Gomes MS, Cui L, Hiramatsu K, Mamizuka EM. Isolation in Brazil of nosocomial Staphylococcus aureus with reduced susceptibility to vancomycin. Infect Control Hosp Epidemiol. 2001;22(7):443-8.

10 Chang S, Sievert DM, Hageman JC, Boulton ML, Tenover FC, Downes FP, Shah S, Rudrik JT, Pupp GR, Brown WJ, Cardo D, Fridkin SK; Vancomycin-Resistant Staphylococcus aureus Investigative Team. Infection with vancomycin-resistant Staphylococcus aureus containing the vanA resistance gene. N Engl J Med. 2003;348(14):1342-7.

11 DIH/CVE/SES. Disponível em: www.cve.saude.sp.gov.

12 Bush K, Jacoby GA, Medeiros AA. A functional classification scheme for ß-lactamases and its correlation with molecular structure. Antimicrob Agents Chemother. 1995;39(6):1211-33.

13 Murray BE. The life and times of Enterococcus. Clin Microbiol Rev. 1990;3(1):46-65.

14 Morrison Jr AJ, Wenzel RP. Nosocomial urinary tract infections due to enterococcus: ten years' experience at a university hospital. Arch Intern Med. 1986;146(8):1549-51.

15 Centers for Disease Control. CDC surveillance summaries. National nosocomial infection surveillance, 1984. MMWR Morbid Mortal Weekly Rep. 1986;35(Special Suppl. 1):17SS-29SS.

16 Uttley $\mathrm{AH}$, Collins $\mathrm{CH}$, Naidoo J, George RC. Vancomycin-resistant enterococci. Lancet. 1988;1(8575-6):57-8.

17 Cetinkaya Y, Falk P, Mayhall G. Vancomycin-eesistant enterococci. Clin Microbiol Rev. 2000;13(4):686-707. 
18 Leclercq R, Derlot E, Duval J, Courvalin P. Plasmid-mediated resistance to vancomycin and teicoplanin in Enterococcus faecium. $\mathrm{N}$ Engl J Med. 1988;319(3):157-61.

19 Uttley $\mathrm{AH}$, Collins $\mathrm{CH}$, Naidoo J, George RC. Vancomycin-resistant enterococci. Lancet. 1988;1(8575-6):57-8.

20 Boyce JM. Vancomycin-resistant enterococci: pervasive and persistent pathogens. Infect Control Hosp Epidemiol. 1995;16(12):676-9.

21 Centers for Disease Control and Prevention (CDC). Nosocomial enterococci resistant to vancomycin-United States, 1989-1993. MMWR Morb Mortal Wkly Rep. 1993;42(30):597-9.

22 Jones RN, Erwin ME, Anderson SC. Emerging multiply resistant enterococci among clinical isolates: validation of $E$ test to recognize glycopeptide-resistant strains. Diagn Microbiol Infect Dis. 1995;21(2):95-100.

23 Dalla Costa LM, Souza DC, Martins LT, Zanella RC, Brandilone MC, Bokermann S, Sader HS, Souza HA. Vancomycin-resistant Enterococcus faecium: First Case in Brazil. Braz J Infect Dis. 1998;2(3):160-3.

24 Tuon FF, Penteado-Filho SR, Camilotti J, van der Heijden IM, Costa SF. Outbreak of vancomycin-resistant Enterococcus in a renal transplant unit. Braz J Infect Dis. 2011;15(4):403-5.

25 Perugini MR, Nomi SM, Lopes GK, Belei RA, van der Heijden IM, Mostachio AK, Grion C, Couto EB Jr, Costa SF. Impact of the reduction of environmental and equipment contamination on vancomycin-resistant enterococcus rates. Infection. 2011;39(6):587-93.

26 Campbell Jr GD, Silberman R. Drug-resistant Streptococcus pneumoniae. Clin Infect Dis. 1998;26(5):1188-95. 
27 Austrian R. Confronting drug-resistant pneumococci. Ann Intern Med. 1994;121(10):807-9.

28 Tomasz A. Antibiotic resistance in Streptococcus pneumoniae. Clin Infect Dis. 1997;24 (Suppl 1):S85-8.

29 Abraham EP, Chain E. An enzyme from bacteria able to destroy penicillin. Nature. 1940;146:837.

30 Bradford PA. Extended-spectrum $\beta$-lactamases in thye $21^{\text {st }}$ century: characterization, epidemiology, and detection of this important resistance threat. Clin Microbiol Rev. 2001;14(4):933-51.

31 Datta N, Kontomichalou P. Penicillinase synthesis controlled by infectious R Factors in Enterobacteriaceae. Nature. 1965;208(5007):239-41.

32 Medeiros AA. $\beta$-Lactamases. Br Med Bull. 1984;40(1):18-27.

33 Kliebe C, Nies BA, Meyer JF, Tolxdorff-Neutzling RM, Wiedemann B. Evolution of plasmid-coded resistance to broad-spectrum cephalosporins. Antimicrob Agents Chemother. 1985;28(2):302-7.

34 Jacoby GA, Muñoz-Price LS. The new $\beta$-Lactamases. $N$ Eng J Med 2005;352(4):380-91.

35 Walder M, Haeggman S, Tullus K, Burman LG. A hospital outbreak of high-level beta-lactam-resistant Enterobacter spp: association more with ampicillin and cephalosporin therapy than with nosocomial transmission. Scand J Infect Dis. 1996;28(3):293-6. 
36 Lautenbach E, Patel JB, Bilker WB, Edelstein PH, Fishman NO. Extended-spectrum beta-lactamase-producing Escherichia coli and Klebsiella pneumoniae: risk factors for infection and impact of resistance on outcomes. Clin Infect Dis. 2001;32(8):1162-71.

37 Koeleman JG, Parlevliet GA, Dijkshoorn L, Savelkoul PH, Vandenbroucke-Grauls CM. Nosocomial outbreak of multi-resistant Acinetobacter baumannii on a surgical ward: epidemiology and risk factors for acquisition. J Hosp Infect. 1997;37(2):113-23.

38 Husni RN, Goldstein LS, Arroliga AC, Hall GS, Fatica C, Stller JK, Gordon SM. Risk factors for an outbreak of multi-drug-resistant Acinetobacter nosocomial pneumonia among intubated patients. Chest. 1999;115(5):137882.

39 Guyot A, Barrett SP, Threfall EJ, Hampton MD, Cheasty T. Molecular epidemiology of multi-resistant Escherichia coli. J Hosp Infect. 1999; 43(1):39-48.

40 Dziekan G, Hahn A, Thune K, Schwarzer G, Schafer K, Daschner F, Grundmann H. Methicillin resistant Staphylococcus aureus in a teaching hospital: investigation of nosocomial transmission using a matched casecontrol. J Hosp Infect. 2000;46(4):263-70.

41 Olsen SJ, DeBess EE, McGiven TE, Marano N, Eby T, Mazuvais S, Balan VK, Zirstein G, Cieslak PR, Angulo FJ. A nosocomial outbreak of fluoroquinolone-resistant Salmonella infection. N Engl Med. 2001; 344(21):1572-9.

42 Steinke DT, Seaton RA, Phillips G, MacDonald TM, Davey PG. Prior trimethoprim use and trimethoprim-resistant urinary tract infection: a nested case-control study with multivariate analysis for other risk factors. J Antimicrob Chemother. 2001;47(6):781-7. 
43 Asensio A, Oliver A, Gonzalez-Diego P, Baquero F, Perez-Diaz JC, Ros P, Cobo J, Palacios M, Lasheras D, Canton R. Outbreak of a multiresistant Klebsiella pneumoniae strain in an intensive care unit: antibiotic use as risk factor for colonization and infection. Clin Infect Dis. 2000;30(1):55-60.

44 Khayr W, Rheault W, Waiters L, Waiters A. Epidemiology of ciprofloxacin-resistant Pseudomonas aeruginosa in a veterans affairs hospital. Am J Ther. 2000;7(5):309-12.

45 Richard $\mathrm{P}$, Delangle MH, Raffi F, Espaze E, Richet H. Impact of fluoroquinolone administration on the emergence of fluoroquinolone-resistant gram-negative bacilli from gastrointestinal flora. Clin Infect Dis. 2001;32(1):162-6.

46 Nourse C, Murphy H, Byrne C, O'Meara A, Breatnach F, Kaufman M, Clarke A, Butler K. Control of a nosocomial outbreak of Vancomycin resistant Enterococcus faecium in a pediatric oncology unit: risk factors for colonization. Eur J Pediatr. 1998;157(1):20-7.

47 Levin AS, Mendes CM, Sinto SI, Sader HS, Scarpitta CR, Rodrigues E, Sauaia N, Boulos M. An outbreak of multiresistant Acinetobacter baumannii in a university hospital in São Paulo, Brazil. Infect Control Hosp Epidemiol 1996;17(6):366-8.

48 Chow JW, Fine MJ, Shlaes DM, Quinn JP, Hooper DC, Johnson MP, Ramphal R, Wagener MM, Miyashiro DK, Yu VL. Enterobacter bacteremia: clinical features and emergence of antibiotic resistance during therapy. Ann Intern Med. 1991;115(8):585-90.

49 Jacobson KL, Cohen SH, Inciardi JF, King JH, Lippert WE, Iglesias T, Van Couwenberghe CJ. The relationship between antecedent antibiotic use and resistance to extended-spectrum cephalosporins in group I ß-lactamaseproducing organisms. Clin Infect Dis. 1995;21(5):1107-13. 
50 Carmeli Y, Troillet N, Eliopoulos GM, Samore MH. Emergence of antibiotic-resistant Pseudomonas aeruginosa: comparison of risks associated with different antipseudomonal agents. Antimicrob Agents Chemother. 1999;43(6):1379-82.

51 Ferreira AC, Gobara S, Costa SE, Sauaia N, Mamizuka EM, van der Heijden IM, Soares RE, Almeida GD, Fontana C, Levin AS. Emergence of resistance in Pseudomonas aeruginosa and Acinetobacter species after the use of antimicrobials for burned patients. Infect Control Hosp Epidemiol. 2004;25(10):868-72.

52 Hsueh PR, Teng LJ, Chen CY, Chen WH, Yu CJ, Ho SW, Luh KT. Pandrug-resistant Acinetobacter baumannii causing nosocomial infections in a university hospital, Taiwan. Emerg Infect Dis. 2002;8(8):827-32.

53 Pittet D, Allegranzi B, Sax H, Dharan S, Pessoa-Silva CL, Donaldson L, Boyce JM; WHO Global Patient Safety Challenge, World Alliance for Patient Safety. Evidence-based model for hand transmission during patient care and the role of improved practices. Lancet Infect Dis. 2006;6(10): 641-52.

54 Levin AS, Gobara S, Mendes CM, Cursino MR, Sinto S. Environmental contamination by multi-drug resistant Acinetobacter baumannii in an intensive care unit. Infect Control Hosp Epidemiol. 2001;22(11):717-20.

55 Gaynes R. The impact of antimicrobial use on the emergence of antimicrobial-resistant bacteria in hospitals. Infect Dis Clin N Am. 1997; 11(4):757-65.

56 Kollef MH, Vlasnik J, Sharpless L, Pasque C, Murphy D, Fraser V. Scheduled change of antibiotic classes: a strategy to decrease the incidence of ventilator-associated pneumonia. Am J Repirat Crit Care Med. 1997;156(4 Pt 1):1040-8. 
57 Niederman MS. Is "crop rotation"of antibiotic the solution to a "resistant" problem in the ICU? Am J Respirat Crit Care Med. 1997;156(4 Pt 1):1029-31.

58 Gerding DN, Larson TA, Hughes RA, Weiler M, Shanholtzer C, Peterson LR. Aminoglycoside resistance and aminoglycoside usage: ten years of experience in one hospital. Antimicrob Agents Chemother. 1991;35(7):1284-90.

59 Brasil, Portaria 2616, 13 de maio de 1998. Disponível em: www.portal.saude.gov.br/saude.

60 File Jr TM. Overview of resistance in the 1990s. Chest. 1999;115(3 Suppl):3S-8S.

61 Levin AS, Teixeira LM, Sessegolo JF, Barone AA. Resistance of Streptococcus pneumoniae to antimicrobials in São Paulo, Brazil: clinical features and serotypes. Rev Inst Med Trop São Paulo. 1996;38(3):187-92.

62 Arason VA, Gunnlaugsson A, Sigurdsson JA, Erlendsdottir $H$, Gudmundsson S, Kristinsson KG. Clonal spread of resistant pneumococci despite diminished antimicrobial use. Microb Drug Resist. 2002;8(3):187-92.

63 Corneli J. Avaliação de promotores de crescimento alternativos em substituição aos convencionais sobre o desempenho, características de carcaça e morfometria intestinal em frangos de corte [Dissertação Zootecnia]. Santa Maria: Centro de Ciências Rurais, Universidade Federal de Santa Maria; 2004.

64 Sumano LH, Ocampo CL, Brumbaugh GW, Lizarraga RE. Effectiveness of two fluoroquinolones for the treatment of chronic respiratory disease in broilers. Br Poult Sci. 1998;39(1):42-6. 
65 Morck DW, Merrill JK, Thorlakson BE, Olson ME, Tonkinson LV, Costerton JW. Prophylactic efficacy of tilmicosin for bovine respiratory tract disease. J Am Vet Med Assoc. 1993;202(2):273-7.

66 Singer RS, Finch R, Wegener HC, Bywater R, Walters J, Lipsitch M. Antibiotic resistance - the interplay between antibiotic use in animals and human beings. Lancet Infect Dis. 2003;3(1):47-51.

67 Bager F, Madsen M, Christensen J, Aarestrup FM. Avoparcin used as a growth promoter is associated with the occurrence of vancomycin-resistant Enterococcus faecium on Danish poultry and pig farms. Prev Vet Med. 1997; 31(1-2): 95-112.

68 Kruse H, Johansen BK, Rørvik LM, Schaller G. The use of avoparcin as a growth promoter and the occurrence of vancomycin-resistant Enterococcus species in Norwegian poultry and swine production. Microb Drug Resist. 1999;5(2):135-9.

69 Brasil. Ministério da Agricultura. Ofício Circular 19/98 de 16/11/98. Disponível em: www.extranet.agricultura.gov.br/sislegis-consulta

70 Davey P, Brown E, Fenelon L, Finch R, Gould I, Holmes A, Ramsay C, Taylor E, Wiffen $P$, Wilcox M. Systematic review of antimicrobial drug prescribing in hospitals. Emerg Infect Dis 2006; 12(2):211-6.

71 van de Sande-Bruinsma N, Grundmann H, Verloo D, Tiemersma E, Monen J, Goossens H, Ferech M; European Antimicrobial Resistance Surveillance System Group; European Surveillance of Antimicrobial Consumption Project Group. Antimicrobial drug use and resistance in Europe. Emerg Infect Dis 2008;14(11):1722-30.

72 Snow J. Sobre a maneira de transmissão do cólera. $2^{a}$ ed. São Paulo: Brasileira, Hucitec-Abrasco; 1990. 
73 Wendel S. Risco residual da transmissão de infecção por Trypanosoma cruzi por via transfusional no Brasil [Tese - Moléstias Infecciosas e Parasitárias]. São Paulo: Faculdade de Medicina, Universidade de São Paulo; 2005.

74 Richards TB, Croner CM, Rushton G, Brown CK, Fowler L. Geographic information systems and public health: mapping the future. Public Health Rep. 1999;114(4):359-73.

75 McKee Jr KT, Shields TM, Jenkins PR, Zenilman JM, Glass GE. Application of a geographic information system to the tracking and control of an outbreak of shigellosis. Clin Infect Dis. 2000;31(3):728-33.

76 Agência Nacional de Vigilância Sanitária (ANVISA) - Critérios diagnósticos de infecção relacionada à assistência à saúde. Maio de 2013. Disponível em: http://portal.anvisa.gov.br/wps/wcm/connect/fb486e004025bf44a2e4f2dc5a1 2ff52/Modulo_2_Criterios_Diagnosticos_IRA_Saude.pdf?MOD=AJPERES

77 Brasil. Lei 11.445 de 5 de janeiro de 2007.

78 Klugman J, Rodríguez F, Choi HJ, Daponte BO, Fuentes-Nieva R, Gebretsadik M, et al. Relatório de desenvolvimento humano 2010. Programa das Nações Unidas para o Desenvolvimento (PNUD). Traduzido para o português pelo Instituto Português de Apoio ao Desenvolvimento. A verdadeira riqueza das nações: vias para o desenvolvimento humano. New York: Programa das Nações Unidas para o Desenvolvimento; 2010.

79 Antonaci GA. Comparação de métodos para estimação de índices de pobreza em pequenas áreas. [Dissertação de Mestrado]. Rio de Janeiro: Instituto de Matemática, Universidade Federal do Rio de Janeiro; 2012. 
80 Almeida Filho N, Rouquayrol MZ. Introdução à Epidemiologia Moderna. $1^{\text {a }}$ edição. Rio de Janeiro: Apce; 1990.

81 Organização Mundial da Saúde (OMS). Anatomical Therapeutic Chemical (ATC/DDD). Disponível em: www.whocc.no/atc_ddd_index acesso em 30/04/2011.

82 WHO Collaborating Centre for Drug Statistics Methodology, Guidelines for ATC classification and DDD assignment 2011. Oslo, 2010.

83 Anselin L. Spatial regression analysis in R. A workbook. Urbana: University of Illinois; 2005.

84 Victora CG, Huttly SR, Fuchs SC, Olinto MT. The role of conceptual frameworks in epidemiological analysis: a hierarchical approach. Int $\mathrm{J}$ Epidemiol. 1997;26(1):224-7.

85 Lima S, Carvalho ML, Vasconcelos AG. Proposta de modelo hierarquizado aplicado à investigação de fatores de risco de óbito infantil neonatal. Cad Saúde Pública. 2008;24(8):1910-6.

86 Blangiardo M, Cameletti M. Spatial and spatio-temporal Bayesian models with R-INLA. Hoboken, NJ: John Wiley \& Sons, 2015.

87 Gelman A, Hwang J, Vehtari A. Understanding predictive information criteria for Bayesian models. Statistics and Computing. 2014;24(6):997-1016.

88 Rue H, Martino S, Chopin N. Approximate Bayesian inference for latent Gaussian models using inte-grated nested Laplace approximations. J R Statist Soc B. 2009;71(2):319-92.

89 Baquero OS. INLAOutputs: Process Outputs from 'INLA' Package. (2015). Disponível em: http://oswaldosantos.github.io/INLAOutputs 
90 Timsit JF, Soubirou JF, Voiriot G, Chemam S, Neuville M, Mourvillier B, Sonneville R, Mariotte E, Bouadma L, Wolff M. Treatment of bloodstream infections in ICUs. BMC Infect Diseases 2014; 14:489.

91 Siegel JD, Rhinehart E, Jackson M, Chiarello L; Healthcare Infection Control Practices Advisory Committee. Management of multidrug-resistant organisms in healthcare settings. Am J Infect Control. 2007;35(10 Suppl 2):S165-93.

92 Barlam TF, Cosgrove SE, Abbo LM, MacDougall C, Schuetz AN, Septimus EJ, Srinivasan A, Dellit TH, Falck-Ytter YT, Fishman NO, Hamilton CW, Jenkins TC, Lipsett PA, Malani PN, May LS, Moran GJ, Neuhauser MM, Newland JG, Ohl CA, Samore MH, Seo SK, Trivedi KK. Implementing an Antibiotic Stewardship Program: guidelines by the Infectious Diseases Society of America and the Society for Healthcare Epidemiology of America. Clin Infect Dis. 2016;62(10):e51-77.

93 Tacconelli, Cataldo MA, Dancer SJ, De Angelis G, Falcone M, Frank U, Kahlmeter G, Pan A, Petrosillo N, Rodríguez-Baño J, Singh N, Venditti M, Yokoe DS, Cookson B; European Society of Clinical Microbiology. ESCMID guidelines for the management of the infection control measures to reduce transmission of multidrug-resistant Gram-negative bacteria in hospitalized patients. Clin Microbiol Infect. 2014;20(Suppl 1):1-55.

94 Organização Mundial da Saúde. Disponível em: http://www.who.int/mediacentre/factsheets/fs194/en/

95 Moura ML, Boszczowski I, Mortari N, Barrozo LV, Chiaravalloti Neto F, Lobo RD, Pedroso de Lima AC, Levin AS. The impact of restricting over-thecounter sales of antimicrobial drugs. Medicine (Baltimore). 2015; 94(38):e1605. 
96 Skalet AH, Cevallos V, Ayele B, Gebre T, Zhou Z, Jorgensen JH, Zerihun M, Habte D, Assefa Y, Emerson PM, Gaynor BD, Porco TC, Lietman TM, Keenan JD. Antibiotic selection pressure and macrolide resistance in nasopharyngeal Streptococcus pneumoniae: a cluster-randomized clinical trial. PLoS Med. 2010;7(12):e1000377.

97 Ramsay C, Brown E, Hartman G, Davey P. Room for improvement: a systematic review of the quality of evaluations of interventions to improve hospital antibiotic prescribing. J Antimicrobial Chemother. 2003;52(5):764-71.

98 Schwaber MJ, Carmeli Y. An ongoing national intervention to contain the spread of carbapenem-resistant Enterobacteriaceae. Clin Infect Dis. 2014; 58(5):697-703.

99 Derde L, Cooper BS, Goossens H, Malhotra-Kumar S, Willems RJ, Gniadkowski M, Hryniewicz W, Empel J, Dautzenberg MJ, Annane D, Aragão I, Chalfine A, Dumpis U, Esteves F, Giamarellou H, Muzlovic I, Nardi G, Petrikkos GL, Tomic V, Martí AT, Stammet P, Brun-Buisson C, Bonten MJ; MOSAR WP3 Study Team. Interventions to reduce colonisation and transmission of antimicrobial-resistant bacteria in intensive care units: an interrupted time series study and cluster randomised trial. Lancet Infect Dis. 2014;14(1):31-9.

100 Maciel ALP, de Assis DB, Madalosso G, Padoveze MC. Evaluating the quality of outbreak reports on health care-associated infections in São Paulo, Brazil, during 2000-2010 using the ORION statement findings and recommendations. Am J Infect Control. 2014;42(40):e47-53.

101 Evangelista SS, Oliveira AC. Staphylococcus aureus meticilino resistente adquirido na comunidade: um problema mundial. Rev Bras Enferm. 2015; 68(1):128-35. 
102 Witzel C de L, Fortaleza CM, de Souza CS, Riboli DF, da Cunha ML Nasopharyngeal carriage of Staphylococcus aureus among imprisoned males from Brazil without exposure to healthcare: risk factors and molecular characterization. Ann Clin Microbiol Antimicrob. 2014;13:25.

103 Bonesso MF, Marques SA, Camargo CH, Fortaleza CM, da Cunha ML. Community-associated methicillin-resistant Staphylococcus aureus in non-outbreak skin infections. Braz J Microbiol. 2015;45(4):1401-7.

104 Tosas Auguet O, Betley JR, Stabler RA, Patel A, loannou A, Marbach H, Hearn P, Aryee A, Goldenberg SD, Otter JA, Desai N, Karadag T, Grundy C, Gaunt MW, Cooper BS, Edgeworth JD, Kypraios T. Evidence for community transmission of community-associated but not health-careassociated methicillin-resistant Staphylococcus aureus strains linked to social and material deprivation: spatial analysis of cross-sectional data. PLoS Med. 2016; 13(1):e1001944.

105 Meyer E, Buttler J, Schneider C, Strehl E, Schroeren-Boersch B, Gastmeier P, Ruden H, Zentner J, Daschner FD, Schwab F. Modified guidelines impact on antibiotic use and costs: duration of treatment for pneumonia in a neurosurgical ICU is reduced. J Antimicrob Chemother. 2007; 59(6):1148-54.

106 Spoor LE, McAdam PR, Weinert LA, Rambaut A, Hasman H, Aarestrup FM, Kearns AM, Larsen AR, Skov RL, Fitzgerald JR. Livestock origin for a human pandemic clone of community-associated methicillinresistant Staphylococcus aureus. MBio. 2013; 4(4):e356-13. 
8 Anexos 
Entre as páginas 94 e 117, reapresentamos os mapas das páginas 41 a 46 em maior dimensão. 


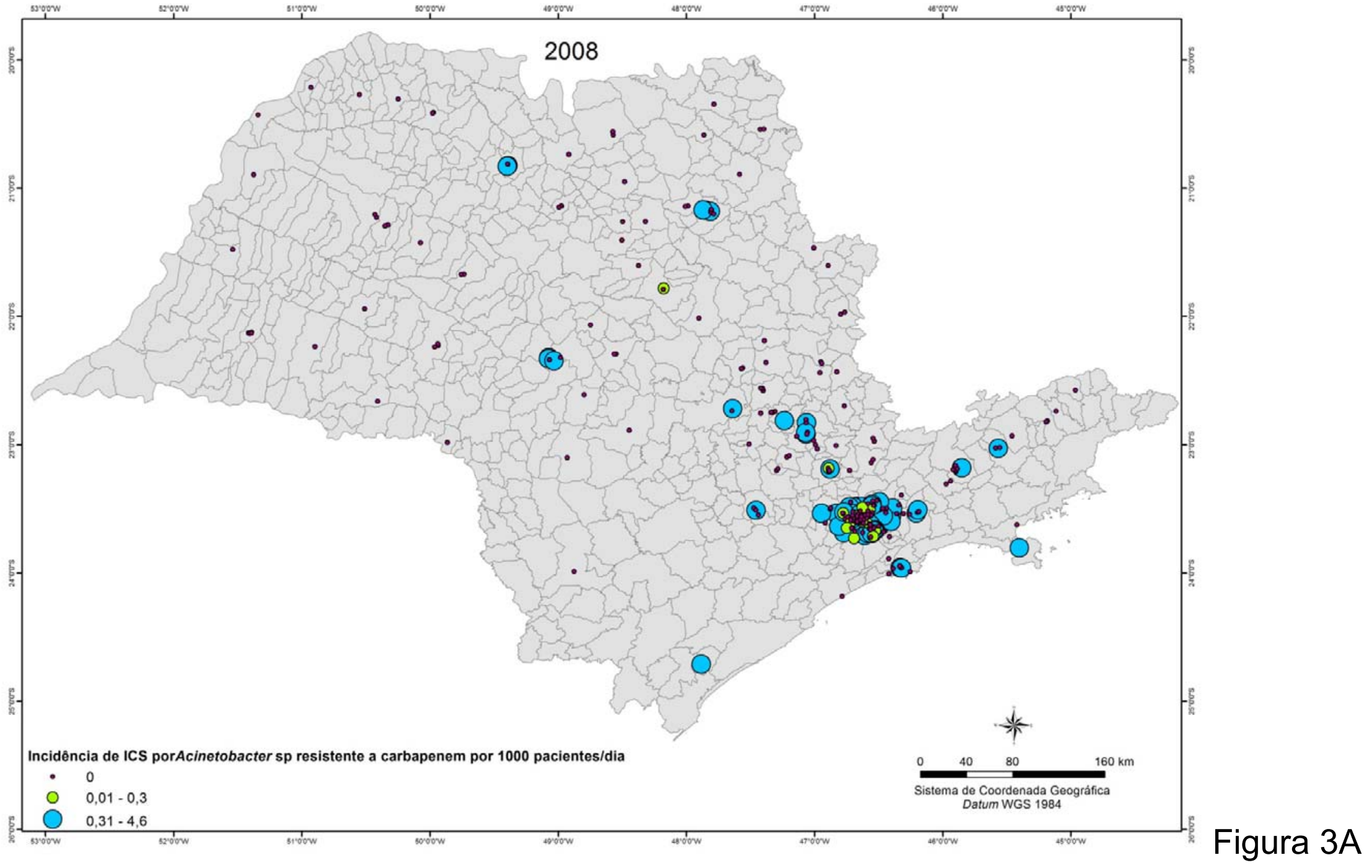




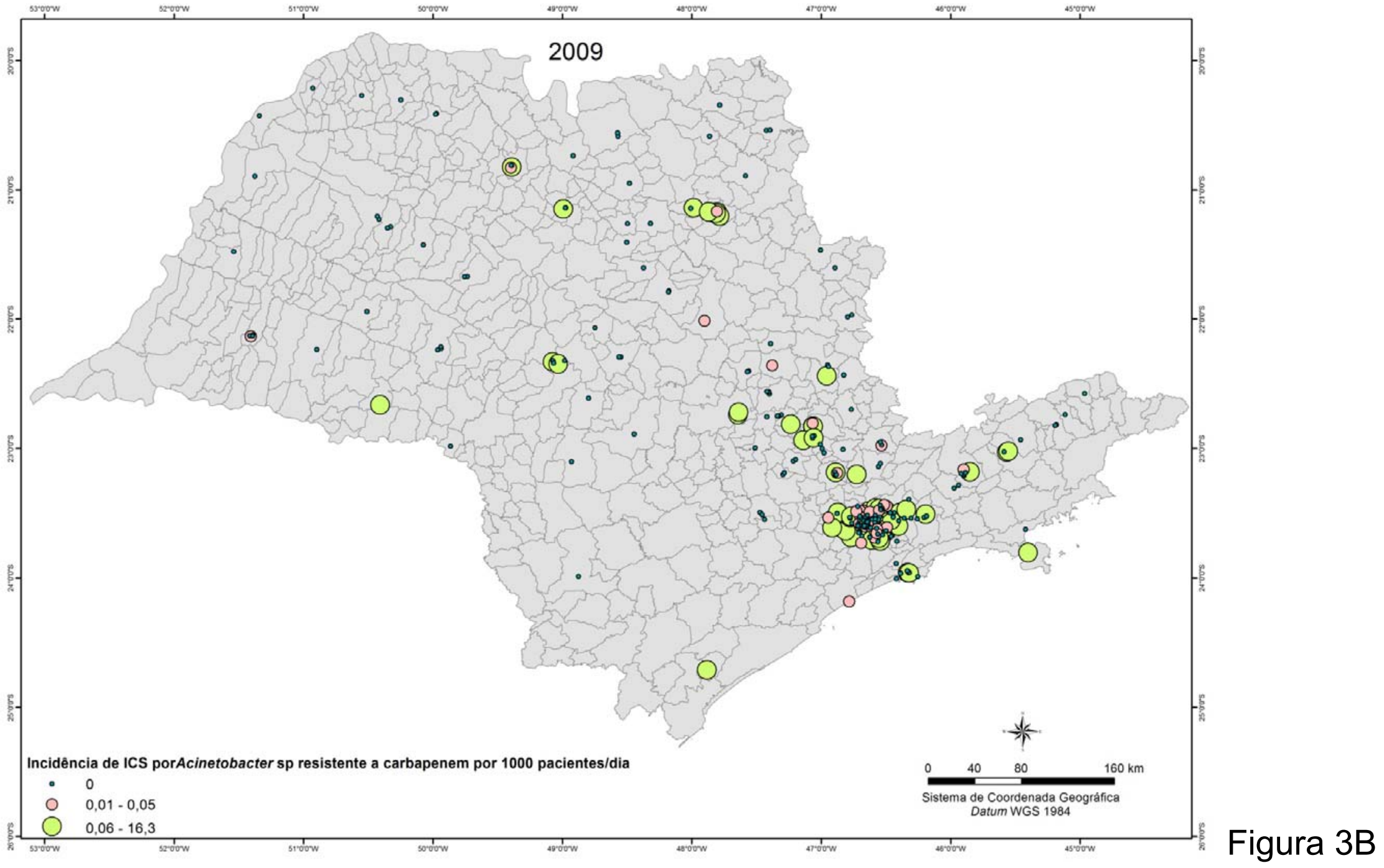




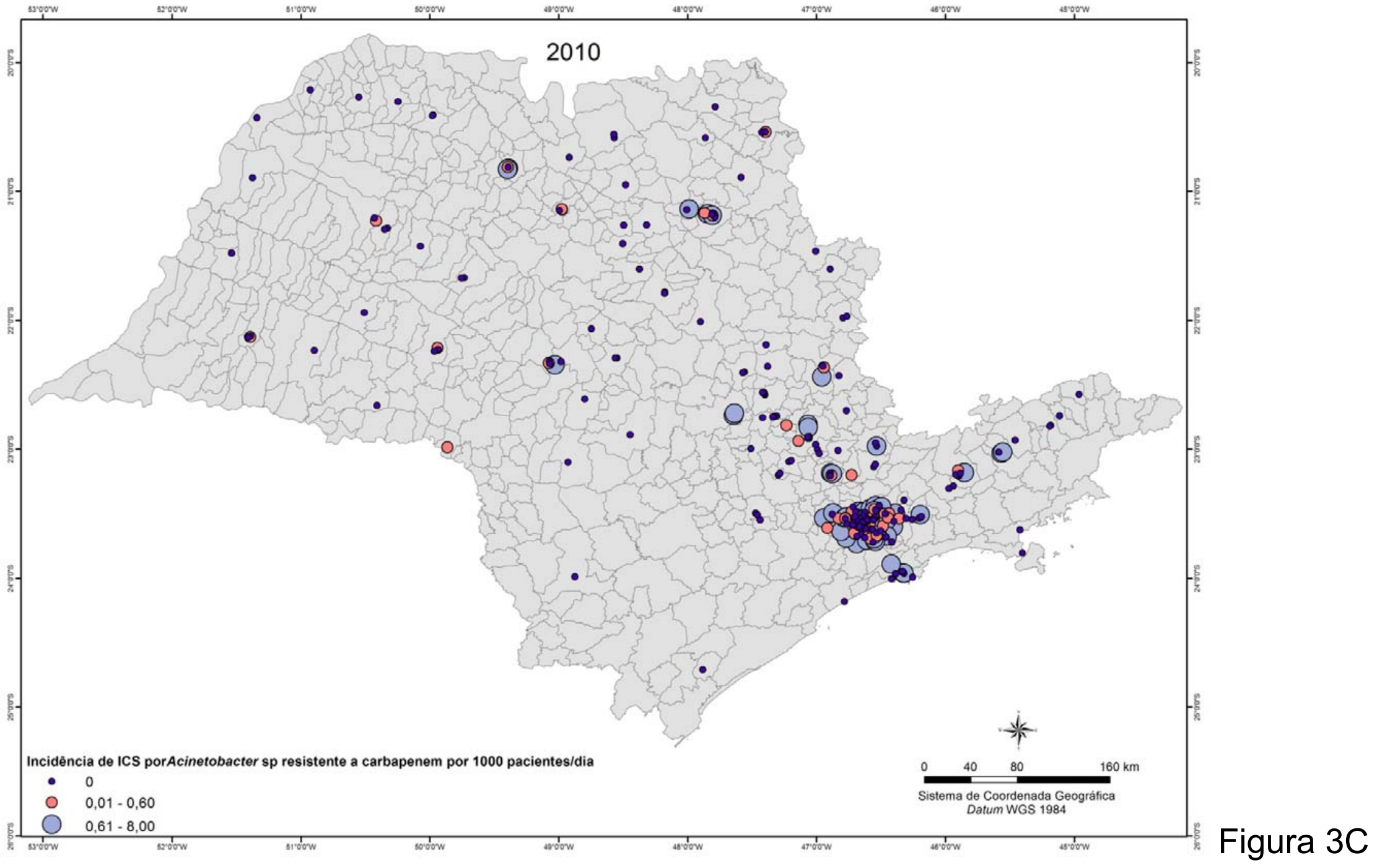




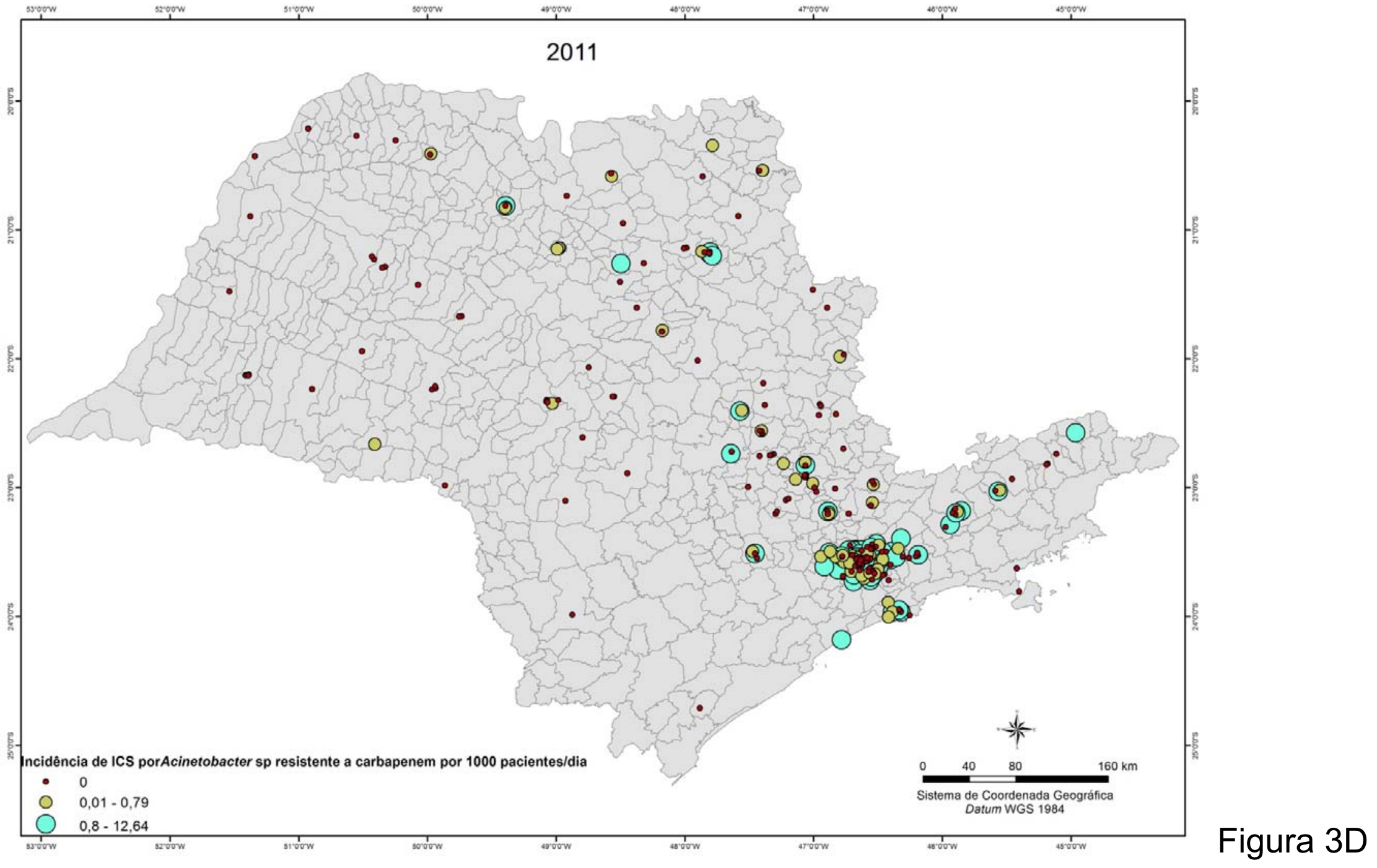




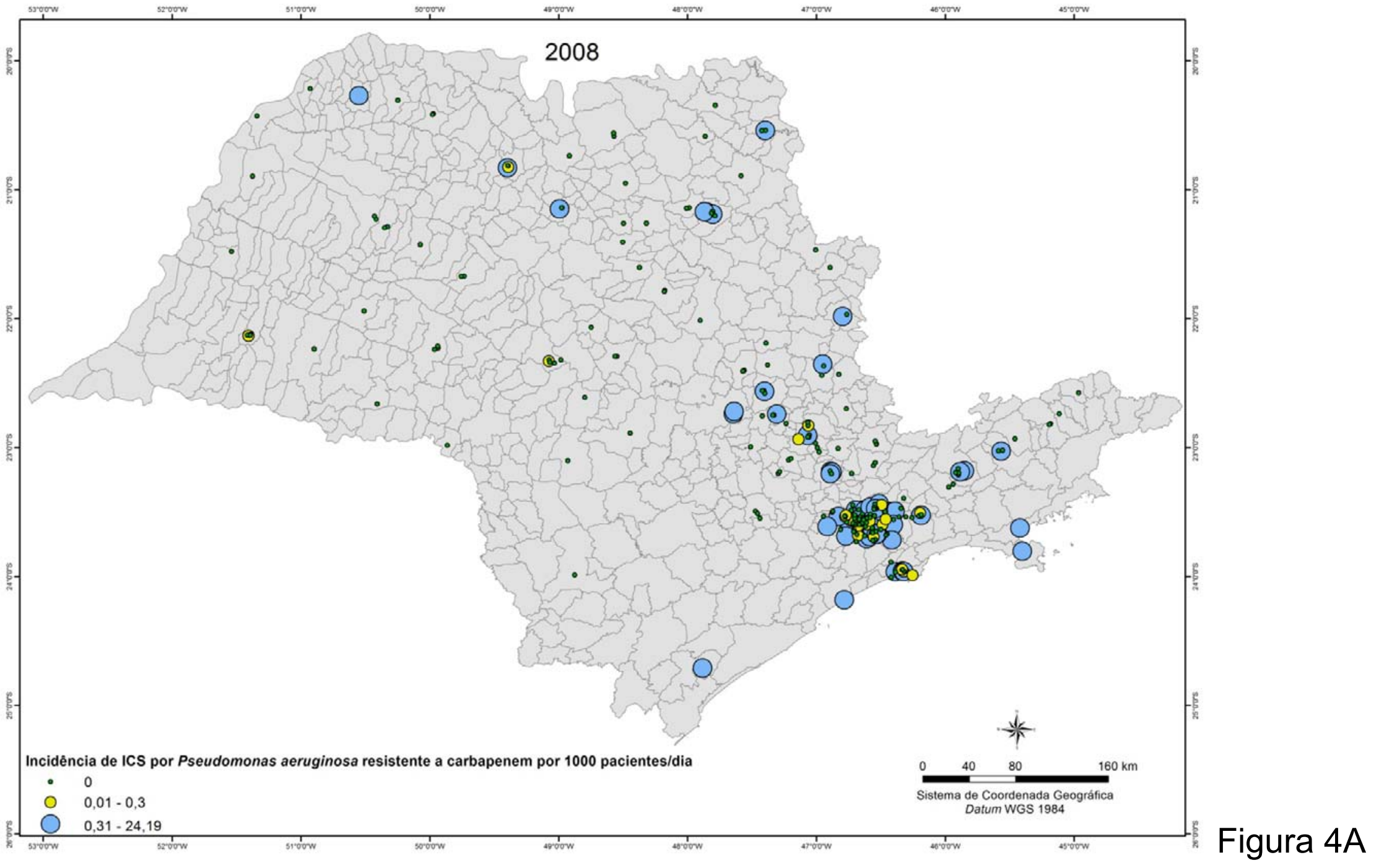




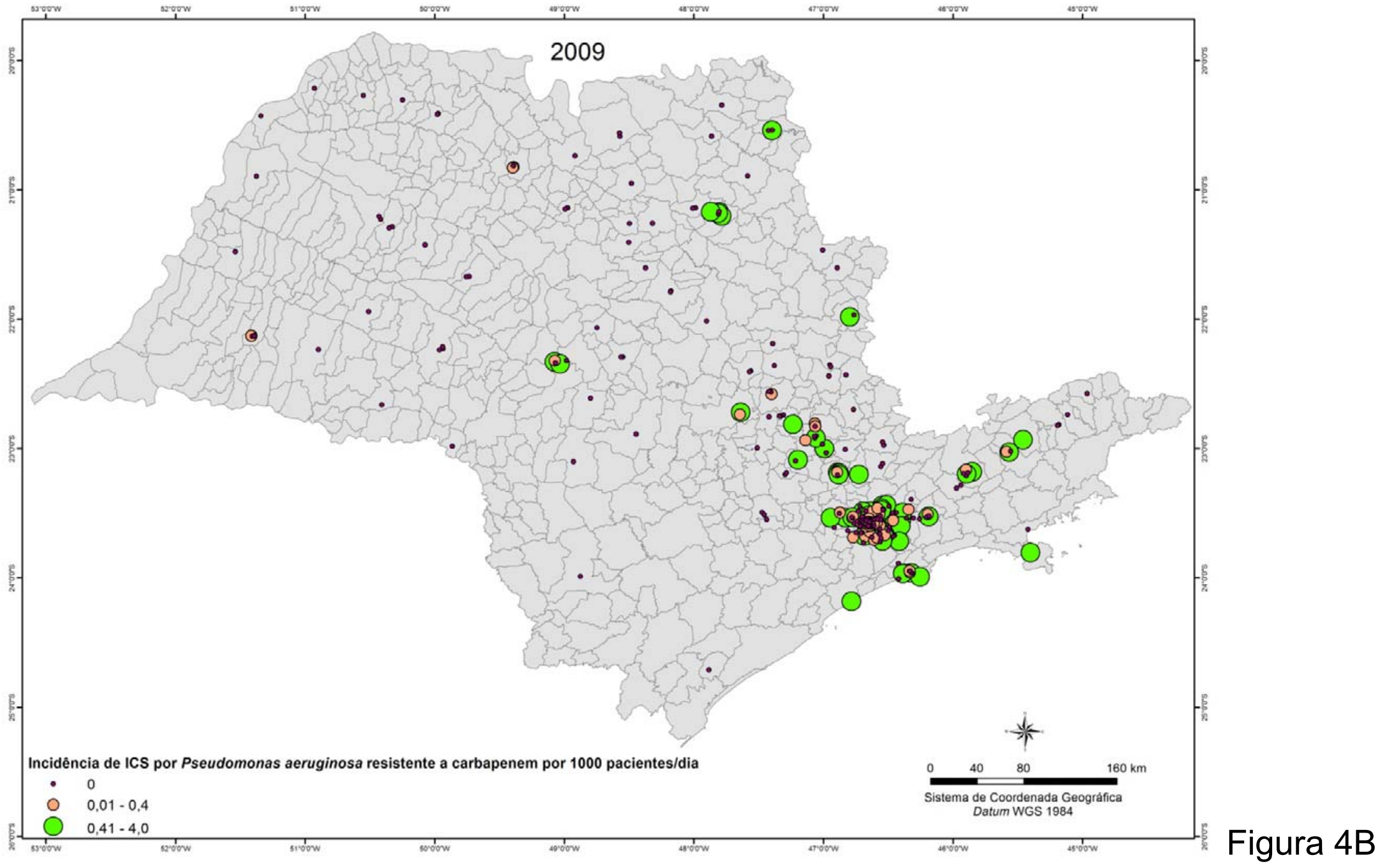




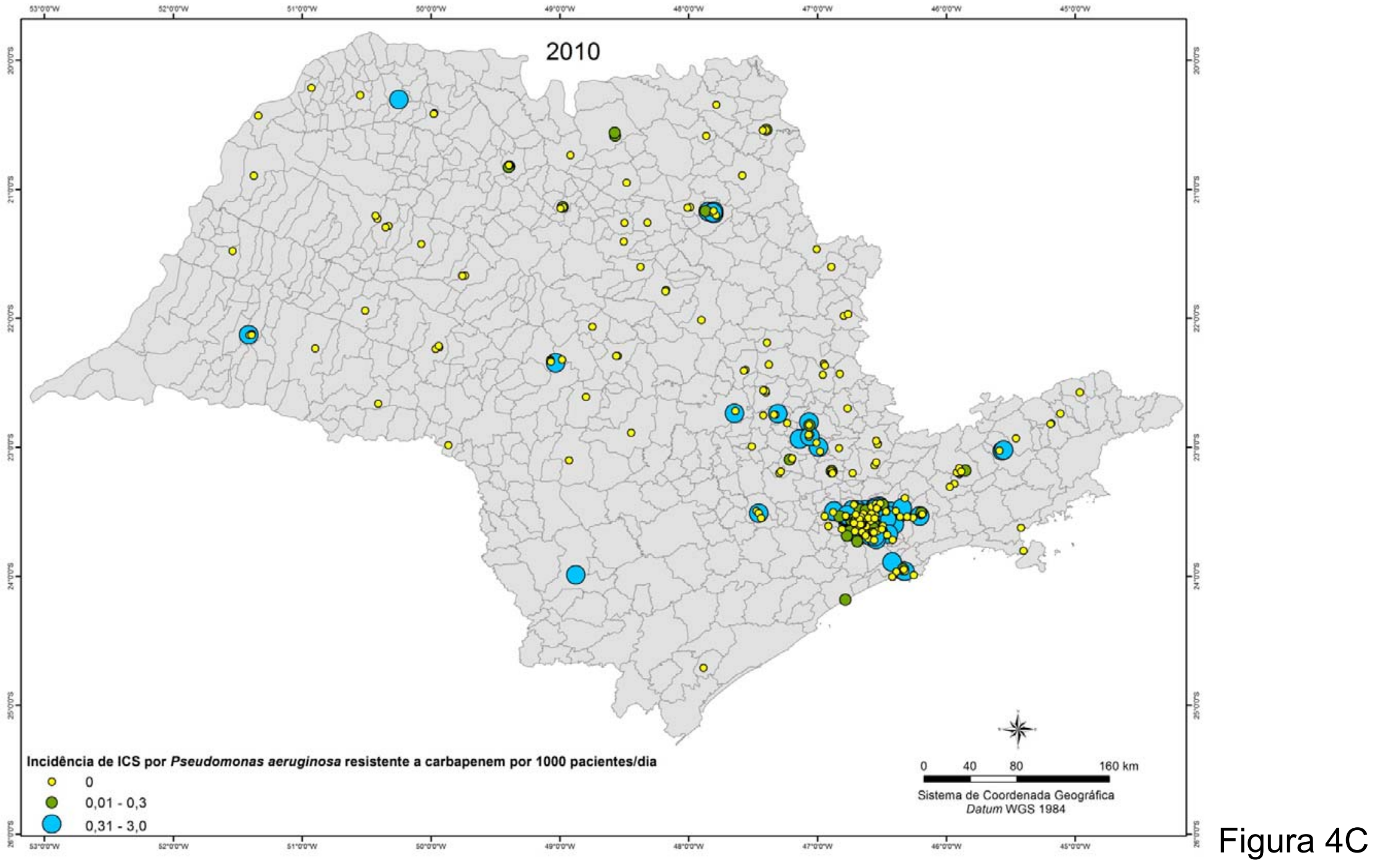




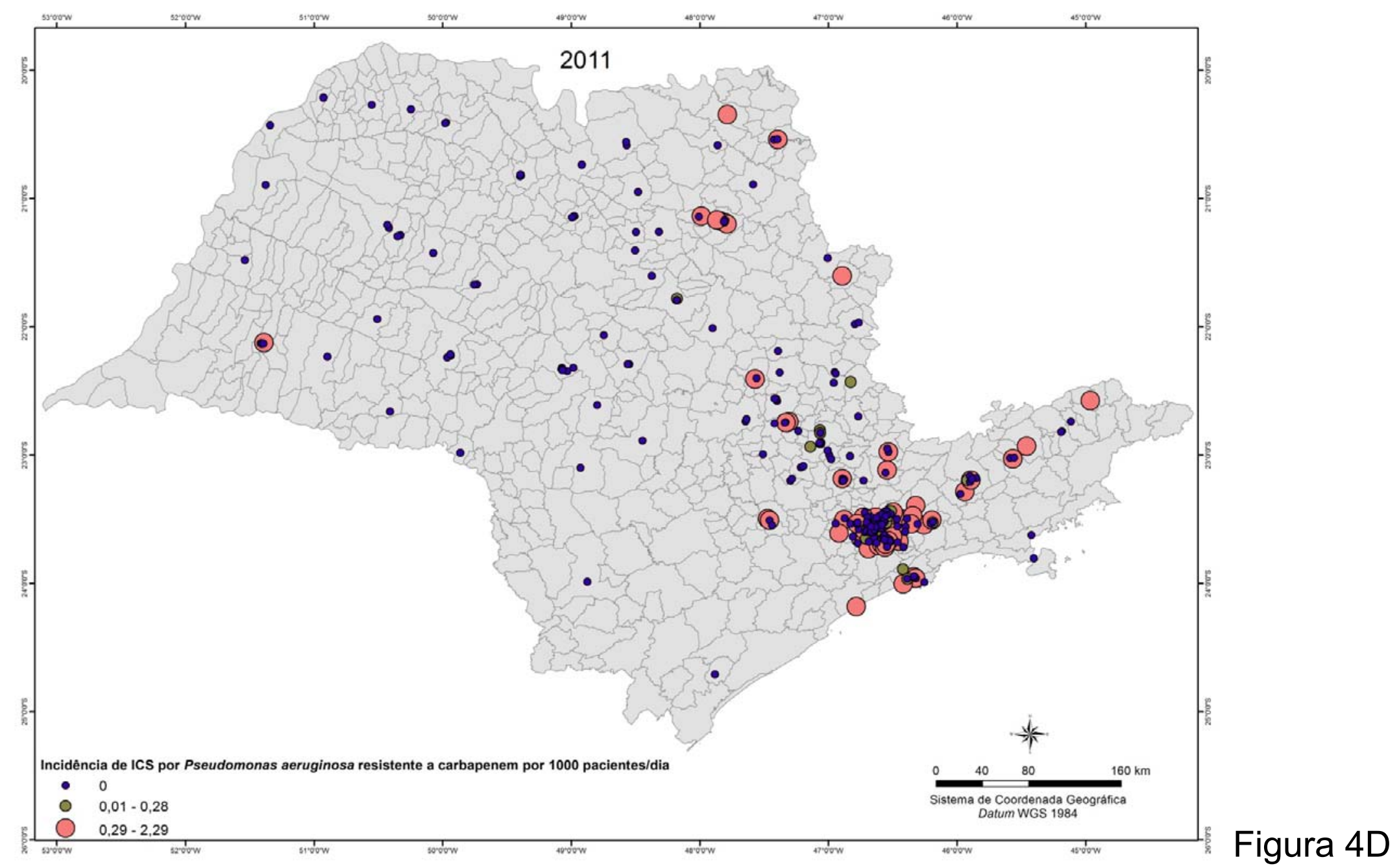




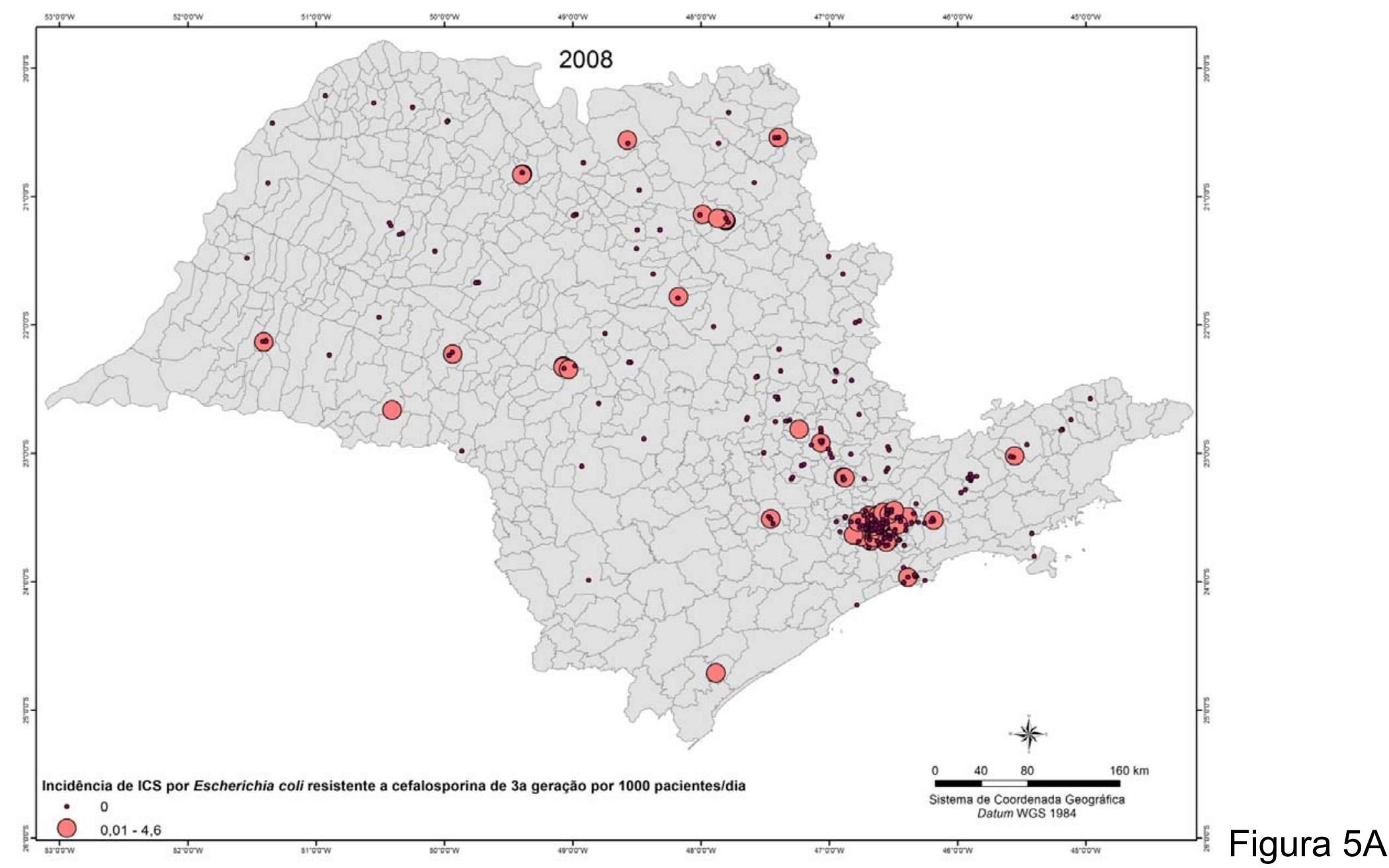




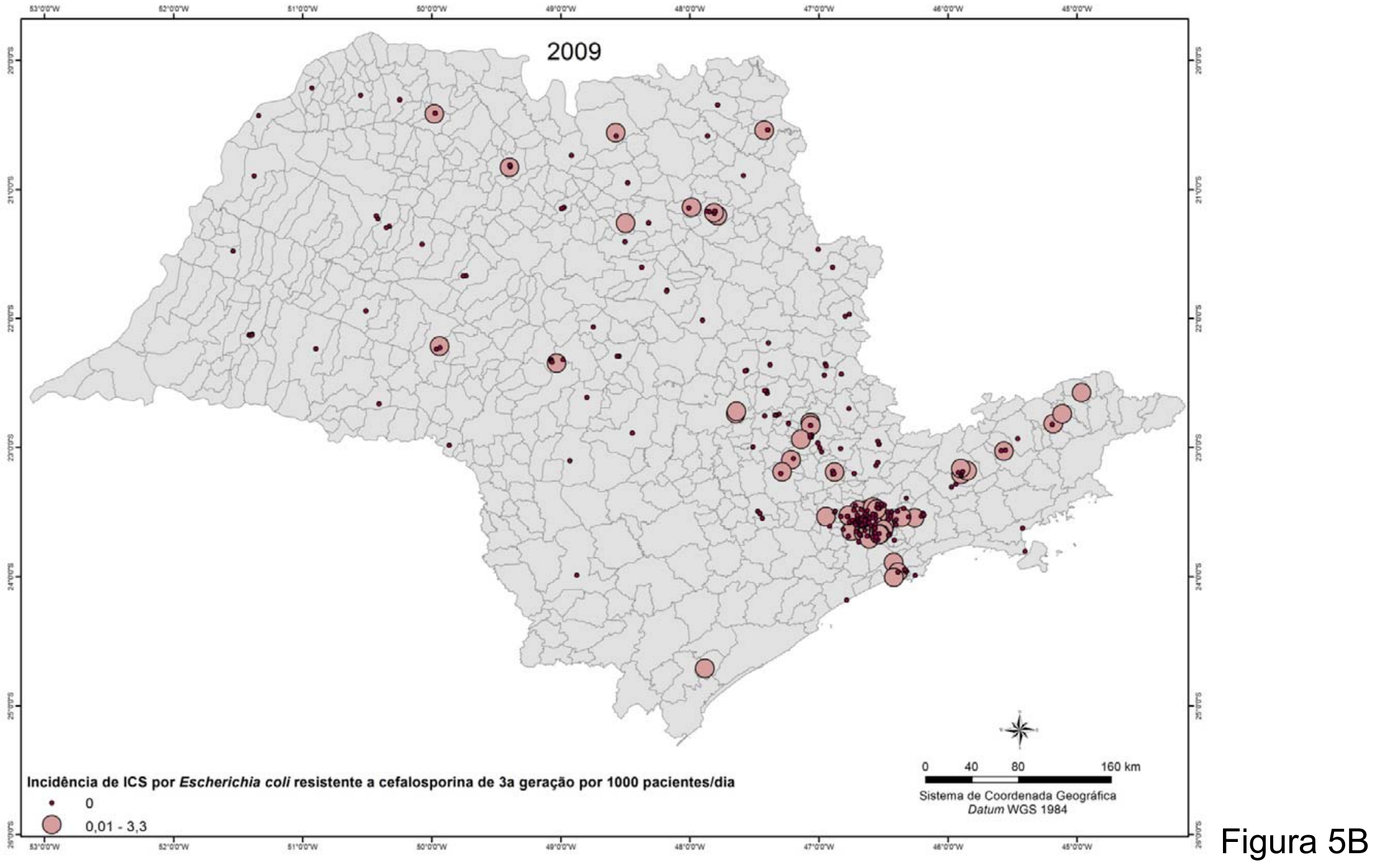




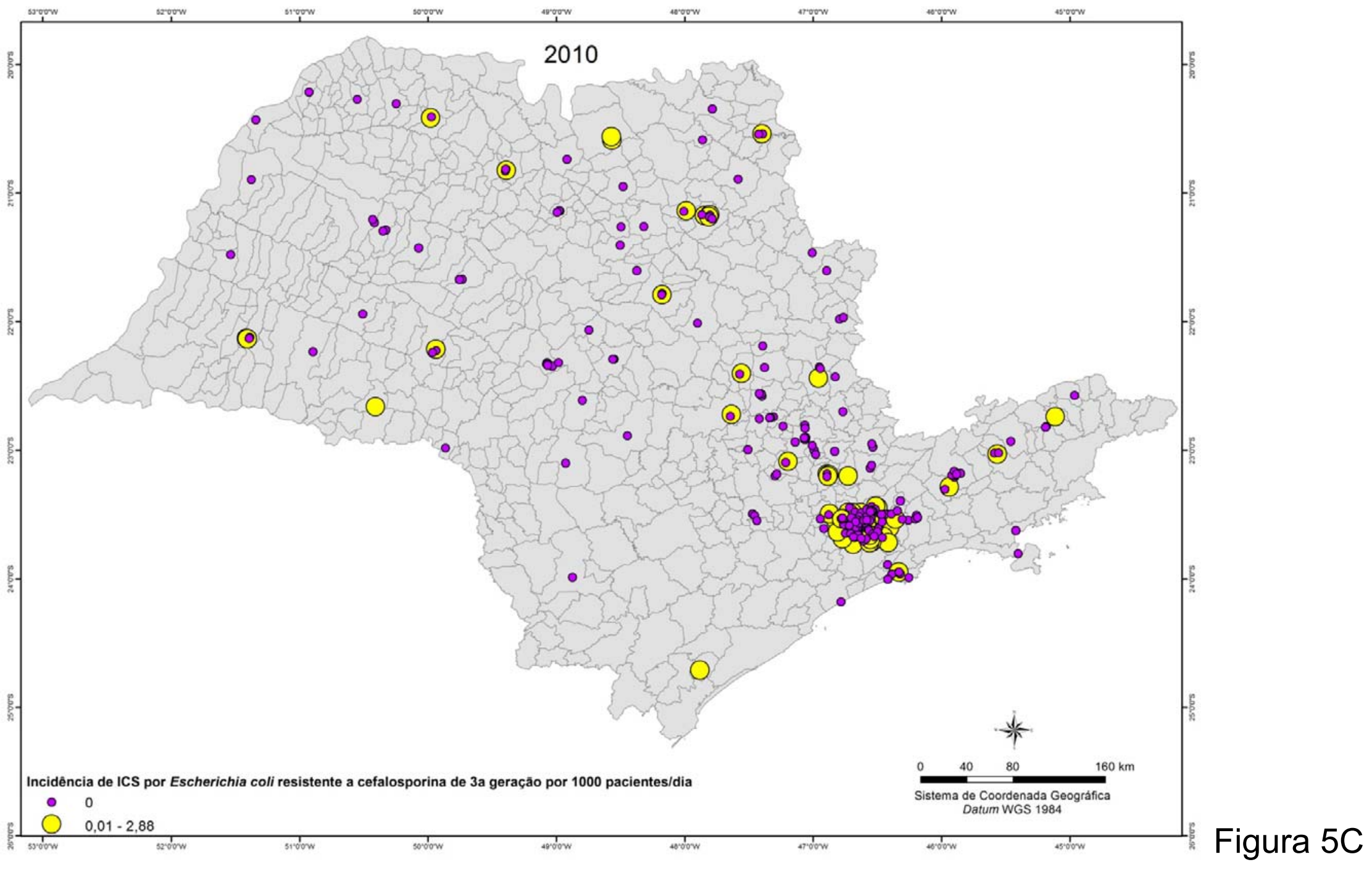




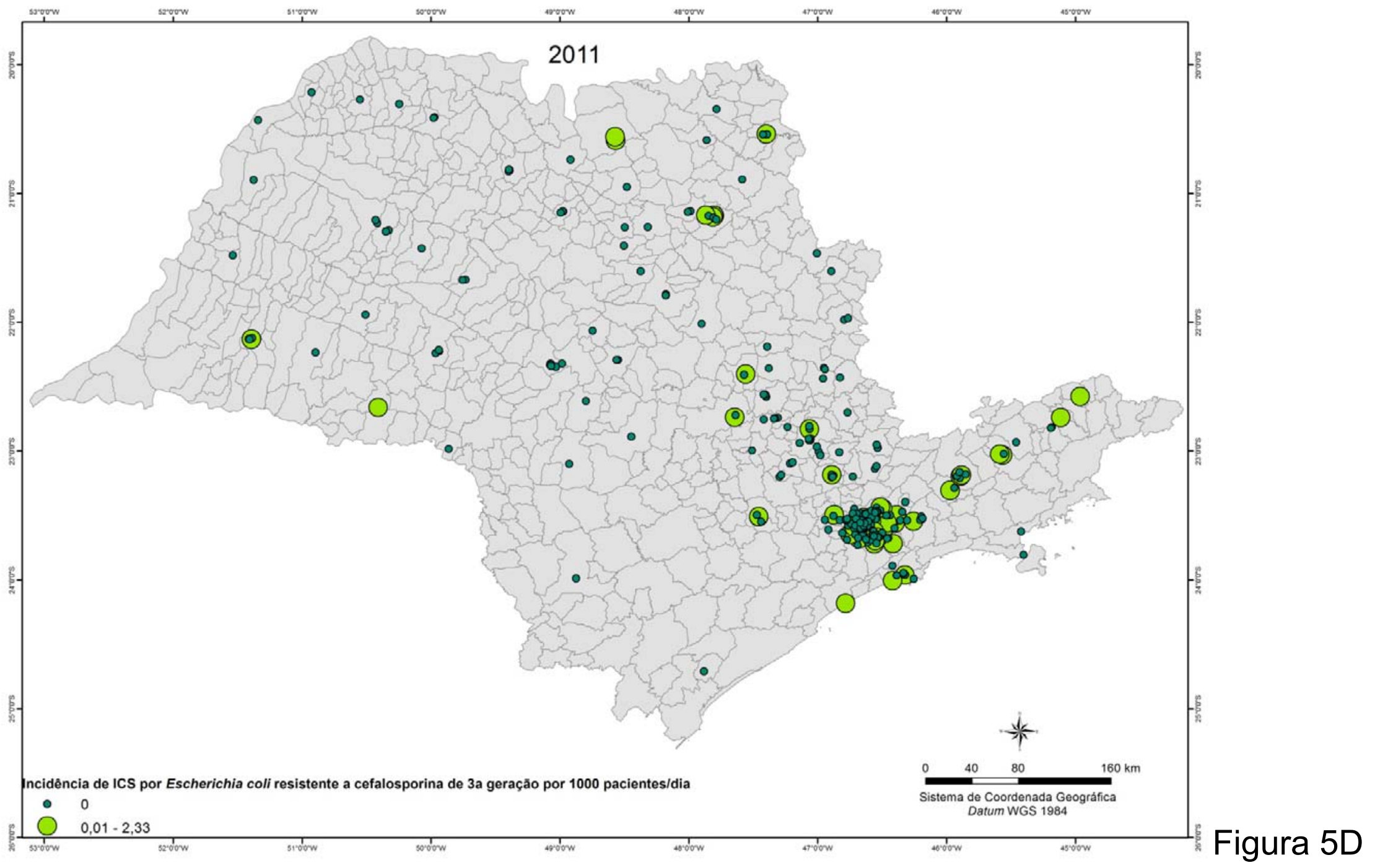




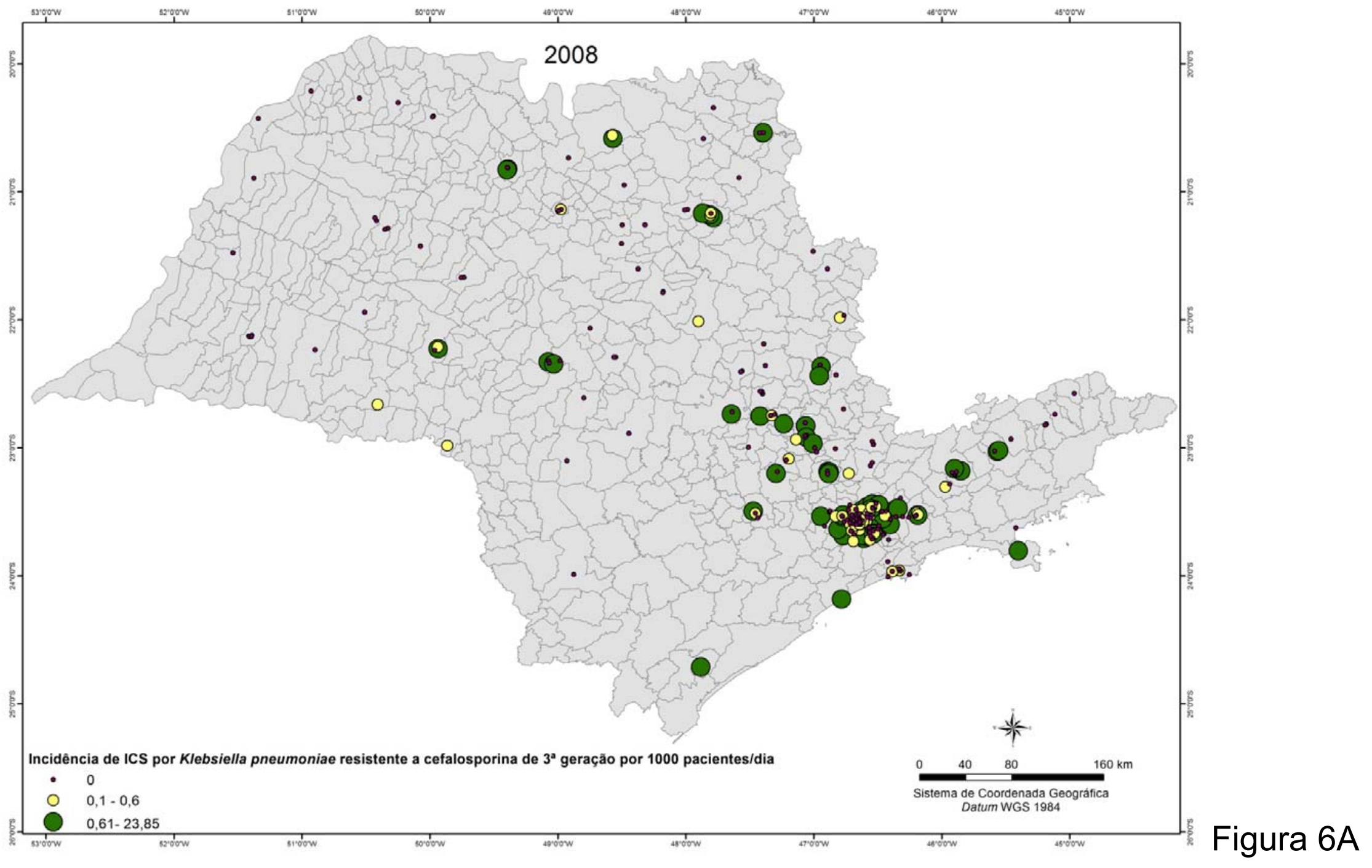




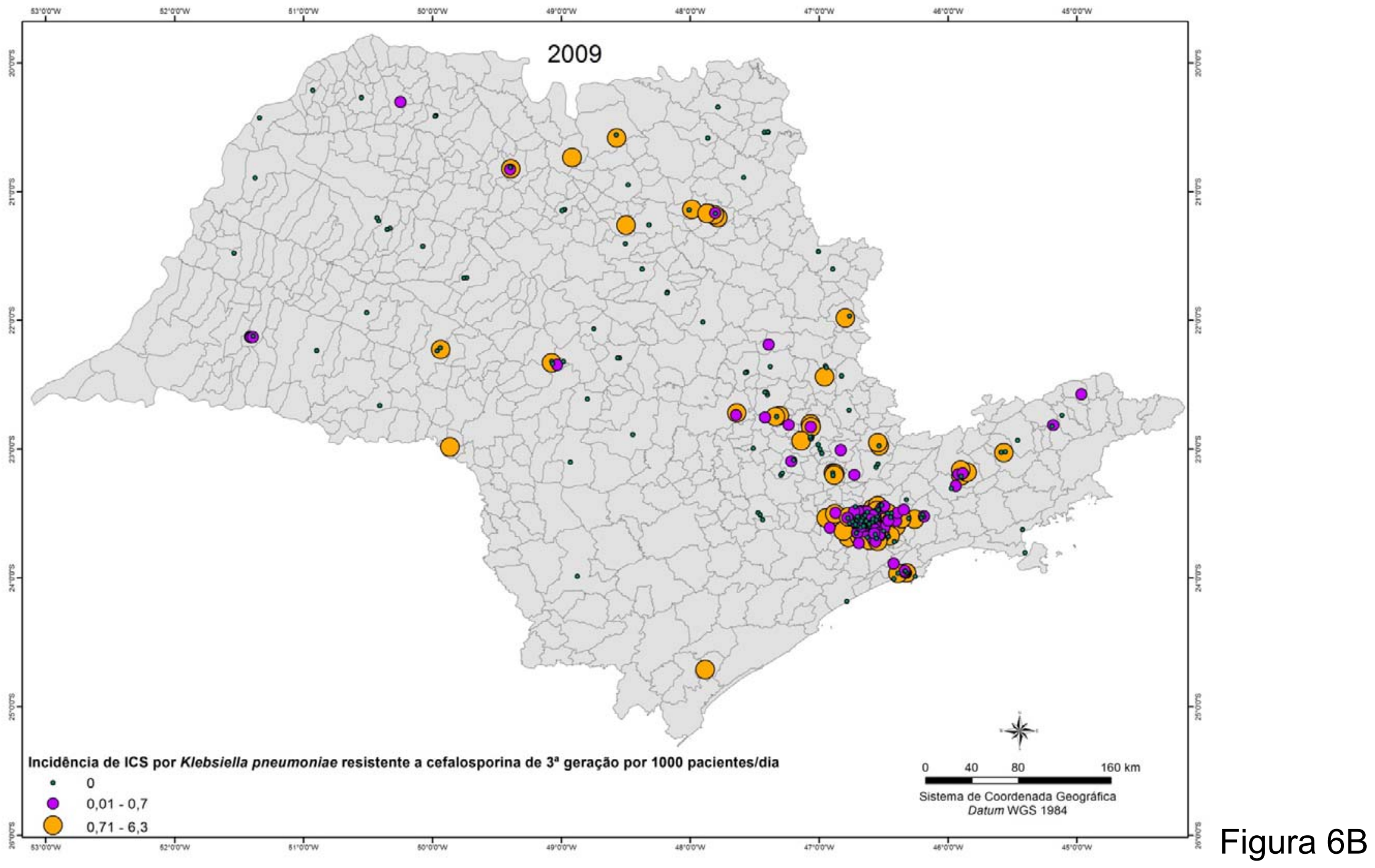




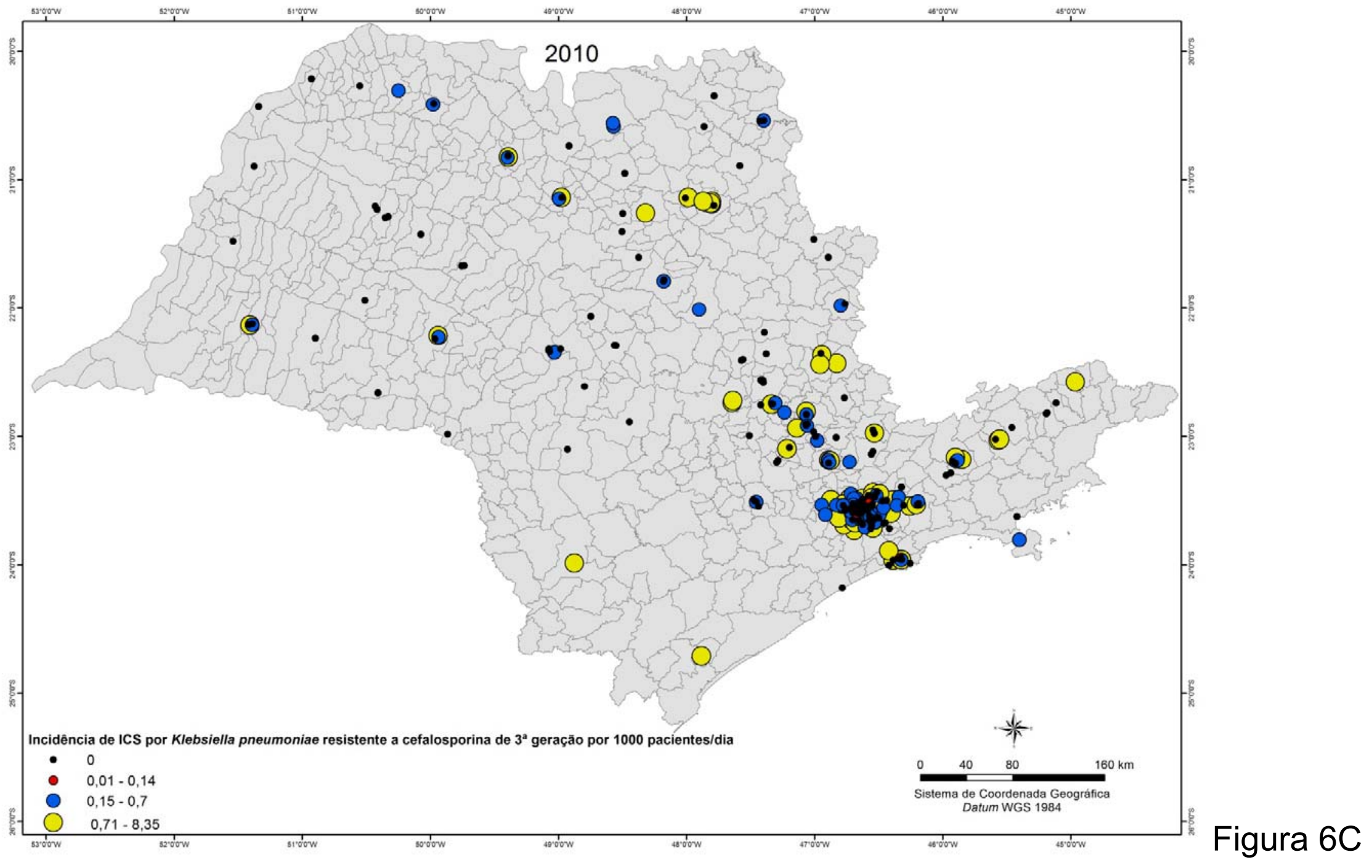




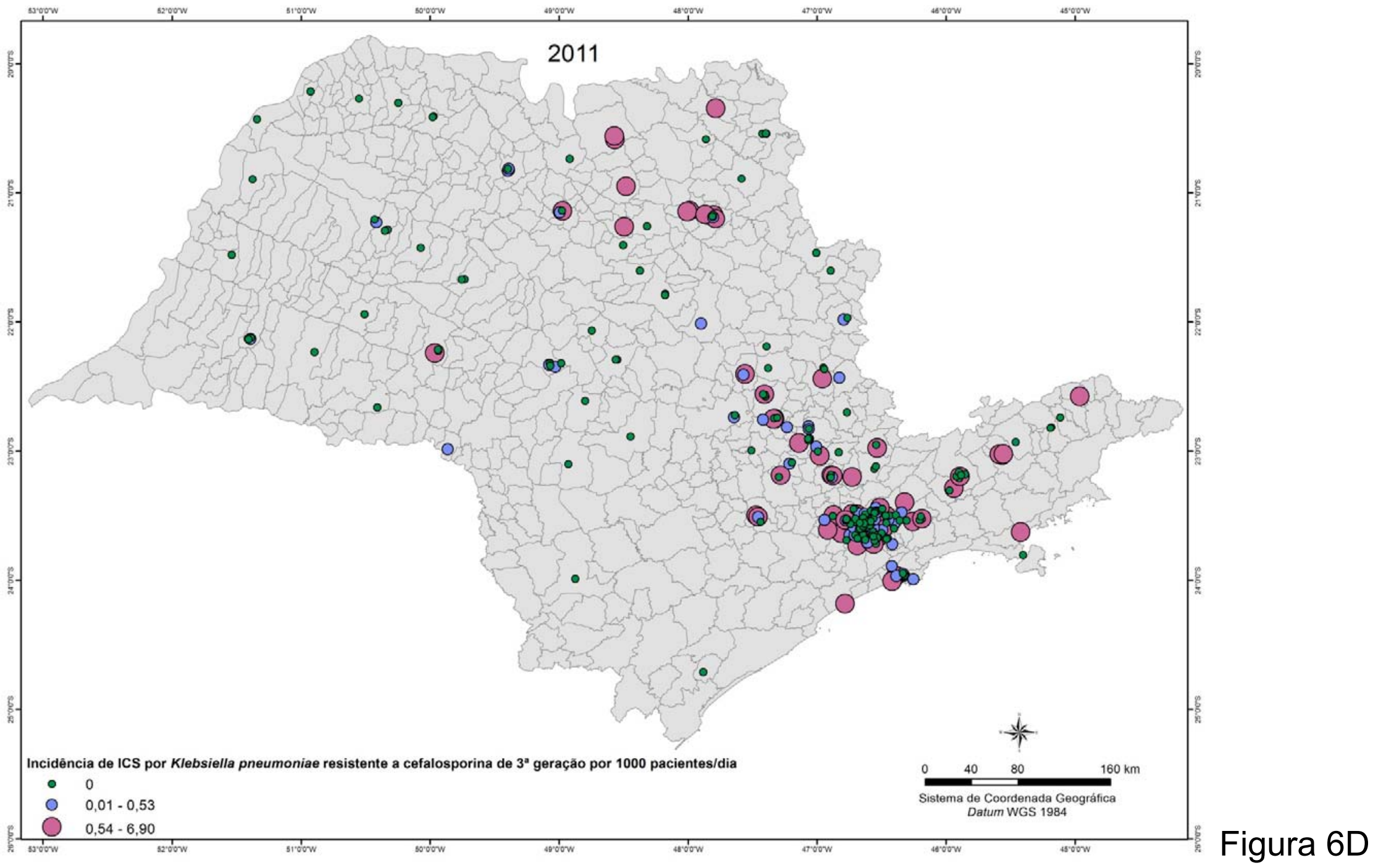




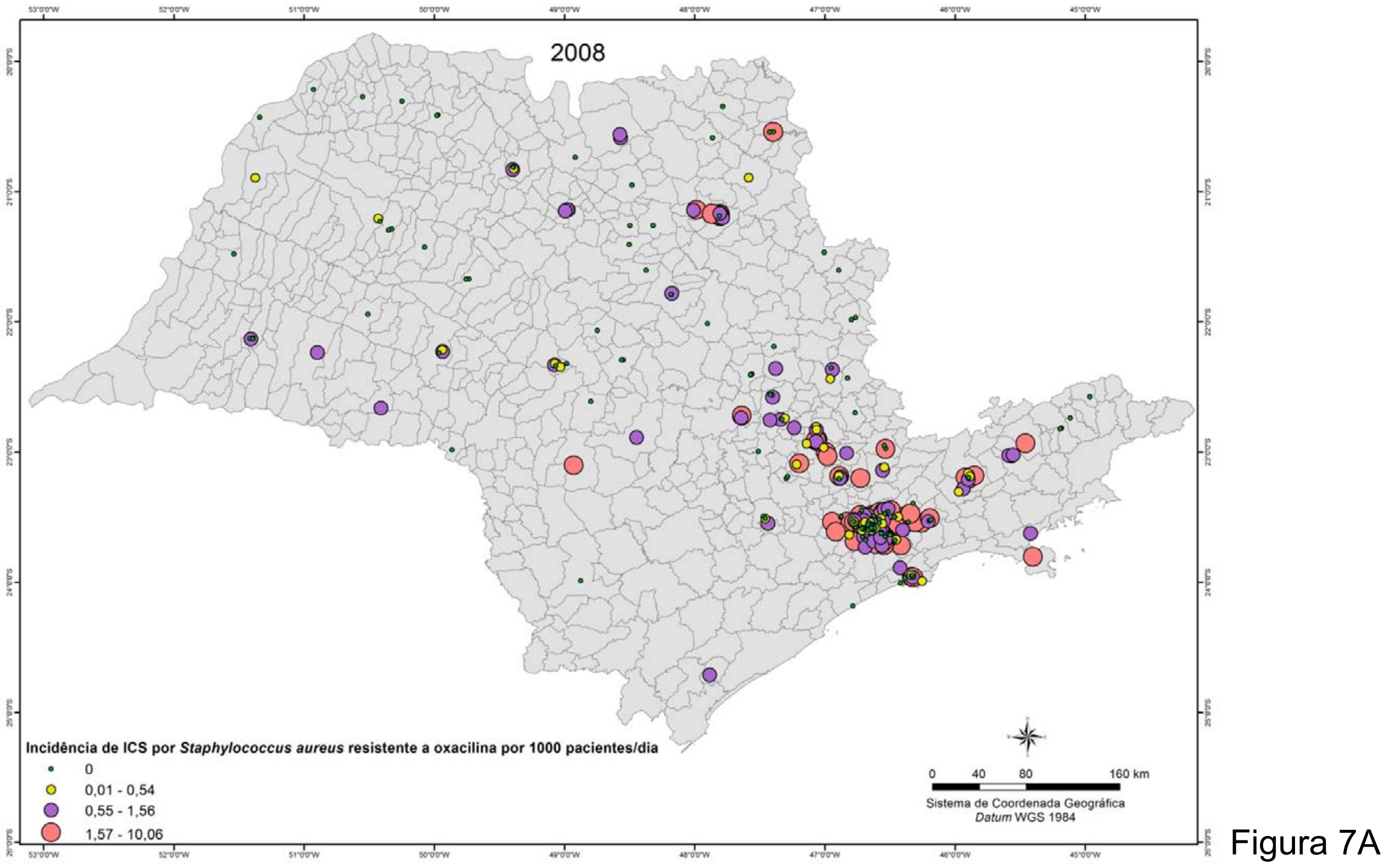




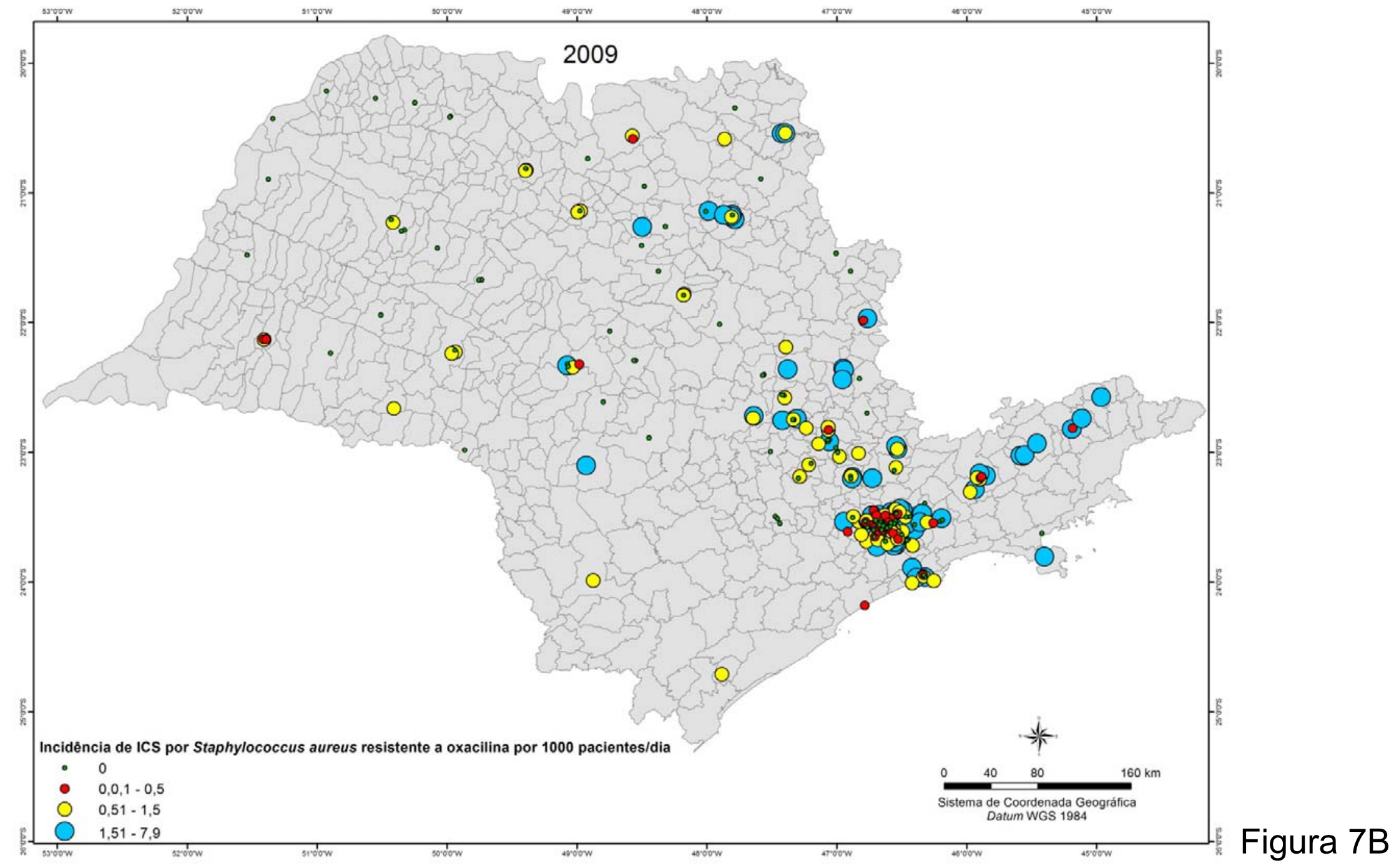




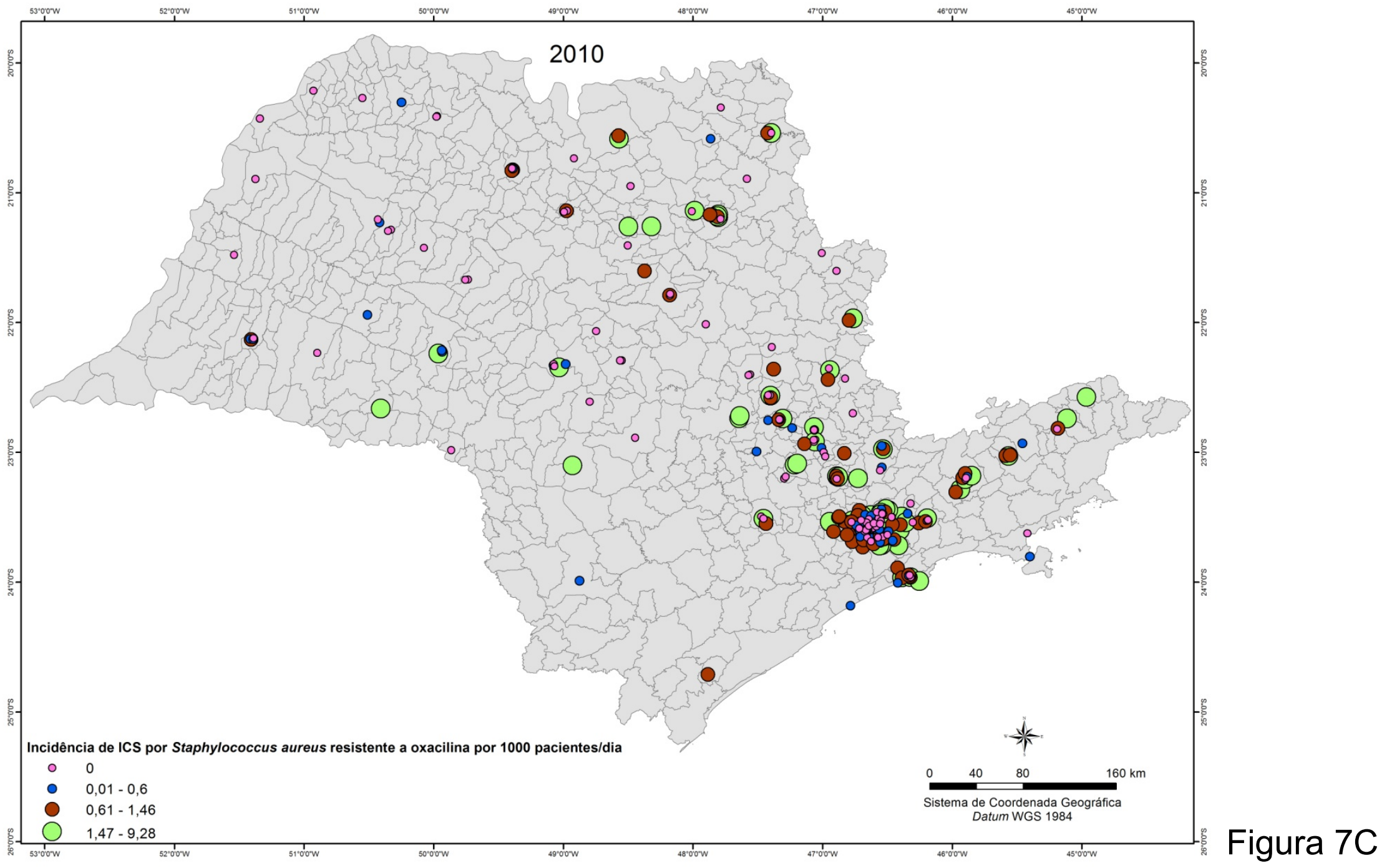




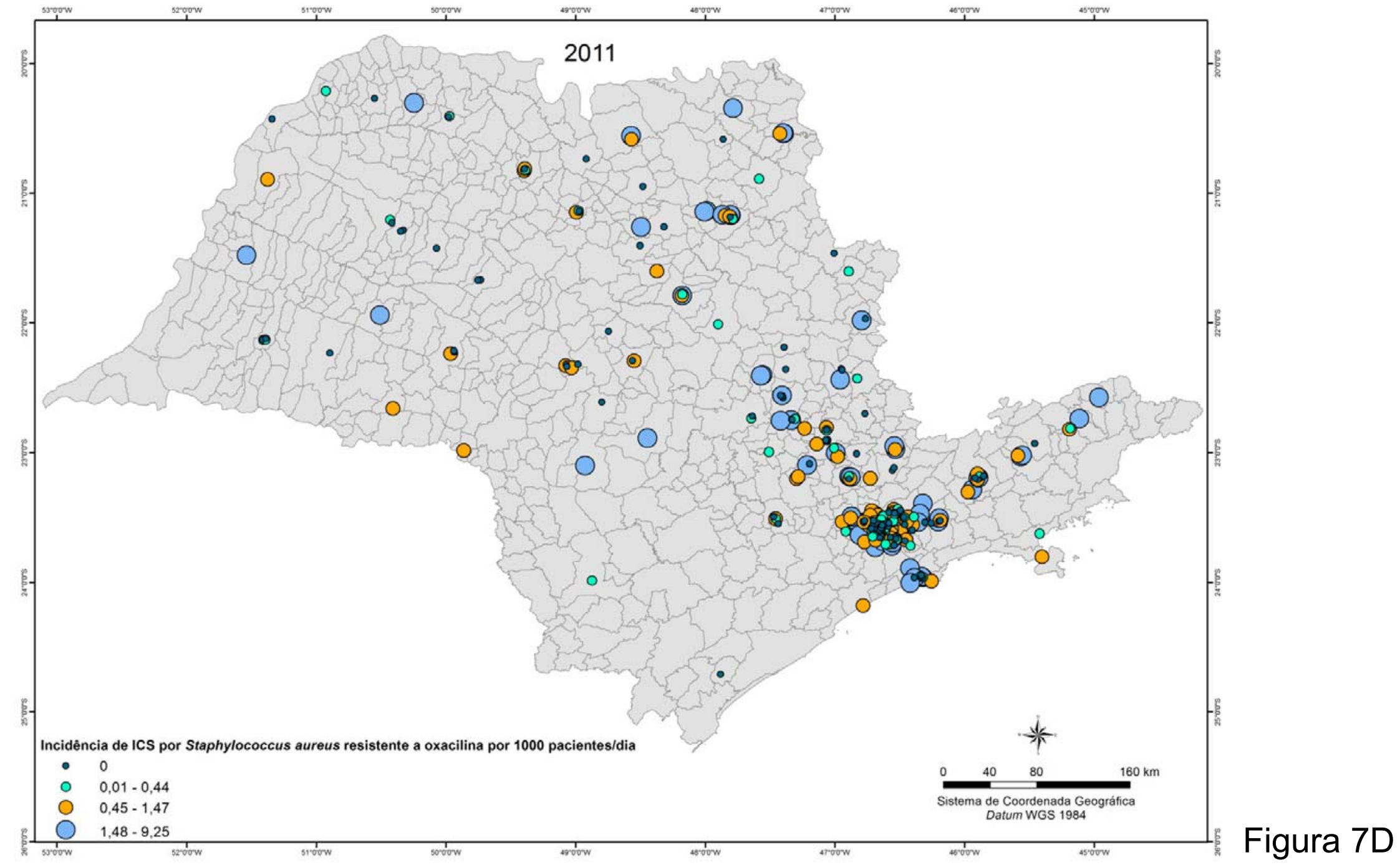




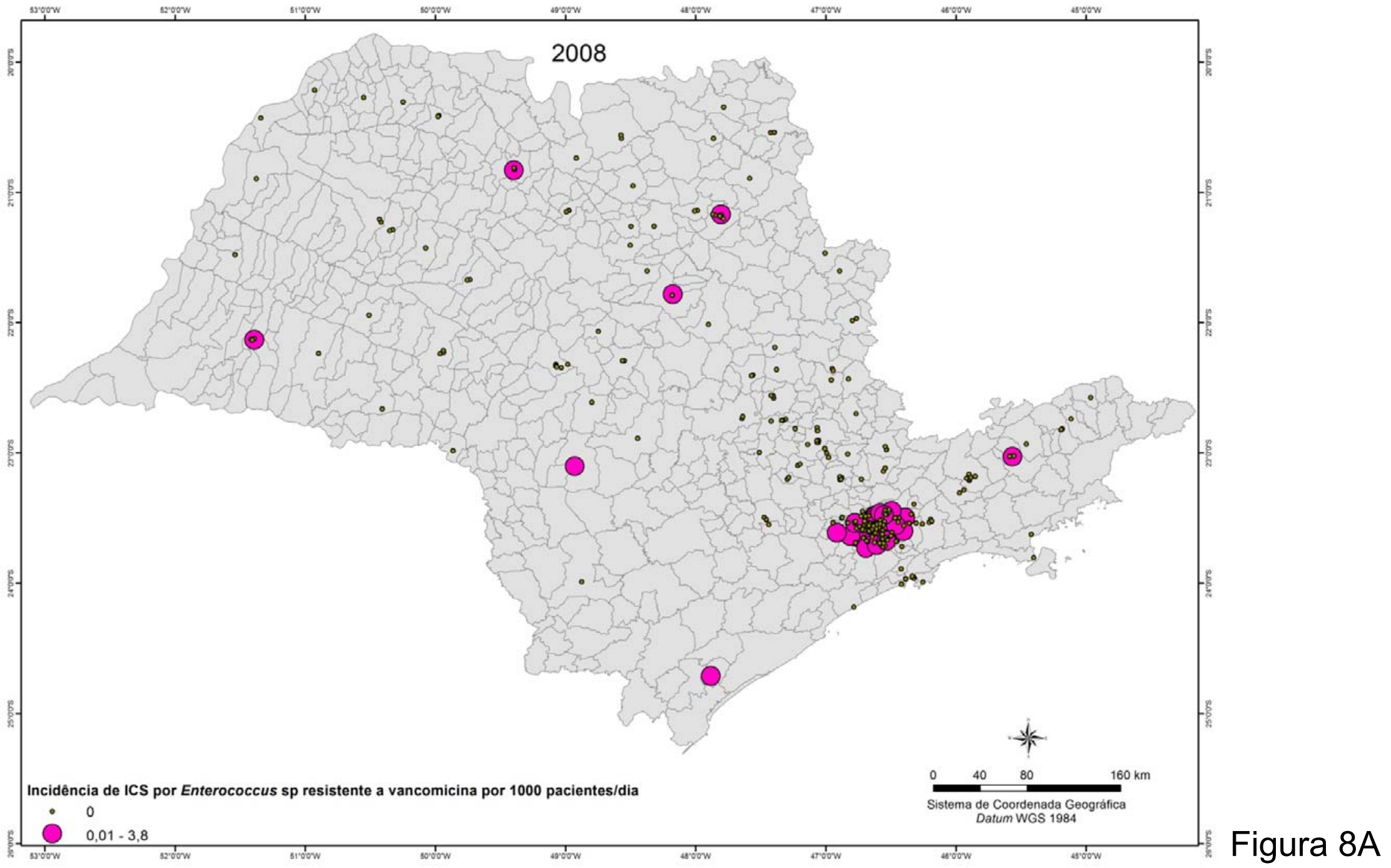




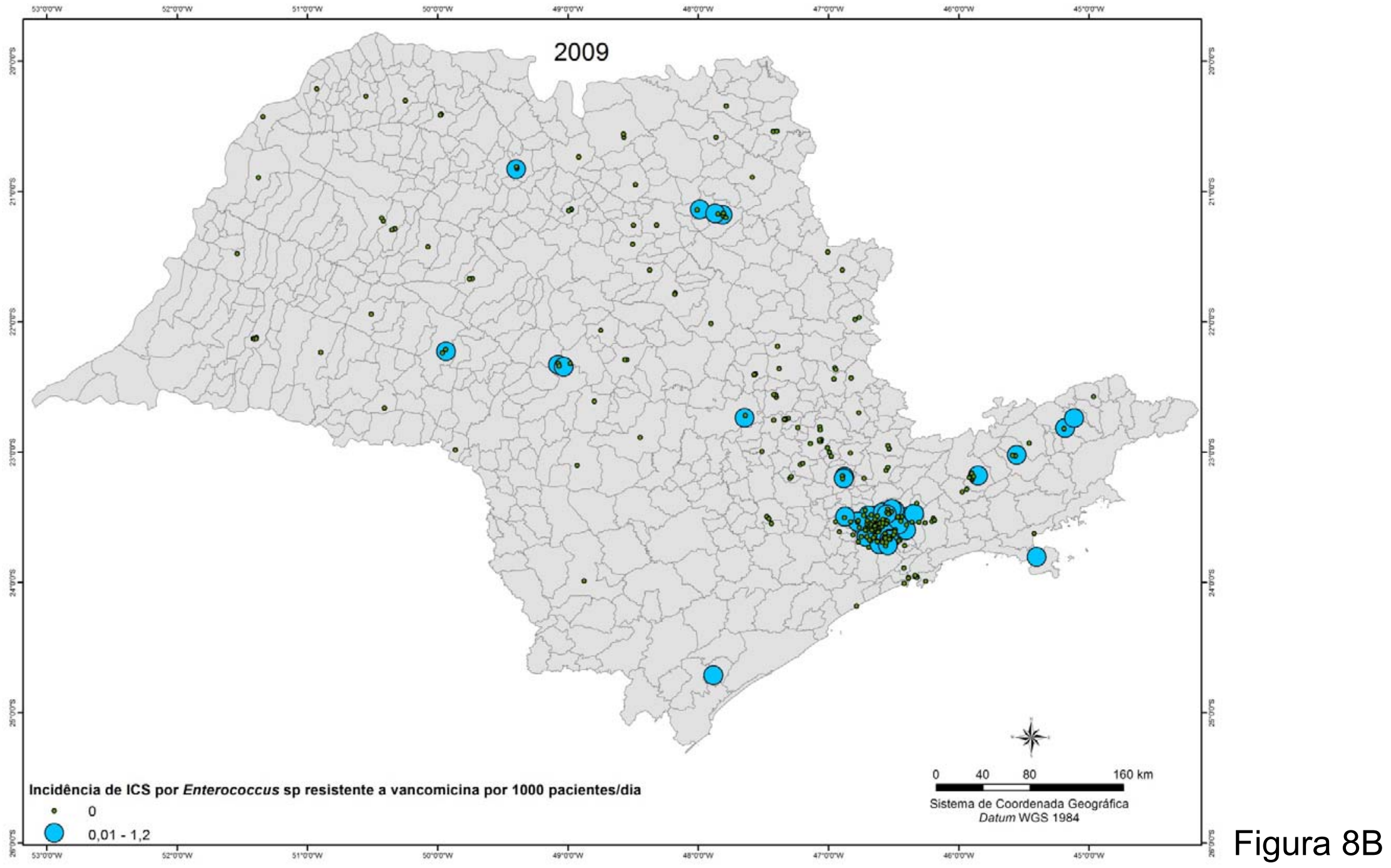




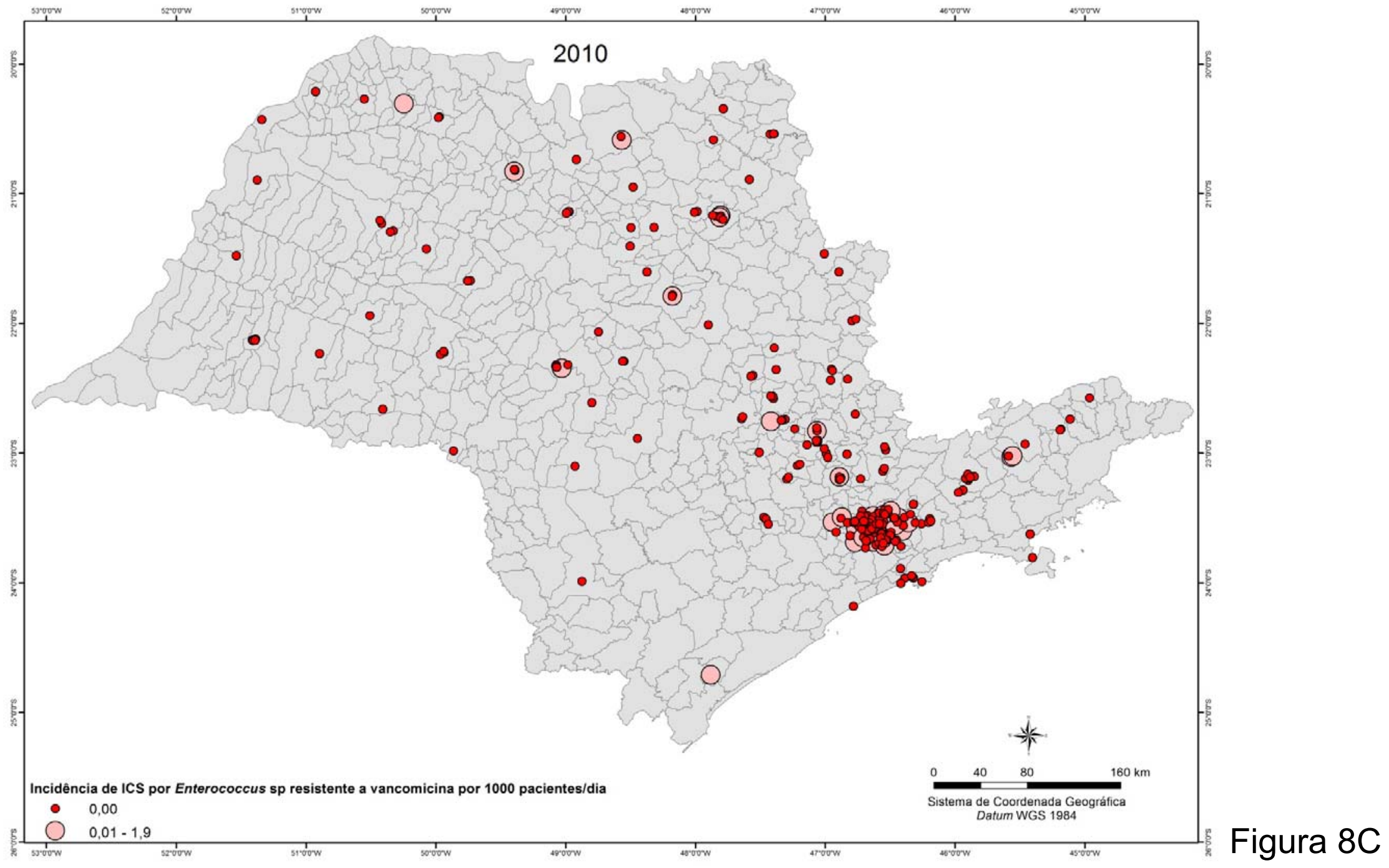




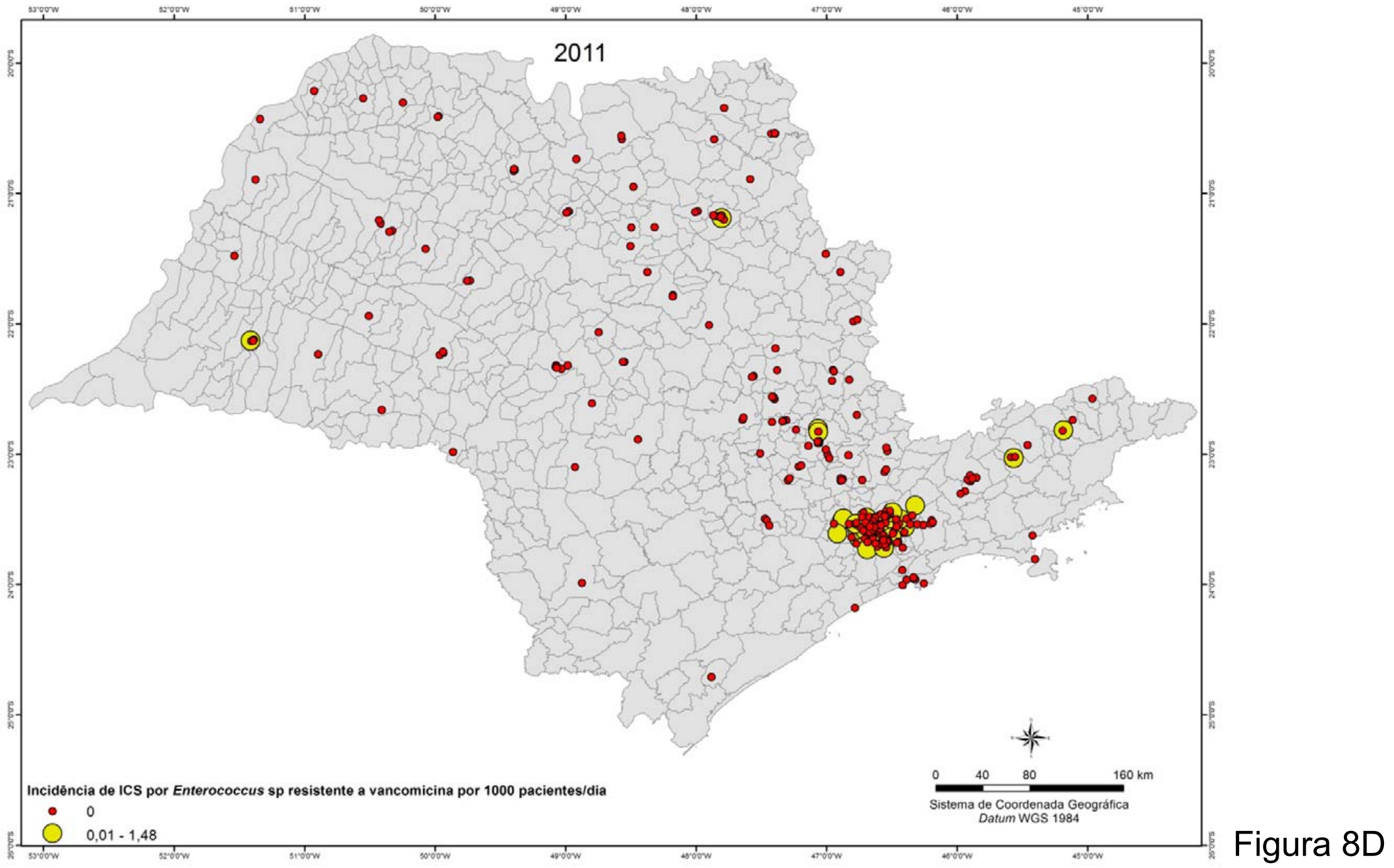


ANEXO 1 - Relação de hospitais participantes, município de localização, natureza administrativa, e número total de leitos e número de leitos de unidade de terapia intensiva

\begin{tabular}{|c|c|c|c|c|}
\hline Município & Hospital & $\begin{array}{l}\text { Natureza } \\
\text { Administrativa }\end{array}$ & $\begin{array}{c}\mathrm{N} \text { de } \\
\text { leitos } \\
\text { Total }\end{array}$ & $\begin{array}{c}\mathbf{N} \text { de } \\
\text { leitos } \\
\text { UTI }\end{array}$ \\
\hline Americana & Clínica São Lucas & Privado & 102 & 7 \\
\hline Americana & Hospital Municipal Waldemar Tebaldi & Público & 128 & 9 \\
\hline Americana & Hospital São Francisco (SCM) & Privado & 105 & 6 \\
\hline Americana & Hospital Unimed Americana & Privado & 131 & 9 \\
\hline Amparo & Santa Casa de Amparo & Santa Casa & 96 & 8 \\
\hline Andradina & Santa Casa de Andradina & Santa Casa & 100 & 7 \\
\hline Araçatuba & Hospital Unimed de Araçatuba & Privado & 89 & 8 \\
\hline Araçatuba & Santa Casa de Araçatuba & Santa Casa & 309 & 11 \\
\hline Araraquara & Beneficência Portuguesa de Araraquara & Privado & 150 & 10 \\
\hline Araraquara & Hospital São Paulo UNIMED Araraquara & Privado & 163 & 14 \\
\hline Araraquara & Santa Casa de Araraquara & Santa Casa & 151 & 7 \\
\hline Araras & Santa Casa de Araras & Santa Casa & 181 & 11 \\
\hline Arujá & Hospital Lions Clube (AMA) & Privado & 85 & 9 \\
\hline Assis & Hospital Regional de Assis & Público & 131 & 10 \\
\hline Atibaia & Hospital e Maternidade Albert Sabin & Privado & 80 & 8 \\
\hline Atibaia & Hospital Novo Atibaia & Privado & 95 & 8 \\
\hline Avaré & Santa Casa de Avaré & Santa Casa & 168 & 11 \\
\hline Bariri & Santa Casa de Bariri & Santa Casa & 74 & 5 \\
\hline Barretos & Hospital Pio XII - Hospital de Câncer & Filantrópico & 196 & 20 \\
\hline Barretos & Santa Casa de Barretos & Santa Casa & 370 & 12 \\
\hline Barueri & Hospital Hospitais & Privado & 94 & 13 \\
\hline Barueri & Hospital Municipal de Barueri & Público & 300 & 20 \\
\hline Batatais & Santa Casa de Batatais & Santa Casa & 153 & 8 \\
\hline Bauru & Beneficência Portuguesa & Privado & 50 & 12 \\
\hline Bauru & Hospital de Base & Filantrópico & 181 & 24 \\
\hline Bauru & Hospital Estadual de Bauru & Público & 318 & 11 \\
\hline Bauru & Hospital São Lucas & Privado & 24 & 7 \\
\hline Bauru & Unimed Bauru & Privado & 144 & 16 \\
\hline Bebedouro & Hospital Samaritano (UNIMED) & Privado & 50 & 6 \\
\hline Birigui & Santa Casa de Birigui & Santa Casa & 115 & 7 \\
\hline Birigui & Hospital Unimed Birigui & Privado & 36 & 5 \\
\hline Botucatu & Hospital Misericórdia Botucatuense & Privado & 81 & 11 \\
\hline Bragança Paulista & Hospital Universitário Bragança Paulista & Filantrópico & 159 & 10 \\
\hline
\end{tabular}


ANEXO 1 - Relação de hospitais participantes (continuação)

\begin{tabular}{|c|c|c|c|c|}
\hline Município & Hospital & $\begin{array}{l}\text { Natureza } \\
\text { Administrativa }\end{array}$ & $\begin{array}{l}\mathrm{N} \text { de } \\
\text { leitos } \\
\text { Total }\end{array}$ & $\begin{array}{c}\mathbf{N} \text { de } \\
\text { leitos } \\
\text { UTI }\end{array}$ \\
\hline Bragança Paulista & Santa Casa de Bragança Paulista & Santa Casa & 127 & 8 \\
\hline Campinas & CAISM-UNICAMP & Público & 126 & 26 \\
\hline Campinas & Centro do Coração & Privado & 26 & 8 \\
\hline Campinas & Centro Médico de Campinas & Filantrópico & 190 & 18 \\
\hline Campinas & HC - UNICAMP & Público & 378 & 24 \\
\hline Campinas & $\begin{array}{l}\text { Hospital e Maternidade } \\
\text { Celso Pierro - PUCC }\end{array}$ & Filantrópico & 350 & 19 \\
\hline Campinas & Hospital Samaritano de Campinas & Filantrópico & 147 & 15 \\
\hline Campinas & Hospital Municipal Dr Mario Gatti & Público & 197 & 14 \\
\hline Campinas & $\begin{array}{l}\text { ICC Hospital e Pronto } \\
\text { Socorro do Coração }\end{array}$ & Privado & 37 & 10 \\
\hline Capivari & Santa Casa de Capivari & Santa Casa & 101 & 7 \\
\hline Caraguatatuba & Casa de Saúde Stella Maris & Filantrópico & 124 & 7 \\
\hline Carapicuíba & Hospital Geral de Carapicuíba & Público & 245 & 10 \\
\hline Catanduva & Hospital Emílio Carlos & Filantrópico & 145 & 10 \\
\hline Catanduva & Hospital Padre Albino & Filantrópico & 209 & 10 \\
\hline Catanduva & $\begin{array}{l}\text { Hospital UNIMED } \\
\text { Catanduva (São Domingos) }\end{array}$ & Privado & 110 & 10 \\
\hline Cotia & Hospital Regional de Cotia & Público & 175 & 10 \\
\hline Cruzeiro & Santa Casa de Cruzeiro & Santa Casa & 158 & 10 \\
\hline Cubatão & $\begin{array}{l}\text { Hospital Dr. Luiz Camargo } \\
\text { da Fonseca e Silva }\end{array}$ & Público & 163 & 7 \\
\hline Diadema & Hospital Estadual de Diadema & Público & 266 & 18 \\
\hline Diadema & Hospital Municipal de Diadema & Público & 256 & 11 \\
\hline Diadema & Hospital São Lucas Diadema & Privado & 95 & 12 \\
\hline Dracena & Santa Casa de Dracena & Santa Casa & 153 & 10 \\
\hline Fernandópolis & Santa Casa de Fernandópolis & Santa Casa & 158 & 11 \\
\hline $\begin{array}{l}\text { Ferraz de } \\
\text { Vasconcelos }\end{array}$ & $\begin{array}{l}\text { Hospital Regional Dr Osíris } \\
\text { Florindo Coelho }\end{array}$ & Público & 239 & 10 \\
\hline Franca & Hospital Regional de Franca SA & Privado & 98 & 11 \\
\hline Franca & Hospital São Joaquim (UNIMED) & Privado & 114 & 10 \\
\hline Franca & Santa Casa de Franca & Santa Casa & 306 & 17 \\
\hline Francisco Morato & Hospital Prof. Carlos da Silva Lacaz & Público & 109 & 10 \\
\hline Guaratinguetá & Hospital Maternidade Frei Galvão & Filantrópico & 156 & 15 \\
\hline Guaratinguetá & Santa Casa de Guaratinguetá & Santa Casa & 200 & 8 \\
\hline Guarujá & Hospital Santo Amaro & Filantrópico & 384 & 20 \\
\hline
\end{tabular}


ANEXO 1 - Relação de hospitais participantes (continuação)

\begin{tabular}{|c|c|c|c|c|}
\hline Município & Hospital & $\begin{array}{l}\text { Natureza } \\
\text { Administrativa }\end{array}$ & $\begin{array}{l}\mathrm{N} \text { de } \\
\text { leitos } \\
\text { Total }\end{array}$ & $\begin{array}{l}\mathrm{N} \text { de } \\
\text { leitos } \\
\text { UTI }\end{array}$ \\
\hline Guarulhos & Casas André Luiz & Filantrópico & 630 & 10 \\
\hline Guarulhos & Hospital Bom Clima & Privado & 133 & 13 \\
\hline Guarulhos & Hospital Carlos Chagas & Privado & 241 & 20 \\
\hline Guarulhos & $\begin{array}{l}\text { Hospital e Maternidade } \\
\text { Guarulhos }\end{array}$ & Privado & 104 & 10 \\
\hline Guarulhos & Hospital Geral de Guarulhos & Público & 306 & 18 \\
\hline Guarulhos & Hospital Municipal de Urgências & Público & 100 & 8 \\
\hline Guarulhos & Hospital Padre Bento & Público & 164 & 9 \\
\hline Guarulhos & Hospital Saúde Guarulhos & Privado & 54 & 9 \\
\hline Guarulhos & Hospital Stella Maris & Filantrópico & 213 & 10 \\
\hline Ilha Solteira & $\begin{array}{l}\text { Associação Hospitalar } \\
\text { Ilha Solteira (H Base II) }\end{array}$ & Filantrópico & 127 & 5 \\
\hline Indaiatuba & $\begin{array}{l}\text { Hospital Augusto de } \\
\text { Oliveira Camargo }\end{array}$ & Filantrópico & 149 & 13 \\
\hline Indaiatuba & Hospital Santa Ignez & Privado & 67 & 5 \\
\hline Itanhaém & Hospital Regional de Itanhaém & Público & 91 & 5 \\
\hline Itapeva & Santa Casa de Itapeva & Santa Casa & 210 & 12 \\
\hline Itapevi & Hospital Geral de Itapevi & Público & 262 & 10 \\
\hline Itapira & Hospital Municipal de Itapira & Público & 101 & 5 \\
\hline Itaquaquecetuba & $\begin{array}{l}\text { Hospital OSS Santa } \\
\text { Marcelina de Itaquaquecetuba }\end{array}$ & Público & 244 & 10 \\
\hline Itatiba & Santa Casa de Itatiba & Santa Casa & 98 & 6 \\
\hline Itu & Hospital Sanatorinhos & Filantrópico & 187 & 10 \\
\hline Ituverava & Santa Casa de Ituverava & Santa Casa & 112 & 10 \\
\hline Jaboticabal & Santa Casa de Jaboticabal & Santa Casa & 101 & 8 \\
\hline Jacareí & $\begin{array}{l}\text { Hospital São Francisco } \\
\text { de Assis - Jacareí }\end{array}$ & Filantrópico & 113 & 8 \\
\hline Jacareí & $\begin{array}{l}\text { Santa Casa de Misericórdia } \\
\text { de Jacareí }\end{array}$ & Santa Casa & 210 & 10 \\
\hline Jales & Santa Casa de Jales & Santa Casa & 115 & 6 \\
\hline Jales & Hospital Amaral Carvalho & Filantrópico & 298 & 7 \\
\hline Jales & Santa Casa de Jales. & Santa Casa & 253 & 13 \\
\hline Jundiaí & $\begin{array}{l}\text { Hospital de Caridade } \\
\text { São Vicente de Paulo }\end{array}$ & Filantrópico & 218 & 36 \\
\hline Jundiaí & Hospital Paulo Sacramento & Privado & 148 & 10 \\
\hline Jundiaí & Hospital Santa Elisa & Privado & 92 & 11 \\
\hline Jundiaí & Hospital Universitário Jundiaí & Público & 117 & 6 \\
\hline
\end{tabular}


ANEXO 1 - Relação de hospitais participantes (continuação)

\begin{tabular}{|c|c|c|c|c|}
\hline Município & Hospital & $\begin{array}{l}\text { Natureza } \\
\text { Administrativa }\end{array}$ & $\begin{array}{l}\mathrm{N} \text { de } \\
\text { leitos } \\
\text { Total }\end{array}$ & $\begin{array}{l}\mathrm{N} \text { de } \\
\text { leitos } \\
\text { UTI }\end{array}$ \\
\hline Jundiaí & $\begin{array}{l}\text { Sobam Centro Médico Hospitalar } \\
\text { (Pitangueiras) }\end{array}$ & Privado & 160 & 13 \\
\hline Leme & Santa Casa de Leme & Santa Casa & 116 & 7 \\
\hline Lençóis Paulista & Hospital N Sra da Piedade & Filantrópico & 81 & 5 \\
\hline Limeira & Hospital Medical & Privado & 64 & 5 \\
\hline Limeira & Santa Casa de Limeira & Santa Casa & 280 & 22 \\
\hline Limeira & Unimed Limeira & Privado & 70 & 5 \\
\hline Limeira & Sociedade Operária Humanitária & Privado & 86 & 9 \\
\hline Lins & Hospital São Lucas & Privado & 51 & 7 \\
\hline Lins & Santa Casa de Lins & Santa Casa & 100 & 6 \\
\hline Lorena & Santa Casa de Lorena & Santa Casa & 132 & 10 \\
\hline Marília & Hospital das Clínicas de Marília & Público & 112 & 24 \\
\hline Marília & Hospital Universitário UNIMAR & Filantrópico & 80 & 7 \\
\hline Marília & Santa Casa de Marília & Santa Casa & 0 & 9 \\
\hline Matão & Hospital Carlos Fernando & Filantrópico & 154 & 10 \\
\hline Mauá & $\begin{array}{l}\text { Hospital de Clínicas Radamés } \\
\text { Nardini }\end{array}$ & Público & 179 & 10 \\
\hline Mauá & Santa Casa de Mauá & Santa Casa & 108 & 11 \\
\hline Mococa & Santa Casa de Mococa & Santa Casa & 145 & 10 \\
\hline Mogi das Cruzes & Hospital Arnaldo P. Cavalcante & Público & 195 & 10 \\
\hline Mogi das Cruzes & Hospital e Maternidade Ipiranga & Privado & 120 & 7 \\
\hline Mogi das Cruzes & Hospital e Maternidade Mogi Dor & Privado & 80 & 7 \\
\hline Mogi das Cruzes & Hospital e Maternidade Santana & Privado & 100 & 7 \\
\hline Mogi das Cruzes & Hospital Luzia de Pinho Melo & Público & 304 & 14 \\
\hline Mogi das Cruzes & Santa Casa Mogi das Cruzes & Santa Casa & 197 & 9 \\
\hline Mogi Guaçu & Hospital São Francisco & Privado & 82 & 8 \\
\hline Mogi Guaçu. & Santa Casa de Mogi Guaçu. & Santa Casa & 174 & 8 \\
\hline Mogi Mirim & Santa Casa de Mogi Mirim & Santa Casa & 106 & 8 \\
\hline Monte Alto & Santa Casa de Monte Alto & Santa Casa & 100 & 5 \\
\hline Olímpia & Santa Casa de Olímpia & Santa Casa & 98 & 7 \\
\hline Osasco & Hospital Cruzeiro do Sul & Privado & 149 & 10 \\
\hline Osasco & Hospital Montreal & Privado & 104 & 12 \\
\hline Osasco & Hospital Municipal Antonio Giglio & Público & 198 & 11 \\
\hline Osasco & $\begin{array}{l}\text { Hospital e Maternidade } \\
\text { Renascença }\end{array}$ & Privado & 85 & 9 \\
\hline Osasco & $\begin{array}{l}\text { Hospital e Maternidade } \\
\text { Sino Brasileiro }\end{array}$ & Privado & 80 & 10 \\
\hline
\end{tabular}


ANEXO 1 - Relação de hospitais participantes (continuação)

\begin{tabular}{|c|c|c|c|c|}
\hline Município & Hospital & $\begin{array}{l}\text { Natureza } \\
\text { Administrativa }\end{array}$ & $\begin{array}{l}\mathrm{N} \mathrm{de} \\
\text { leitos } \\
\text { Total }\end{array}$ & $\begin{array}{l}\mathrm{N} \text { de } \\
\text { leitos } \\
\text { UTI }\end{array}$ \\
\hline Ourinhos & Santa Casa de Ourinhos & Santa Casa & 130 & 11 \\
\hline Penápolis & Santa Casa de Penápolis & Santa Casa & 112 & 8 \\
\hline Pindamonhangaba & Santa Casa de Pindamonhangaba & Santa Casa & 208 & 10 \\
\hline Piracicaba & Hospital dos Fornecedores de Cana & Filantrópico & 240 & 21 \\
\hline Piracicaba & Santa Casa de Piracicaba & Santa Casa & 335 & 14 \\
\hline Piracicaba & Unimed Piracicaba & Privado & 99 & 7 \\
\hline Praia Grande & Hospital Municipal Irmão Dulce & Privado & 228 & 20 \\
\hline $\begin{array}{l}\text { Presidente } \\
\text { Prudente }\end{array}$ & Hospital e Maternidade lamada & Privado & 100 & 10 \\
\hline $\begin{array}{l}\text { Presidente } \\
\text { Prudente }\end{array}$ & $\begin{array}{l}\text { Hospital e Maternidade } \\
\text { Nossa Senhora das Graças }\end{array}$ & Privado & 70 & 11 \\
\hline $\begin{array}{l}\text { Presidente } \\
\text { Prudente }\end{array}$ & Hospital Regional (Universitário) & Filantrópico & 285 & 14 \\
\hline $\begin{array}{l}\text { Presidente } \\
\text { Prudente }\end{array}$ & Santa Casa de Presidente Prudente & Santa Casa & 186 & 11 \\
\hline Rancharia & Hospital e Maternidade de Rancharia & Filantrópico & 105 & 5 \\
\hline Ribeirão Pires & Hospital Ribeirão Pires & Privado & 101 & 12 \\
\hline Ribeirão Preto & Hospital das Clínicas - FMRP & publico & 692 & 25 \\
\hline Ribeirão Preto & Hospital e Maternidade São Lucas & Privado & 96 & 9 \\
\hline Ribeirão Preto & Hospital Santa Lydia & Privado & 69 & 5 \\
\hline Ribeirão Preto & Hospital São Francisco & Privado & 148 & 15 \\
\hline Ribeirão Preto & Hospital São Lucas Ribeirânia & Privado & 67 & 7 \\
\hline Ribeirão Preto & Santa Casa de Ribeirão Preto & Santa Casa & 241 & 23 \\
\hline Ribeirão Preto & Sociedade Portuguesa Beneficência & Filantrópico & 143 & 11 \\
\hline Ribeirão Preto & Unidade de Emergência - HC & publico & 169 & 16 \\
\hline Rio Claro & Santa Casa de Rio Claro & Santa Casa & 148 & 11 \\
\hline Rio Claro & Unimed Rio Claro & Privado & 107 & 6 \\
\hline Salto & Unimed Salto Itu & Privado & 50 & 6 \\
\hline Salto & $\begin{array}{l}\text { Hospital de Salto - } \\
\text { Banco de Olhos de Sorocaba }\end{array}$ & publico & 75 & 10 \\
\hline $\begin{array}{l}\text { Santa Barbara } \\
\text { d'Oeste }\end{array}$ & $\begin{array}{l}\text { Santa Casa de Santa } \\
\text { Barbara d'Oeste }\end{array}$ & Santa Casa & 131 & 8 \\
\hline Santa Fé do Sul & Santa Casa de Santa Fé do Sul & Santa Casa & 87 & 6 \\
\hline Santo André & Hospital AMICO rede Foccus & Privado & 46 & 6 \\
\hline Santo André & Centro Hospitalar Santo André & Público & 243 & 17 \\
\hline Santo André & $\begin{array}{l}\text { Hospital da Mulher Maria } \\
\text { Jose dos Santos Stein }\end{array}$ & Público & 119 & 9 \\
\hline
\end{tabular}


ANEXO 1 - Relação de hospitais participantes (continuação)

\begin{tabular}{|c|c|c|c|c|}
\hline Município & Hospital & $\begin{array}{l}\text { Natureza } \\
\text { Administrativa }\end{array}$ & $\begin{array}{l}\mathrm{N} \text { de } \\
\text { leitos } \\
\text { Total }\end{array}$ & $\begin{array}{c}\mathrm{N} \text { de } \\
\text { leitos } \\
\text { UTI }\end{array}$ \\
\hline Santo André & $\begin{array}{l}\text { Hospital e Maternidade } \\
\text { Dr.Cristovão da Gama }\end{array}$ & Privado & 168 & 21 \\
\hline Santo André & Hospital e Maternidade Brasil & Privado & 249 & 24 \\
\hline Santo André & Hospital Estadual Mário Covas & Público & 317 & 20 \\
\hline Santos & Casa de Saúde de Santos SA & Privado & 130 & 9 \\
\hline Santos & Hospital Ana Costa & Privado & 257 & 26 \\
\hline Santos & Hospital Beneficência Portuguesa & Filantrópico & 206 & 18 \\
\hline Santos & Hospital Frei Galvão & Privado & 31 & 9 \\
\hline Santos & Hospital Guilherme Álvaro & publico & 296 & 21 \\
\hline Santos & Hospital São Lucas & Privado & 84 & 10 \\
\hline Santos & Santa Casa de Santos & Santa Casa & 724 & 38 \\
\hline São Bernardo & Hospital de Ensino FUABC (Anchieta) & Público & 125 & 6 \\
\hline São Bernardo & Hospital e Maternidade Assunção & Privado & 142 & 15 \\
\hline São Bernardo & Hospital Municipal Universitário & Público & 134 & 7 \\
\hline São Bernardo & Hospital São Bernardo S.A. & Privado & 150 & 22 \\
\hline São Bernardo & PS Municipal Central de SBC & Público & 135 & 5 \\
\hline $\begin{array}{l}\text { São Caetano } \\
\text { do Sul }\end{array}$ & Complexo Hospitalar Maria Braido & Público & 179 & 10 \\
\hline $\begin{array}{l}\text { São Caetano } \\
\text { do Sul }\end{array}$ & Hospital e Maternidade Central & Privado & 60 & 11 \\
\hline $\begin{array}{l}\text { São Caetano } \\
\text { do Sul }\end{array}$ & Hospital Nossa Senhora de Fátima & Privado & 163 & 21 \\
\hline São Carlos & Santa Casa de São Carlos & Santa Casa & 332 & 10 \\
\hline $\begin{array}{l}\text { São João da Boa } \\
\text { Vista }\end{array}$ & $\begin{array}{l}\text { Santa Casa de São João da } \\
\text { Boa Vista "D.Carolina Malheiros" }\end{array}$ & Santa Casa & 156 & 9 \\
\hline $\begin{array}{l}\text { São João da Boa } \\
\text { Vista }\end{array}$ & UNIMED Leste Paulista & Privado & 52 & 7 \\
\hline $\begin{array}{l}\text { São Joaquim } \\
\text { da Barra }\end{array}$ & $\begin{array}{l}\text { Santa Casa de São Joaquim } \\
\text { da Barra }\end{array}$ & Santa Casa & 128 & 8 \\
\hline $\begin{array}{l}\text { São José do Rio } \\
\text { Pardo }\end{array}$ & $\begin{array}{l}\text { Santa Casa de São José do } \\
\text { Rio Pardo }\end{array}$ & Santa Casa & 187 & 7 \\
\hline $\begin{array}{l}\text { São José do } \\
\text { Rio Preto }\end{array}$ & Beneficência Portuguesa & Privado & 180 & 20 \\
\hline $\begin{array}{l}\text { São José do } \\
\text { Rio Preto }\end{array}$ & Hospital de Base SJRP & Filantrópico & 716 & 64 \\
\hline $\begin{array}{l}\text { São José do } \\
\text { Rio Preto }\end{array}$ & Instituto Espírita Nosso Lar IELAR & Filantrópico & 104 & 8 \\
\hline $\begin{array}{l}\text { São José do } \\
\text { Rio Preto }\end{array}$ & Santa Casa de SJ Rio Preto & Santa Casa & 196 & 13 \\
\hline $\begin{array}{l}\text { São José dos } \\
\text { Campos }\end{array}$ & Hospital e Maternidade São José & Privado & 92 & 6 \\
\hline
\end{tabular}


ANEXO 1 - Relação de hospitais participantes (continuação)

\begin{tabular}{|c|c|c|c|c|}
\hline Município & Hospital & $\begin{array}{l}\text { Natureza } \\
\text { Administrativa }\end{array}$ & $\begin{array}{l}\mathrm{N} \text { de } \\
\text { leitos } \\
\text { Total }\end{array}$ & $\begin{array}{l}\mathrm{N} \text { de } \\
\text { leitos } \\
\text { UTI }\end{array}$ \\
\hline $\begin{array}{l}\text { São José dos } \\
\text { Campos }\end{array}$ & $\begin{array}{l}\text { Hospital Materno-Infantil } \\
\text { Antoninho da Rocha Marmo }\end{array}$ & Filantrópico & 73 & 9 \\
\hline $\begin{array}{l}\text { São José dos } \\
\text { Campos }\end{array}$ & $\begin{array}{l}\text { Hospital Municipal "Dr José } \\
\text { de Carvalho Florence" }\end{array}$ & Público & 295 & 16 \\
\hline $\begin{array}{l}\text { São José dos } \\
\text { Campos }\end{array}$ & Hospital Policlínica - 9 de julho & Privado & 93 & 13 \\
\hline $\begin{array}{l}\text { São José dos } \\
\text { Campos }\end{array}$ & Hospital Vivalle & Privado & 43 & 8 \\
\hline $\begin{array}{l}\text { São José dos } \\
\text { Campos }\end{array}$ & $\begin{array}{l}\text { Obra de Ação Social Pio XII } \\
\text { (Hospital Pio XII) }\end{array}$ & Filantrópico & 81 & 9 \\
\hline $\begin{array}{l}\text { São José dos } \\
\text { Campos }\end{array}$ & $\begin{array}{l}\text { Santa Casa de Miseric } 3 / 4 \text { rdia } \\
\text { de SJ dos Campos }\end{array}$ & Santa Casa & 145 & 12 \\
\hline São Paulo & $\begin{array}{l}\text { Hospital Beneficência } \\
\text { Portuguesa }\end{array}$ & Privado & 1189 & 183 \\
\hline São Paulo & $\begin{array}{l}\text { Hospital Israelita Albert } \\
\text { Einstein }\end{array}$ & Privado & 526 & 32 \\
\hline São Paulo & Hospital Alvorada - Moema & Privado & 253 & 43 \\
\hline São Paulo & Hospital Aviccena & Privado & 70 & 18 \\
\hline São Paulo & Hospital Bandeirantes & Privado & 163 & 20 \\
\hline São Paulo & Hospital Cruz Azul & Privado & 445 & 30 \\
\hline São Paulo & $\begin{array}{l}\text { Hospital Don Antonio de } \\
\text { Alvarenga }\end{array}$ & Filantrópico & 150 & 20 \\
\hline São Paulo & Hospital A C Camargo & Privado & 237 & 29 \\
\hline São Paulo & $\begin{array}{l}\text { Hospital do Coração da } \\
\text { Associação Sanatório Sírio }\end{array}$ & Privado & 316 & 30 \\
\hline São Paulo & Hospital da Mooca (ex-Dom Pedro) & Filantrópico & 106 & 22 \\
\hline São Paulo & Hospital Estadual Dante Pazzanese & Público & 303 & 36 \\
\hline São Paulo & Hospital Estadual Regional Sul & Público & 206 & 16 \\
\hline São Paulo & Hospital do Servidor Público Municipal & Público & 285 & 25 \\
\hline São Paulo & Hospital Estadual Pedreira & Público & 270 & 13 \\
\hline São Paulo & Hospital Estadual Geral de São Mateus & Público & 205 & 14 \\
\hline São Paulo & Hospital Estadual Geral de Guaianazes & Público & 250 & 9 \\
\hline São Paulo & Hospital Estadual Geral de Taipas & Público & 230 & 10 \\
\hline São Paulo & $\begin{array}{l}\text { Hospital Estadual Geral de } \\
\text { V N Cachoeirinha }\end{array}$ & Público & 180 & 9 \\
\hline São Paulo & Hospital Estadual Heliópolis & Público & 389 & 14 \\
\hline São Paulo & Conjunto Hospitalar do Mandaqui & Público & 333 & 22 \\
\hline São Paulo & Hospital Estadual de Sapopemba & Público & 193 & 16 \\
\hline São Paulo & Hospital Estadual Vila Alpina & Público & 250 & 16 \\
\hline São Paulo & Hospital Estadual Vila Penteado & Público & 206 & 14 \\
\hline
\end{tabular}


ANEXO 1 - Relação de hospitais participantes (continuação)

\begin{tabular}{|c|c|c|c|c|}
\hline Município & Hospital & $\begin{array}{l}\text { Natureza } \\
\text { Administrativa }\end{array}$ & $\begin{array}{l}\mathrm{N} \text { de } \\
\text { leitos } \\
\text { Total }\end{array}$ & $\begin{array}{l}\mathrm{N} \text { de } \\
\text { leitos } \\
\text { UTI }\end{array}$ \\
\hline São Paulo & $\begin{array}{l}\text { Hospital Instituto Arnaldo } \\
\text { Vieira de Carvalho }\end{array}$ & Filantrópico & 50 & 8 \\
\hline São Paulo & Hospital IGESP & Privado & 93 & 19 \\
\hline São Paulo & Hospital Metropolitano & Privado & 170 & 15 \\
\hline São Paulo & $\begin{array}{l}\text { Hospital Municipal Dr. José } \\
\text { Soares de Hungria (Pirituba) }\end{array}$ & Público & 108 & 7 \\
\hline São Paulo & $\begin{array}{l}\text { Hospital Municipal Dr. Arthur } \\
\text { Ribeiro de Saboya (Jabaquara) }\end{array}$ & Público & 103 & 18 \\
\hline São Paulo & $\begin{array}{l}\text { Hospital Municipal Dr. Fernando } \\
\text { M. P.da Rocha (Campo Limpo) }\end{array}$ & Público & 254 & 16 \\
\hline São Paulo & $\begin{array}{l}\text { Hospital Municipal Dr. Carmino } \\
\text { Caricchio (Tatuapé) }\end{array}$ & Público & 342 & 30 \\
\hline São Paulo & $\begin{array}{l}\text { Hospital Municipal Dr. Alípio Corrêa Neto } \\
\text { (Ermelino) }\end{array}$ & Público & 278 & 10 \\
\hline São Paulo & $\begin{array}{l}\text { Hospital Municipal Ver. José Storopolli } \\
\text { (Vila Maria) }\end{array}$ & Público & 159 & 11 \\
\hline São Paulo & Hospital Municipal Dr. Mario Degni & Público & 72 & 6 \\
\hline São Paulo & Hospital Municipal Tide Setúbal & Público & 200 & 7 \\
\hline São Paulo & $\begin{array}{l}\text { Hospital Municipal Dr. Valdomiro de } \\
\text { Paula }\end{array}$ & Público & 200 & 6 \\
\hline São Paulo & Hospital Nipo Brasileiro & Privado & 222 & 23 \\
\hline São Paulo & Hospital N S da Penha & Privado & 100 & 10 \\
\hline São Paulo & Hospital 9 de julho & Privado & 270 & 50 \\
\hline São Paulo & $\begin{array}{l}\text { Hospital N S de Lourdes/Hospital da } \\
\text { Criança }\end{array}$ & Privado & 300 & 22 \\
\hline São Paulo & Hospital Panamericano & Privado & 72 & 18 \\
\hline São Paulo & Hospital Paulistano & Privado & 197 & 24 \\
\hline São Paulo & Hospital Santa Casa Santo Amaro & Filantrópico & 207 & 10 \\
\hline São Paulo & Hospital Santa Catarina & Privado & 377 & 41 \\
\hline São Paulo & Hospital Santa Virginia & Privado & 100 & 13 \\
\hline São Paulo & Hospital São Camilo - Ipiranga & Privado & 112 & 15 \\
\hline São Paulo & Hospital São Camilo - Pompeia & Privado & 215 & 32 \\
\hline São Paulo & Hospital São Camilo - Santana & Privado & 176 & 31 \\
\hline São Paulo & Hospital e Maternidade São Luiz - Itaim & Privado & 349 & 26 \\
\hline São Paulo & Hospital São Luiz - Morumbi & Privado & 176 & 24 \\
\hline São Paulo & Hospital e Maternidade São Cristovão & Privado & 172 & 15 \\
\hline São Paulo & Hospital SEPACO & Privado & 211 & 40 \\
\hline São Paulo & $\begin{array}{l}\text { Hospital Vasco Gama (Encerrou } \\
\text { atividades em 2010) }\end{array}$ & Privado & 64 & 16 \\
\hline São Paulo & Hospital Vila Mariana rede FOCUS & Privado & 225 & $\begin{array}{c}20 \\
\text { atinua }\end{array}$ \\
\hline
\end{tabular}


ANEXO 1 - Relação de hospitais participantes (continuação)

\begin{tabular}{|c|c|c|c|c|}
\hline Município & Hospital & $\begin{array}{l}\text { Natureza } \\
\text { Administrativa }\end{array}$ & $\begin{array}{l}\mathrm{N} \text { de } \\
\text { leitos } \\
\text { Total }\end{array}$ & $\begin{array}{c}\mathrm{N} \text { de } \\
\text { leitos } \\
\text { UTI }\end{array}$ \\
\hline São Paulo & $\begin{array}{l}\text { Hospital da Aeronáutica de São Paulo } \\
\text { HASP }\end{array}$ & Público & 50 & 5 \\
\hline São Paulo & $\begin{array}{l}\text { Hospital Municipal Dr. Ignácio Proença } \\
\text { de Gouveia }\end{array}$ & Público & 108 & 7 \\
\hline São Paulo & Hospital Sírio Libanês & Privado & 321 & 35 \\
\hline São Paulo & $\begin{array}{l}\text { Hospital Estadual Perola Baygton CR } \\
\text { Saúde da Mulher }\end{array}$ & Público & 150 & 6 \\
\hline São Paulo & Hospital Santa Helena & Privado & 244 & 28 \\
\hline São Paulo & Instituto Central HCFMUSP & Público & 938 & 124 \\
\hline São Paulo & Hospital Bosque da Saúde & Privado & 150 & 14 \\
\hline São Paulo & Hospital Santa Paula & Privado & 189 & 32 \\
\hline São Paulo & INCOR HC FMUSP & Público & 480 & 101 \\
\hline São Paulo & Hospital Estadual do Ipiranga & Público & 300 & 9 \\
\hline São Paulo & Hospital Estadual do Grajaú & Público & 252 & 10 \\
\hline São Paulo & Hospital Estadual do Itaim Paulista & Público & 270 & 10 \\
\hline São Paulo & Hospital Samaritano & Privado & 200 & 22 \\
\hline São Paulo & Hospital Total Cor & Privado & 93 & 19 \\
\hline São Paulo & Instituto de Infectologia Emílio Ribas & Público & 211 & 17 \\
\hline São Paulo & Hospital Universitário USP & Público & 235 & 11 \\
\hline São Paulo & $\begin{array}{l}\text { Instituto de Ortopedia e Traumatologia } \\
\text { FMUSP }\end{array}$ & Público & 158 & 12 \\
\hline São Paulo & Hospital Estadual Brigadeiro & Público & 117 & 8 \\
\hline São Paulo & Hospital Nossa Sra do Rosário & Privado & 112 & 11 \\
\hline São Paulo & Hospital Alemão Osvaldo Cruz & Privado & 259 & 34 \\
\hline São Paulo & Hospital do Rim & Público & 110 & 9 \\
\hline São Paulo & Hospital São Paulo UNIFESP & Público & 792 & 67 \\
\hline São Paulo & $\begin{array}{l}\text { Hospital Itacolomy Butantã ex Iguatemi } \\
\text { atual metropolitano Butantã }\end{array}$ & Privado & 156 & 34 \\
\hline São Paulo & Hospital do Servidor Público Estadual & Público & 1000 & 39 \\
\hline São Paulo & Hospital São Luiz Gonzaga & Público & 177 & 8 \\
\hline São Paulo & $\begin{array}{l}\text { Hospital Jaraguá (encerrou atividades } \\
\text { em 2010) }\end{array}$ & Privado & 88 & 13 \\
\hline São Paulo & Hospital Municipal Cidade Tiradentes & Público & 228 & 13 \\
\hline São Paulo & Hospital São José -BP & Privado & 111 & 14 \\
\hline São Paulo & Hospital Santa Rita & Privado & 147 & 16 \\
\hline São Paulo & Hospital e Maternidade Independência & Privado & 0 & 10 \\
\hline São Paulo & Hospital e Maternidade do Brás & Privado & 182 & 27 \\
\hline São Paulo & Hospital São Luiz Anália Franco & Privado & 218 & $\begin{array}{r}24 \\
\text { ontinua }\end{array}$ \\
\hline
\end{tabular}


ANEXO 1 - Relação de hospitais participantes (conclusão)

\begin{tabular}{|c|c|c|c|c|}
\hline Município & Hospital & $\begin{array}{l}\text { Natureza } \\
\text { Administrativa }\end{array}$ & $\begin{array}{l}\mathrm{N} \text { de } \\
\text { leitos } \\
\text { Total }\end{array}$ & $\begin{array}{l}\mathrm{N} \text { de } \\
\text { leitos } \\
\text { UTI }\end{array}$ \\
\hline São Paulo & Hospital Santa Marcelina Itaquera & Filantrópico & 701 & 58 \\
\hline São Paulo & Hospital Sorocabana & Privado & 150 & 10 \\
\hline São Paulo & Day Hospital Ermelino Matarazzo & Privado & 32 & 6 \\
\hline São Paulo & Hospital G|3/4ria & Privado & 89 & 6 \\
\hline São Paulo & Hospital Municipal M Boi Mirim & Público & 240 & 20 \\
\hline São Paulo & Hospital Alvorada de Santo Amaro & Privado & 0 & 10 \\
\hline São Paulo & Hospital e Maternidade Vidas & Privado & 62 & 11 \\
\hline São Paulo & Hospital Sancta Maggiore Tatuapé & Privado & 35 & 8 \\
\hline São Paulo & $\begin{array}{l}\text { Instituto do Câncer do Estado de São } \\
\text { Paulo }\end{array}$ & Público & 220 & 34 \\
\hline São Paulo & Hospital Leforte & Privado & 105 & 16 \\
\hline São Sebastião & Hospital de Clínicas de São Sebastião & Filantrópico & 87 & 8 \\
\hline São Vicente & CREI & Público & 70 & 6 \\
\hline São Vicente & $\begin{array}{l}\text { Hospital São José (Santa Casa de São } \\
\text { Vicente) }\end{array}$ & Filantrópico & 86 & 10 \\
\hline Sertãozinho & Hospital Netto Campelo & Privado & 63 & 7 \\
\hline Sertãozinho & Santa Casa de Sertãozinho & Santa Casa & 124 & 9 \\
\hline Sorocaba & Conjunto Hospitalar Sorocaba & Público & 398 & 19 \\
\hline Sorocaba & Hospital Modelo de Sorocaba & Privado & 78 & 8 \\
\hline Sorocaba & Hospital Santa Lucinda & Privado & 177 & 10 \\
\hline Sumaré & Hospital Estadual de Sumaré & Público & 220 & 16 \\
\hline Suzano & Hospital e Maternidade Campos Sales & Privado & 76 & 10 \\
\hline Taboão da Serra & Hospital Geral de Pirajussara & Público & 280 & 10 \\
\hline Taquaritinga & Santa Casa de Taquaritinga & Santa Casa & 166 & 8 \\
\hline Taubaté & Hospital Regional do Vale do Paraíba & Público & 185 & 31 \\
\hline Taubaté & Hospital São Lucas & Privado & 91 & 9 \\
\hline Taubaté & Hospital Universitário de Taubaté & Filantrópico & 158 & 6 \\
\hline Tupã & $\begin{array}{l}\text { Sociedade Beneficente São Francisco de } \\
\text { Assis }\end{array}$ & Filantrópico & 115 & 7 \\
\hline Valinhos & Hospital e Maternidade Galileu & Privado & 71 & 10 \\
\hline Valinhos & Santa Casa de Valinhos & Santa Casa & 123 & 12 \\
\hline Vinhedo & Santa Casa de Vinhedo & Santa Casa & 124 & 7 \\
\hline Votorantim & Hospital Santo Antonio & Privado & 59 & 7 \\
\hline Votuporanga & $\begin{array}{l}\text { Casa de Saúde N. Sra. Aparecida } \\
\text { (UNIMED) }\end{array}$ & Privado & 48 & 6 \\
\hline Votuporanga & Santa Casa de Votuporanga & Santa Casa & 204 & 14 \\
\hline
\end{tabular}


ANEXO 2- Variáveis socioeconômicas, de qualidade e acesso aos serviços de saúde inicialmente selecionadas pelos investigadores. Dados do censo de 2010 do Instituto Brasileiro de Geografia e Estatística (IBGE), DATASUS e Sistema Estadual de Análise de Dados (SEADE). As variáveis das linhas em cinza permaneceram na análise após teste de colinearidade (coeficiente de Pearson $\geq 0,5$ )

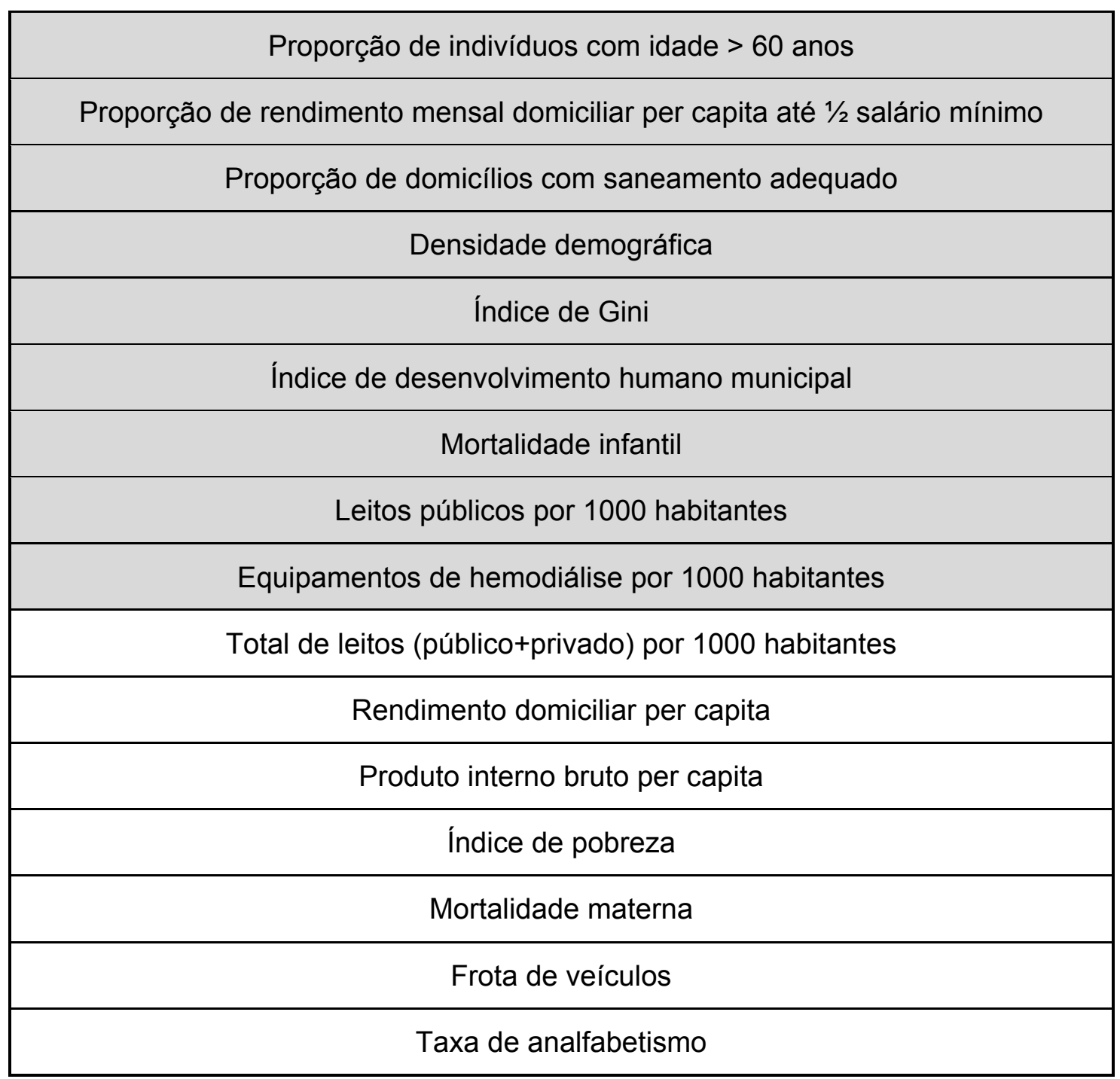


ANEXO 3 - Descrição dos antimicrobianos selecionados inicialmente pelos investigadores. Os antimicrobianos marcados em cinza permaneceram na análise após teste de colinearidade (coeficiente de Pearson $\geq 0,5$ )

\begin{tabular}{|c|c|c|c|}
\hline Ácido nalidíxico & Cefotaxima & Eritromicina & Ofloxacina \\
\hline Amicacina & Cefoxitina & Ertapenem & Penicilina \\
\hline Amoxicilina & Ceftazidima & Gentamicina & Piperacilina \\
\hline Ampicilina & Ceftriaxona & Imipenem & Polimixinas \\
\hline Azitromicina & Cefuroxima & Levofloxacina & Roxitromicina \\
\hline Aztreonam & Ciprofloxacina & Linezolida & Tianfenicol \\
\hline Cefaclor & Clindamicina & Meropenem & Ticarcilina \\
\hline Cefadroxil & Clortetraciclina & Minociclina & Tigeciclina \\
\hline Cefalexina & Cotrimoxazol & Moxifloxacina & Vancomicina \\
\hline Cefalotina & Daptomicina & Nitrofurantoína & \\
\hline Cefepima & Doxiciclina & Norfloxacina & \\
\hline
\end{tabular}


Tabela 13 - Indicadores socioeconômicos, de qualidade e acesso aos serviços de saúde dos 105 municípios incluídos na análise. $\mathrm{O}$ ano base do cálculo do indicador está descrito entre parênteses

\begin{tabular}{|c|c|c|c|c|c|c|c|}
\hline Município & $\begin{array}{c}\text { \% de indivíduos } \\
>60 \text { anos } \\
(2010)\end{array}$ & $\begin{array}{l}\text { \% de domicílios } \\
\text { com saneamento } \\
\text { adequado } \\
(2010)\end{array}$ & $\begin{array}{l}\text { Índice } \\
\text { de Gini } \\
(2003)\end{array}$ & $\begin{array}{l}\text { Mortalidade infantil/ } \\
1000 \text { nascidos vivos } \\
\text { (média-2006-2010) }\end{array}$ & $\begin{array}{c}\text { IDH } \\
(2010)\end{array}$ & $\begin{array}{l}\text { Leitos públicos/ } \\
1000 \text { hab } \\
\text { (2009) }\end{array}$ & $\begin{array}{c}\text { N de equipamentos } \\
\text { de HMD /1000 hab } \\
(2009)\end{array}$ \\
\hline Americana & $13 \%$ & $97 \%$ & 0.4 & 9.2 & 0.81 & 0.60 & 0.12 \\
\hline Amparo & $14 \%$ & $83 \%$ & 0.4 & 11.5 & 0.79 & 0.00 & 0.00 \\
\hline Andradina & $15 \%$ & $89 \%$ & 0.46 & 11.0 & 0.78 & 0.00 & 0.00 \\
\hline Araçatuba & $14 \%$ & $97 \%$ & 0.47 & 15.1 & 0.79 & 0.23 & 0.18 \\
\hline Araraquara & $14 \%$ & $98 \%$ & 0.42 & 11.8 & 0.82 & 0.00 & 0.28 \\
\hline Araras & $13 \%$ & $97 \%$ & 0.41 & 10.6 & 0.78 & 0.17 & 0.20 \\
\hline Arujá & $8 \%$ & $82 \%$ & 0.4 & 12.6 & 0.78 & 0.00 & 0.00 \\
\hline Assis & $14 \%$ & $96 \%$ & 0.42 & 10.8 & 0.81 & 1.48 & 0.26 \\
\hline Atibaia & $13 \%$ & $67 \%$ & 0.43 & 14.8 & 0.77 & 0.00 & 0.36 \\
\hline Avaré & $13 \%$ & $93 \%$ & 0.42 & 16.6 & 0.77 & 0.00 & 0.22 \\
\hline Bariri & $15 \%$ & $94 \%$ & 0.42 & 16.0 & 0.75 & 0.00 & 0.00 \\
\hline Barretos & $14 \%$ & $95 \%$ & 0.45 & 10.6 & 0.79 & 0.04 & 0.24 \\
\hline Barueri & $7 \%$ & $95 \%$ & 0.41 & 9.3 & 0.79 & 1.48 & 0.04 \\
\hline Batatais & $14 \%$ & $95 \%$ & 0.41 & 11.9 & 0.76 & 0.00 & 0.28 \\
\hline Bauru & $13 \%$ & $97 \%$ & 0.43 & 11.5 & 0.80 & 1.35 & 0.20 \\
\hline Bebedouro & $14 \%$ & $95 \%$ & 0.44 & 8.0 & 0.78 & 1.15 & 0.36 \\
\hline Birigui & $13 \%$ & $96 \%$ & 0.44 & 12.8 & 0.78 & 0.00 & 0.00 \\
\hline Botucatu & $13 \%$ & $94 \%$ & 0.42 & 11.9 & 0.80 & 4.32 & 0.24 \\
\hline Bragança Paulista & $13 \%$ & $84 \%$ & 0.4 & 15.3 & 0.78 & 0.00 & 0.76 \\
\hline
\end{tabular}


Tabela 13 - Indicadores socioeconômicos, de qualidade e acesso aos serviços de saúde dos 105 municípios incluídos na análise. $\mathrm{O}$ ano base do cálculo do indicador está descrito entre parênteses (continuação)

\begin{tabular}{|c|c|c|c|c|c|c|c|}
\hline Município & $\begin{array}{c}\text { \% de indivíduos } \\
>60 \text { anos } \\
(2010)\end{array}$ & $\begin{array}{l}\text { \% de domicílios } \\
\text { com saneamento } \\
\text { adequado } \\
(2010)\end{array}$ & $\begin{array}{l}\text { Índice } \\
\text { de Gini } \\
\text { (2003) }\end{array}$ & $\begin{array}{l}\text { Mortalidade infantil/ } \\
1000 \text { nascidos vivos } \\
\text { (média-2006-2010) }\end{array}$ & $\begin{array}{c}\text { IDH } \\
(2010)\end{array}$ & $\begin{array}{l}\text { Leitos públicos/ } \\
1000 \text { hab } \\
(2009)\end{array}$ & $\begin{array}{c}\text { N de equipamentos } \\
\text { de HMD /1000 hab } \\
(2009)\end{array}$ \\
\hline Campinas & $12 \%$ & $91 \%$ & 0.42 & 10.2 & 0.81 & 0.76 & 0.16 \\
\hline Capivari & $11 \%$ & $87 \%$ & 0.42 & 10.9 & 0.75 & 0.00 & 0.00 \\
\hline Caraguatatuba & $11 \%$ & $86 \%$ & 0.44 & 15.9 & 0.76 & 0.00 & 0.00 \\
\hline Carapicuíba & $8 \%$ & $87 \%$ & 0.38 & 11.6 & 0.75 & 0.77 & 0.05 \\
\hline Catanduva & $15 \%$ & $97 \%$ & 0.45 & 10.7 & 0.79 & 0.00 & 0.16 \\
\hline Cotia & $8 \%$ & $76 \%$ & 0.41 & 13.2 & 0.78 & 0.54 & 0.00 \\
\hline Cruzeiro & $12 \%$ & $95 \%$ & 0.42 & 13.6 & 0.79 & 0.05 & 0.22 \\
\hline Cubatão & $8 \%$ & $62 \%$ & 0.45 & 16.1 & 0.74 & 1.15 & 0.00 \\
\hline Diadema & $8 \%$ & $97 \%$ & 0.37 & 12.7 & 0.74 & 1.16 & 0.10 \\
\hline Dracena & $17 \%$ & $92 \%$ & 0.45 & 13.8 & 0.78 & 0.00 & 0.37 \\
\hline Fernandópolis & $16 \%$ & $95 \%$ & 0.45 & 14.0 & 0.76 & 0.00 & 0.00 \\
\hline Ferraz de Vasconcelos & $7 \%$ & $85 \%$ & 0.38 & 16.9 & 0.74 & 1.42 & 0.01 \\
\hline Franca & $11 \%$ & $98 \%$ & 0.4 & 12.5 & 0.78 & 0.00 & 0.33 \\
\hline Francisco Morato & $9 \%$ & $74 \%$ & 0.38 & 11.3 & 0.77 & 0.69 & 0.00 \\
\hline Guaratinguetá & $13 \%$ & $89 \%$ & 0.42 & 13.6 & 0.80 & 0.20 & 0.21 \\
\hline Guarujá & $9 \%$ & $81 \%$ & 0.45 & 17.6 & 0.75 & 0.00 & 0.00 \\
\hline Guarulhos & $8 \%$ & $88 \%$ & 0.4 & 13.0 & 0.76 & 0.29 & 0.08 \\
\hline Ilha Solteira & $14 \%$ & $90 \%$ & 0.47 & 14.7 & 0.76 & 1.99 & 0.00 \\
\hline Indaiatuba & $10 \%$ & $94 \%$ & 0.4 & 10.4 & 0.79 & 0.00 & 0.19 \\
\hline Itanhaém & $15 \%$ & $76 \%$ & 0.42 & 16.9 & 0.75 & 0.82 & 0.00 \\
\hline Itapeva & $10 \%$ & $81 \%$ & 0.41 & 20.6 & 0.73 & 0.00 & 0.33 \\
\hline
\end{tabular}


Tabela 13 - Indicadores socioeconômicos, de qualidade e acesso aos serviços de saúde dos 105 municípios incluídos na análise. O ano base do cálculo do indicador está descrito entre parênteses (continuação)

\begin{tabular}{|c|c|c|c|c|c|c|c|}
\hline Município & $\begin{array}{c}\text { \% de indivíduos } \\
>60 \text { anos } \\
(2010)\end{array}$ & $\begin{array}{l}\text { \% de domicílios } \\
\text { com saneamento } \\
\text { adequado } \\
(2010)\end{array}$ & $\begin{array}{l}\text { Índice } \\
\text { de Gini } \\
(2003)\end{array}$ & $\begin{array}{l}\text { Mortalidade infantill } \\
1000 \text { nascidos vivos } \\
\text { (média-2006-2010) }\end{array}$ & $\begin{array}{c}\text { IDH } \\
(2010)\end{array}$ & $\begin{array}{l}\text { Leitos públicos/ } \\
1000 \text { hab } \\
\text { (2009) }\end{array}$ & $\begin{array}{c}\text { N de equipamentos } \\
\text { de HMD /1000 hab } \\
\text { (2009) }\end{array}$ \\
\hline Itapevi & $6 \%$ & $81 \%$ & 0.38 & 13.7 & 0.74 & 0.00 & 0.00 \\
\hline Itapira & $14 \%$ & $91 \%$ & 0.41 & 11.8 & 0.76 & 1.28 & 0.00 \\
\hline Itaquaquecetuba & $6 \%$ & $79 \%$ & 0.37 & 14.5 & 0.71 & 0.77 & 0.01 \\
\hline Itatiba & $11 \%$ & $86 \%$ & 0.4 & 12.6 & 0.78 & 0.00 & 0.00 \\
\hline Itu & $11 \%$ & $92 \%$ & 0.42 & 12.6 & 0.77 & 2.54 & 0.14 \\
\hline Ituverava & $14 \%$ & $97 \%$ & 0.44 & 12.2 & 0.77 & 0.00 & 0.41 \\
\hline Jaboticabal & $14 \%$ & $96 \%$ & 0.45 & 10.2 & 0.78 & 0.00 & 0.35 \\
\hline Jacareí & $11 \%$ & $93 \%$ & 0.4 & 13.4 & 0.78 & 0.00 & 0.24 \\
\hline Jales & $16 \%$ & $93 \%$ & 0.45 & 9.2 & 0.78 & 0.00 & 0.00 \\
\hline Jaú· & $13 \%$ & $97 \%$ & 0.42 & 12.1 & 0.78 & 0.00 & 0.18 \\
\hline Jundiaí & $13 \%$ & $93 \%$ & 0.39 & 11.1 & 0.82 & 0.33 & 0.01 \\
\hline Leme & $11 \%$ & $97 \%$ & 0.42 & 14.2 & 0.74 & 0.00 & 0.01 \\
\hline Lençóis Paulista & $11 \%$ & $97 \%$ & 0.42 & 10.2 & 0.76 & 0.00 & 0.00 \\
\hline Limeira & $12 \%$ & $96 \%$ & 0.4 & 11.3 & 0.78 & 0.00 & 0.08 \\
\hline Lins & $14 \%$ & $97 \%$ & 0.46 & 14.3 & 0.79 & 4.76 & 0.00 \\
\hline Lorena & $13 \%$ & $95 \%$ & 0.43 & 14.4 & 0.77 & 0.00 & 0.00 \\
\hline Marília & $14 \%$ & $96 \%$ & 0.43 & 12.8 & 0.80 & 0.00 & 0.44 \\
\hline Matão & $12 \%$ & $97 \%$ & 0.41 & 13.7 & 0.77 & 0.00 & 0.00 \\
\hline Mauá & $8 \%$ & $91 \%$ & 0.37 & 15.1 & 0.77 & 0.39 & 0.08 \\
\hline Mococa & $14 \%$ & $91 \%$ & 0.43 & 11.3 & 0.76 & 0.00 & 0.00 \\
\hline
\end{tabular}


Tabela 13 - Indicadores socioeconômicos, de qualidade e acesso aos serviços de saúde dos 105 municípios incluídos na análise. O ano base do cálculo do indicador está descrito entre parênteses (continuação)

\begin{tabular}{|c|c|c|c|c|c|c|c|}
\hline Município & $\begin{array}{c}\text { \% de indivíduos } \\
>60 \text { anos } \\
(2010)\end{array}$ & $\begin{array}{l}\text { \% de domicílios } \\
\text { com saneamento } \\
\text { adequado } \\
(2010)\end{array}$ & $\begin{array}{l}\text { Índice } \\
\text { de Gini } \\
(2003)\end{array}$ & $\begin{array}{l}\text { Mortalidade infantill } \\
1000 \text { nascidos vivos } \\
\text { (média-2006-2010) }\end{array}$ & $\begin{array}{c}\text { IDH } \\
(2010)\end{array}$ & $\begin{array}{l}\text { Leitos públicos/ } \\
1000 \text { hab } \\
\text { (2009) }\end{array}$ & $\begin{array}{c}\text { N de equipamentos } \\
\text { de HMD /1000 hab } \\
\text { (2009) }\end{array}$ \\
\hline Mogi das Cruzes & $10 \%$ & $82 \%$ & 0.43 & 13.4 & 0.78 & 0.98 & 0.15 \\
\hline Mogi Guaçu• & $12 \%$ & $95 \%$ & 0.39 & 9.9 & 0.77 & 0.31 & 0.00 \\
\hline Mogi Mirim & $13 \%$ & $93 \%$ & 0.42 & 13.6 & 0.78 & 0.00 & 0.32 \\
\hline Monte Alto & $15 \%$ & $94 \%$ & 0.39 & 9.0 & 0.77 & 0.00 & 0.00 \\
\hline Olímpia & $15 \%$ & $89 \%$ & 0.44 & 9.5 & 0.77 & 0.00 & 0.00 \\
\hline Osasco & $10 \%$ & $90 \%$ & 0.39 & 12.9 & 0.78 & 0.56 & 0.10 \\
\hline Ourinhos & $13 \%$ & $96 \%$ & 0.44 & 8.5 & 0.78 & 0.00 & 0.60 \\
\hline Pariquera-Açú & $13 \%$ & $66 \%$ & 0.41 & 15.9 & 0.74 & 16.43 & 2.28 \\
\hline Penápolis & $15 \%$ & $95 \%$ & 0.45 & 13.3 & 0.76 & 0.00 & 0.00 \\
\hline Pindamonhangaba & $10 \%$ & $94 \%$ & 0.41 & 15.4 & 0.77 & 0.00 & 0.18 \\
\hline Piracicaba & $13 \%$ & $97 \%$ & 0.44 & 10.2 & 0.79 & 0.03 & 0.13 \\
\hline Praia Grande & $12 \%$ & $93 \%$ & 0.44 & 17.3 & 0.75 & 0.00 & 0.00 \\
\hline Presidente Prudente & $14 \%$ & $97 \%$ & 0.46 & 10.4 & 0.81 & 0.33 & 0.35 \\
\hline Rancharia & $14 \%$ & $89 \%$ & 0.44 & 19.4 & 0.75 & 0.00 & 0.00 \\
\hline Ribeirão Pires & $11 \%$ & $84 \%$ & 0.38 & 13.5 & 0.78 & 0.33 & 0.00 \\
\hline Ribeirão Preto & $13 \%$ & $98 \%$ & 0.45 & 9.3 & 0.80 & 1.57 & 0.24 \\
\hline Rio Claro & $13 \%$ & $98 \%$ & 0.41 & 13.9 & 0.76 & 0.00 & 0.00 \\
\hline Salto & $11 \%$ & $96 \%$ & 0.4 & 10.9 & 0.78 & 0.00 & 0.00 \\
\hline Santa Barbara d'Oeste & $11 \%$ & $98 \%$ & 0.38 & 10.2 & 0.78 & 0.00 & 0.11 \\
\hline Santa Fé do Sul & $17 \%$ & $94 \%$ & 0.46 & 8.2 & 0.78 & 0.00 & 0.00 \\
\hline Santo André & $14 \%$ & $95 \%$ & 0.38 & 12.8 & 0.82 & 0.73 & 0.14 \\
\hline Santos & $19 \%$ & $96 \%$ & 0.47 & 14.7 & 0.84 & 0.87 & 0.26 \\
\hline São Bernardo & $10 \%$ & $92 \%$ & 0.4 & 12.7 & 0.81 & 0.32 & 0.04 \\
\hline São Caetano do Sul & $19 \%$ & $100 \%$ & 0.36 & 6.9 & 0.86 & 1.06 & 0.29 \\
\hline São Carlos & $13 \%$ & $96 \%$ & 0.41 & 8.0 & 0.81 & 0.00 & 0.27 \\
\hline
\end{tabular}


Tabela 13 - Indicadores socioeconômicos, de qualidade e acesso aos serviços de saúde dos 105 municípios incluídos na análise. $\mathrm{O}$ ano base do cálculo do indicador está descrito entre parênteses (conclusão)

\begin{tabular}{|c|c|c|c|c|c|c|c|}
\hline Município & $\begin{array}{c}\text { \% de indivíduos } \\
>60 \text { anos } \\
(2010)\end{array}$ & $\begin{array}{l}\text { \% de domicílios } \\
\text { com saneamento } \\
\text { adequado } \\
(2010)\end{array}$ & $\begin{array}{l}\text { Índice } \\
\text { de Gini } \\
(2003)\end{array}$ & $\begin{array}{l}\text { Mortalidade infantill } \\
1000 \text { nascidos vivos } \\
\text { (média-2006-2010) }\end{array}$ & $\begin{array}{c}\text { IDH } \\
(2010)\end{array}$ & $\begin{array}{l}\text { Leitos públicos/ } \\
1000 \text { hab } \\
\text { (2009) }\end{array}$ & $\begin{array}{c}\text { N de equipamentos } \\
\text { de HMD /1000 hab } \\
(2009)\end{array}$ \\
\hline São João da Boa Vista & $15 \%$ & $94 \%$ & 0.41 & 15.4 & 0.80 & 0.00 & 0.13 \\
\hline São José do Rio Pardo & $14 \%$ & $88 \%$ & 0.42 & 11.5 & 0.77 & 0.00 & 0.02 \\
\hline São José do Rio Preto & $14 \%$ & $88 \%$ & 0.47 & 9.9 & 0.79 & 0.06 & 0.24 \\
\hline São Joaquim da Barra & $12 \%$ & $97 \%$ & 0.42 & 13.9 & 0.76 & 0.00 & 0.00 \\
\hline São José dos Campos & $10 \%$ & $93 \%$ & 0.41 & 10.9 & 0.81 & 0.61 & 0.17 \\
\hline São Paulo & $12 \%$ & $93 \%$ & 0.45 & 12.2 & 0.81 & 0.92 & 0.14 \\
\hline São Sebastião & $8 \%$ & $64 \%$ & 0.44 & 12.1 & 0.77 & 1.11 & 0.30 \\
\hline São Vicente & $11 \%$ & $91 \%$ & 0.46 & 19.8 & 0.77 & 0.19 & 0.15 \\
\hline Sertãozinho & $10 \%$ & $98 \%$ & 0.45 & 12.7 & 0.76 & 0.00 & 0.22 \\
\hline Sorocaba & $11 \%$ & $98 \%$ & 0.41 & 13.3 & 0.80 & 0.57 & 0.22 \\
\hline Sumaré & $8 \%$ & $94 \%$ & 0.38 & 10.5 & 0.76 & 0.79 & 0.18 \\
\hline Suzano & $9 \%$ & $86 \%$ & 0.4 & 0.0 & 0.70 & 0.00 & 0.00 \\
\hline Taboão da Serra & $8 \%$ & $94 \%$ & 0.38 & 13.4 & 0.77 & 1.15 & 0.23 \\
\hline Taquaritinga & $14 \%$ & $94 \%$ & 0.43 & 15.5 & 0.75 & 0.00 & 0.00 \\
\hline Taubaté & $11 \%$ & $95 \%$ & 0.41 & 14.2 & 0.80 & 0.60 & 0.32 \\
\hline Tupã & $17 \%$ & $94 \%$ & 0.45 & 16.0 & 0.77 & 0.00 & 0.33 \\
\hline Valinhos & $12 \%$ & $89 \%$ & 0.4 & 11.1 & 0.82 & 0.00 & 0.02 \\
\hline Vinhedo & $11 \%$ & $92 \%$ & 0.4 & 9.5 & 0.82 & 0.00 & 0.02 \\
\hline Votorantim & $10 \%$ & $94 \%$ & 0.38 & 15.3 & 0.77 & 0.77 & 0.00 \\
\hline Votuporanga & $15 \%$ & $97 \%$ & 0.44 & 17.0 & 0.79 & 0.00 & 0.87 \\
\hline
\end{tabular}

Fonte: Instituto Brasileiro de Geografia e Estatística (IBGE) e Sistema Estadual de Análise de Dados de São Paulo (SEADE). IDH- índice de desenvolvimento humano; HMD - hemodiálise; hab - habitantes. 